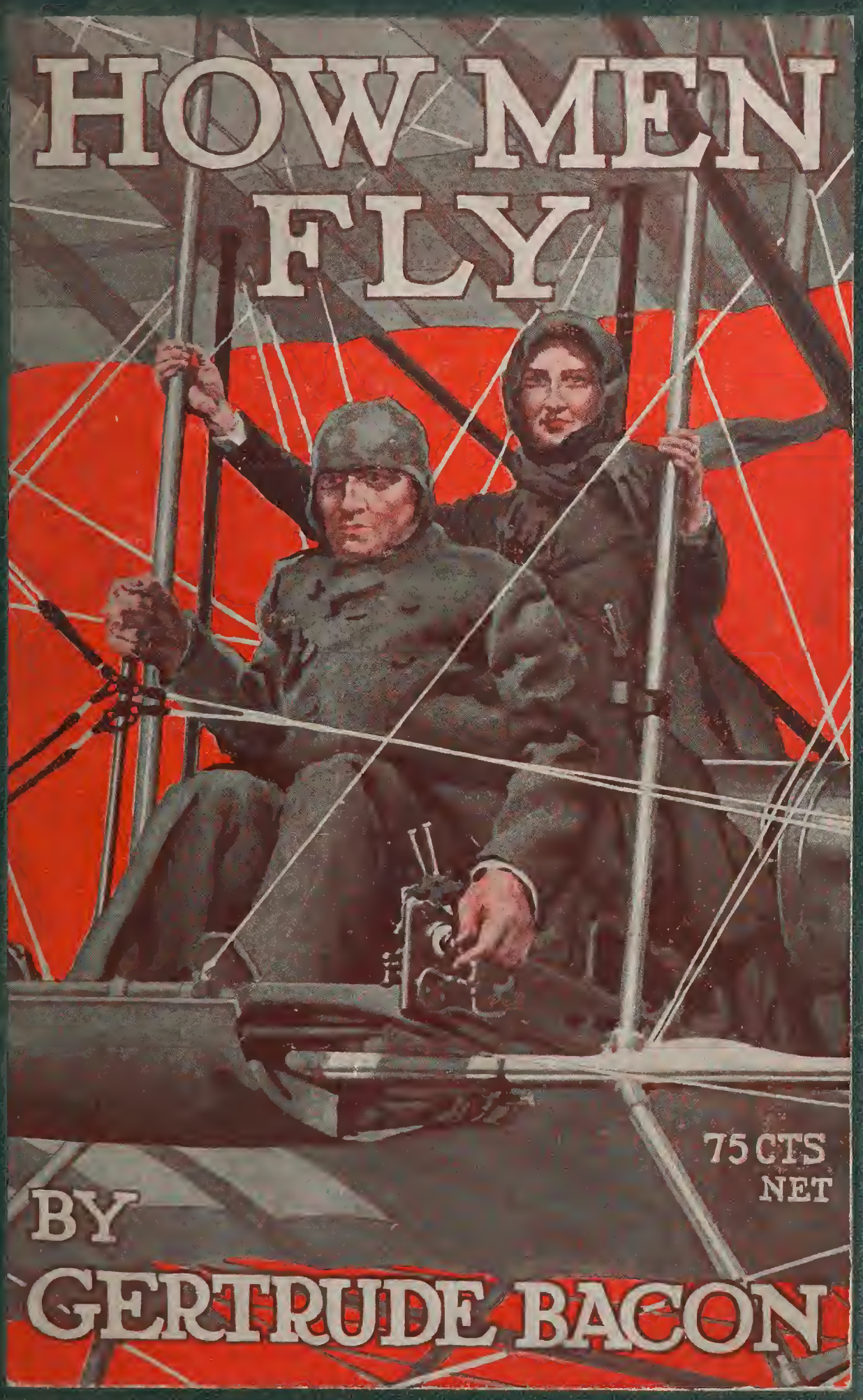


Lo Bro Charles from Bros Nervy Con probation. bee $17^{\text {th }} 1913$ 


$$
Q-1971-5
$$



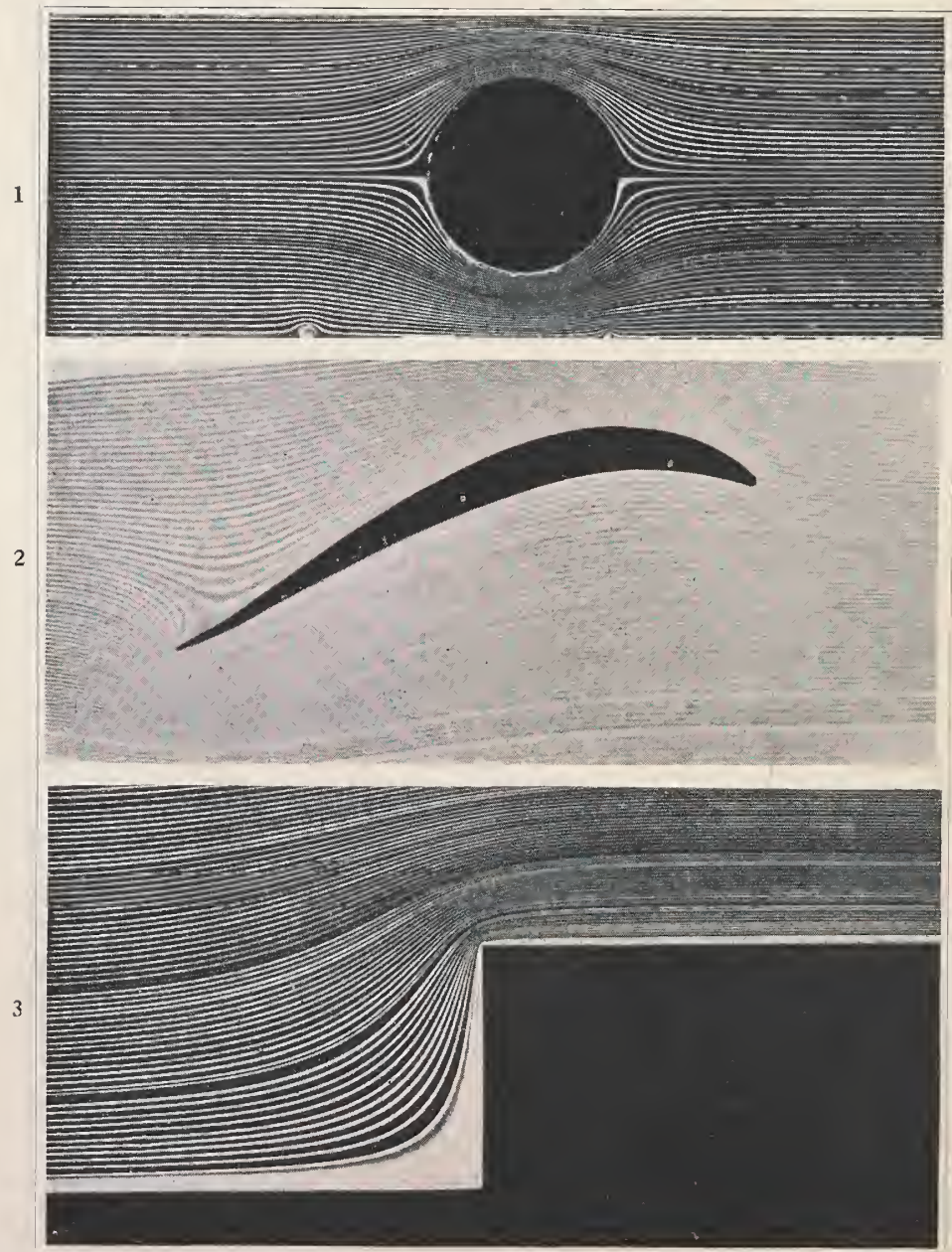

PHOTOGRAPHS OF STREAM-LINE MOTION ROUND VARIOUS OBJECTS.

(1) A Cylinder.

(2) An Aeroplane.

(3) A Sharp Corner.

(Obtained by Professor Hele Shaw's Apparatus.) 


\section{HOW MEN FLY}

BY

GERTRUDE BACON

WITH FIFTEEN BLACK-AND-WHITE ILLUSTRATIONS AND NUMEROUS DIAGRAMS

CASSELL AND COMPANY, LIMITED

London, New York, Toronto and Melbourne 1911 



\section{PREFACE}

THIs little book is intended as a very simple and elementary introduction to the study of aviation. Within the last half-dozen years a new art has come into being, an art with a wonderful future before it, and destined, some think, to revolutionise the civilisation of the world-the art of flight. Many of us feel, as I have felt, deeply interested in this marvel, and wishful to understand its outlines; but we are ignorant of scientific phraseology and technical knowledge, and the unfamiliar terms and mathematical formulx of the text-books are incomprehensible to us. Speaking from personal experience, there seems to me to exist the need for some small and extremely popular book on a most fascinating but certainly abstruse and difficult subject. As to my own fitness for undertaking a none too easy task, I can but plead that it is the student with lively recollection of his own recent struggles, and not the master of his subject, who sees the difficulties of the beginner most clearly and is likely to deal with them most sympathetically.

Of the expert and critic I would humbly beg indulgence if, in my efforts to express in unscientific terms matters that they themselves are prone to dispute about, I have erred-albeit in a good cause. And I wish to express my most grateful thanks to the several friends who, with delightful illustrations, advice, and most kindly criticism, have afforded me quite invaluable assistance.

Gertrude Bacon.

June, IgII. 



\section{CONTENTS}

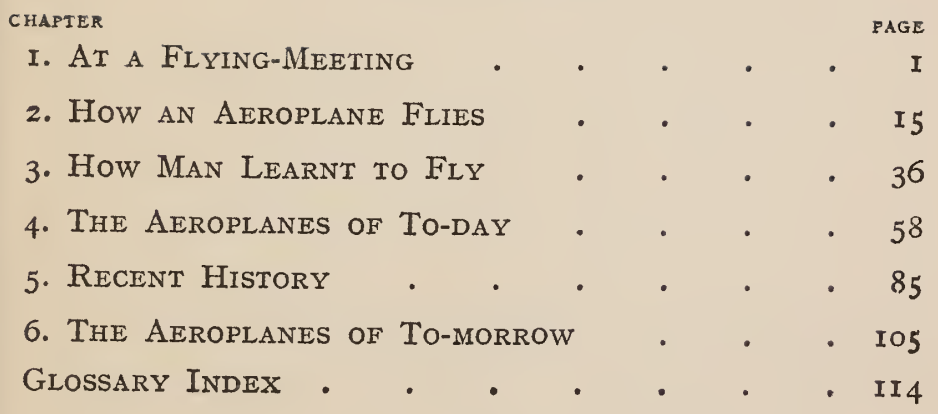




\section{LIST OF ILLUSTRATIONS}

Photographs of Stream-Line Motion round various

ОвJECTS . . . . . . Frontispiece

At a Flying-Meeting . . . . Facing page 6

Henson's (PROPOSED) Flying MACHINE-I840 " " 44

Latham's "Antornette" Monoplane-rgro " " 44

The First American Biplane . . " " 56

The First French Biplane . . . " " " 56

A Blériot Monoplane in Flight . . " " " 68

The First British Aviator . . . " , " 68

The Howard-Wright Biplane • . " , 76

A Bleriot Monoplane with a Gnome Engine, , , 76

The "Bristol" Biplane in the Air . " " 96

The Controls of a Farman Biplane . " " " 96

The Warfare of THE Future? . . " , II2

\section{DIAGRAMS}

TYPICAI KITES - PAGE

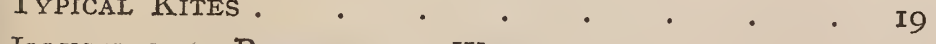

Illustrating Pressure of Wind . . . . 20

A Cambered Plane. . . . . . . 23

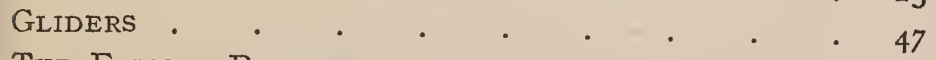

The Farman Biplane . . . . . . 61

The Blériot Monoplane. . . . . . 75 


\section{HOW MEN FLY}

\section{CHAPTER I}

\section{AT A FLYING-MEETING}

"HAVE you ever seen a man fly?" A few years ago this question was too ridiculous to be worth answering seriously. A very few years hence it will be equally pointless. As well ask, "Have you ever seen a man drive a motor-car, or ride a bicycle, or push a wheelbarrow ?"

It always seems to me that we-we who live at the present time-are very fortunate because we have seen the fruition of a great discovery. How interesting this will make us in future years! With what delight do we now listen to an old man who tells us how he remembers the first railway trains, - when the third-class passengers travelled in open carriages like cattle-trucks, and the guard, in a red coat, sat up behind! With equal delight, another day, our grandchildren will listen while we tell them how we recollect when aeroplanes first came into prominent notice, when Blériot flew the Channel, when Paulhan flew from London to Manchester, when GrahameWhite won the Gordon-Bennett Cup.

True, many of us will also remember other great discoveries in the art of travel- the coming of the motor-car, of the bicycle, and so forth; but these seemed to us at the time much less marvellous. Man has always been able to move, quicker or slower, upon the earth. Since the very earliest times he has travelled, at varying speeds, 
upon the water. In our day and in our recollection, after thousands and thousands of years, he has learnt the secret of the birds, and now, at last, he can move in the air also. Man's discovery of flight marks a new era in the progress of the world.

But to go back to our original question: "Have you ever seen a man fly ?" Probably you have, but, at the present time, equally probably you have not, for public flying in Great Britain has up till now been confined principally to a few big aviation meetings, a few famous cross-country flights, and the practice work carried on daily at the flying-grounds that are springing up in various parts of the country. The days are not yet-though who can say how soon they will be upon us?-when flying will have become general, and the passing of an aeroplane over our heads will be as commonplace an event as the passing of a motor-car down the road.

If we have been to a flying-meeting, let us recall what we have seen, or-better still, perhaps-let us suppose that we are going for the first time, and are about to have our initiation into the mysteries of flight. Probably it will be more or less of a journey to reach the spot, for flying-grounds must be well away from houses and the busy haunts of man; and if we have chosen our time luckily there will be no wind, or only the lightest breeze, stirring, and so the chances are that it will be hot, and there will be dust and crowds to contend with. But these little drawbacks will not damp our ardour, since they are the inevitable accompaniments of a successful day. And when we have reached our destination and passed the turnstiles we shall find a large open space, a wide, flat, grass-covered plain, without trees or hedges, or fences, and as level and smooth of surface as Nature and the hand of man can ensure.

The flying-ground is probably, under ordinary cir- 


\section{AT A FLYING-MEETING}

cumstances, a race-course, and ranged around it will be the variously priced grand-stands, the public enclosures, the refreshment tents and booths and band-stands common to such places of resort. But apart from these, and jealously guarded from the throng, along one end of the ground, and opening on to it, will be a long range of low, wooden buildings, each bearing an aviator's name in large letters over the wide door, and the flag of his nationality floating on the roof. If we are of the independent John Bull kind of nature, and insist upon plain English words for everything, we shall speak of these buildings simply as "the sheds." If we prefer to be very precise, or to air our knowledge, we shall give them their French title of " hangars."

In that case we shall probably call the flying-ground an "aerodrome" (on the same principle that we call a place where horses practice a "hippodrome"). In this newly discovered art of flight or " aviation," a number of new words have naturally come into use; and since aviation largely originated in France a great number of these words are purely French. Lately, an attempt has been made to do away entirely with these French words and to give them English equivalents. The attempt has not been altogether successful or perhaps wise, for frequently the foreign word is much more distinctive and descriptive; and as we have adopted so many French terms in the past (as in motoring, etc.), there is no great point in quarrelling at a few more. In any case, the French words must be known to anyone who would seek any knowledge of the principles of flight, and so they will be given and explained here in their proper places.

The sheds, of course, are to house the flying machines, or aeroplanes. The word "aeroplane" means an apparatus for flying which has "planes" or fixed "carrying surfaces" to support it in the air. It may have any 
number of these "planes." It may have one and be called a "monoplane," or two and be called a "biplane," or three and be called a "triplane," or many and be known as a "multiplane." The word " aeroplane" covers the lot. Just as we may call a brig or a barque or a schooner a "ship" (or a spaniel, or terrier, or retriever a "dog "), we may call a monoplane, biplane, triplane or multiplane an aeroplane, or-a yet wider term-a flying machine. One thing we must never style it, and that is an airship. An "airship" is a different thing altogether; different in appearance, different in principle. It follows the lines of the balloon, it is simply a "dirigible" balloon-a balloon that can be steered. It is kept up in the air by the use of a big gas-bag filled with buoyant gas. It is kept up in the air because it is lighter than air. A flying machine, on the contrary, has no gas-bag to keep it aloft. It is heavier than air. This great difference must always be borne in mind for, as will be explained later, it goes to the root of the whole matter of aerial travel.

Meantime we are waiting for the flying to commence. In all probability we have to wait some time. A sudden treacherous breeze, perhaps, has sprung up, and is fluttering the flags in the fierce little unexpected gusts that the flying man specially abhors. It is lunch-hour, maybe, and judges and aviators must be given time for digestion. The engine of some principal flyer is giving trouble, and he may be allowed a little more grace. So the time goes on, and the band plays and the crowd waits, more or less patiently, until, as the shadows lengthen, the breeze dies down, the flags hang limp and motionless upon their halyards, there is bustle and activity about the sheds whose doors are now standing wide, and the people cheer as the red streamer on the signal post, meaning "Flying may shortly be expected," is hauled down, and the white one-" Flying is now taking place"-is run up in its stead. 
Field-glasses are levelled on the spot where a group of men surround a white object they have pushed from one of the sheds, and suddenly there uprises from their midst the loud, deep roar of a powerful engine running at top speed. The noise is the rapid, even drone of a motor-car, but fifty times louder; because whereas a motor-car carries a "silencer" to deaden the sound of the innumerable internal explosions that drive the pistons in and out, an aeroplane, for the sake of lightness, has no such appliance, and nothing mitigates the thunder of its machinery.

And when the noise is at its height suddenly the group of men parts, and from their midst comes tearing across the ground an extraordinary object-a huge white bird it seems, with wide, outstretched wings, a long, narrow body, and a broad tail; but a bird that runs on bicycle wheels instead of legs, and bears in place of a head a whirling propeller moving so rapidly that we see it merely as a dark, transparent blur. Swift and swifter it hastens along, gathering speed as it runs, its tail carried high in the air. Then, as we look, suddenly the tail flaps downwards, the nose points upwards, the little wheels, still rapidly revolving, are no longer on the grass, but rising from it, higher-higher-till, with a roar and a rush, the aeroplane sweeps past us and down the course thirty, fifty, one hundred feet in the air. The crowd shouts and cheers, for it is the first flight of the day, and we shout too. I defy anyone to see, for the first time, an aeroplane leave the ground in fine style and not shout, or, at least, want to shout, for that is the effect it has upon the human mind.

"Radley on a Blériot monoplane," explains a man at our side to his companion; but the latter-a ladydemurs. "Surely you mean a biplane?" she says. "You said that a biplane had two planes, and this has two wings like a bird." A little explanation follows. 
Wings and planes are not synonymous terms. In a Blériot, as in other monoplanes, the "planes" or supporting surfaces are placed on each side of the front of the body, as are the wings of a bird. But they count as one surface because they are both on the same level or plane, not one above the other. The plane is cut in half and attached in two pieces as a matter of convenience and expediency merely, and this fact does not prevent its being considered technically as a single surface.

As the great bird flies round the aerodrome, steering its course outside the tall, chequered marking posts that the Frenchmen have taught us to call " pylons," it loses somewhat of its birdlike appearance, perhaps because of the rigid immobility of its wings, and takes unto itself the likeness of an enormous insect. And as it turns and flies towards us, dark against the sky, its fierce, rapid movement, its broad, blunt, outstretched planes, its deep droning note, remind us irresistibly of warm summer evenings in the country, and the fussing, energetic flight of a big brown cockchafer through the gloaming.

While we follow it with our eyes in the air there comes another burst of machinery, and swiftly into the sky rises, in pursuit, another aeroplane; but how different in appearance! Two long, narrow stretches of white fabric, suggesting lengths of boat awning, are ranged one above the other-like the top and bottom of an oblong box without sides or ends-mounted on a framework carrying not only wheels but long, curved sledge-runners fastened alongside them. Long, slender spars, projecting in front, carry a much smaller single plane, placed well ahead. Longer spars, thicker but still slender and light, form the open-work body that stretches behind and carries the square-shaped tail. The engine is in the midst of the lower plane, behind which is the big screw propeller 

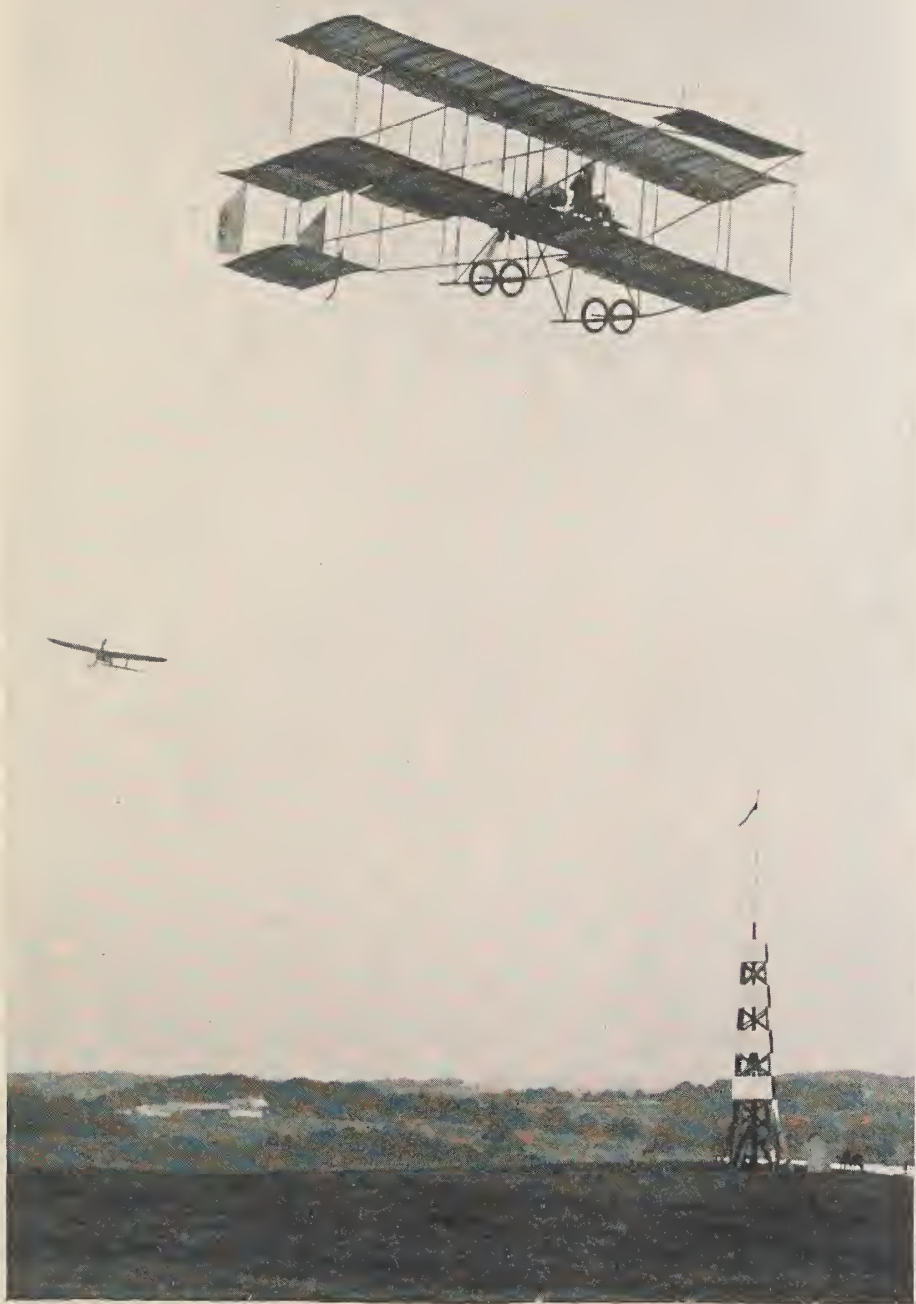

Photo: Illustrations Burean.

AT A FLYING MEETING.

Farman Biplane and Blériot Monoplane.

See page 6. 



\section{AT A FLYING-MEETING}

and in front of the engine, perched on the front edge, sits the aviator. Rounds of applause arise from the crowd as he is recognised, for this is Grahame-White, the popular hero, on a Farman biplane; and now at once we see the difference between monoplane and biplane, for the two planes of the latter, one above the other, are unmistakable. There is no suggestion of bird or insect about this strange aerial craft, which, indeed, resembles nothing in nature. But its lines are light and elegant, its flight graceful and beautiful exceedingly, and as it rises higher into the sky we see it as indeed it is-a magnificent box kite.

Round and round the course they go, biplane and monoplane, the latter easily outspeeding the former; but the biplane somehow suggesting (though there is really no foundation for the suggestion) a safer, steadier flight. Presently the Blériot sinks to earth, light as a feather, before its shed; but by this time another biplane has taken its place in the air. But not a Farman. Even in the extreme distance, when we see it simply as two parallel lines, one above the other, against the sky, we note the difference. There seems something more compressed about this last, something "wanting," and we soon see what it is. There are no wheels underneath, nor framework to carry them, but two long sledge-runners only are placed close below the lower plane. Had we noticed the machine before it left the ground we should have seen that in consequence it sat lower on the grass than any other aeroplane, and instead of running along the ground to gather speed for its flight, it slid along a low, long wooden rail placed for the purpose.

And as it turns in the air we note another difference. The small front plane or "elevator" is a double plane instead of a single one, and in place of the long framework body supporting the square, box-like tail, two much 


\section{HOW MEN FLY}

shorter spars carry two long, narrow, upright, fabriccovered surfaces, like the top and bottom of a sideless box placed on end. The flight of this machine, moreover, is not quite as the others; it seems more sensitive and "nervous," if this latter word may be used in its broad meaning of "easily affected"; and the two propellers, which it carries at the back of the main planes, revolving in opposite directions, give it a flickering, fluttering appearance. "That is the famous old American machine," explains the man beside us. "The original biplane of the Brothers Wright. Look at it carefully, for the Wright aeroplane was the first that ever flew."

The Wright pilot is evidently "out for height," for he circles the track in rising spirals until presently we see him as a tiny object high above our heads, and the whir of his engine reaches us faintly from far aloft. But suddenly the sound ceases altogether, and anxiously we glance upwards. Yes, the engine has stopped, for now we can distinguish the blades of the slackening propeller, and the machine is falling, falling! A sudden ghastly fear clutches at our heart, and we feel our blood run chill. The lady at our side gives a little cry of fear, but her companion reassures her. "No, no; he's all right! Watch!"

Down the biplane comes, and down, but not vertically, and not at an increasing speed, but in one long, gentle, sloping glide, beautiful and graceful beyond words. The propellers have entirely stopped revolving by the time the aviator reaches the earth, and yet he alights upon the grass as lightly and softly as if he had descended but one foot instead of a thousand. A perfect thunder of applause goes up from the crowd, and our friend exclaims, "The most magnificent vol plané I have ever seen! Nothing like a Wright for a gliding flight!" And, indeed, though we see "vol plané" (planing flight, where the 


\section{AT A FLYING-MEETING}

aeroplane glides or "planes" down the sky with its engine stopped) several times again during the afternoon, and effected by both biplanes and monoplanes of all sorts, we see no example so striking as that given by the Wright machine, probably for this reason, that whereas, in order to glide, the other aeroplanes tilted their noses down at a more or less steep angle, and gave the idea of coming down on their heads, the Wright machine altered its angle to a much less degree, so that, seen from below, it seemed almost to plane down on "an even keel."

And so the afternoon wears on, and biplanes and monoplanes succeed each other; Blériots and Farmans, and English-designed machines that approximate to, but differ in all sorts of important details from, these two most popular types. Competitors for cross-country flights sail outside the ground altogether, and we lose sight of them and forget them for awhile until a round of applause greets their triumphant reappearance. At one time there are seven machines in the air at once, and later a thrill of exultation stirs the crowd to rapturous shouts when on the notice-board is displayed the number that indicates "British record beaten."

It has been a magnificent and exciting day, marred by no mishap, but towards the close comes perhaps the most beautiful, sight of all. Suddenly against the glowing glories of a sunset sky comes darting a monoplane-but such a monoplane! Considerably larger than a Blériot, its huge, snowy wings are square tipped, its long, tapering body is built of polished wood, boat fashion, and, like a boat, narrows to a prow at the front. Its tail is a striking and beautiful combination of an horizontal and vertical surface crossed; its lines are exceedingly graceful and elegant, as the lines of a racing yacht, and its flight is not the fussy, business-like progress of a homely cockchafer, but the proud and graceful swoop of the kingly dragon-fly. 
As it nears the stands we see, leaning back on a padded seat, a little steering wheel in each hand, a cool and nonchalant young man, a lazy smile on his face, a cigarette between his lips. The crowd wave hats and handkerchiefs towards him and bellow themselves hoarse with shouts of "Latham! Bravo, Latham!" "Latham on his "Antoinette," " explains our informant. "We are in luck to see him, for the "Antoinette" is the most beautiful of all the aeroplanes, and Latham is its most skilled pilot. By Jove! look at that "virage!' " The great dragon-fly has rounded a pylon so closely and faultlessly that she has almost touched it with the tip of her inner wing as she heels over to such a degree that she displays the whole snowy spread of her planes, tilted to a wonderful angle. No other aeroplane can take a curve, or effect a "virage," in such perfect style.

This is certainly the most striking sight of the day, typifying as it does, in ideal fashion, man's conquest of the air. As we follow the happy crowd from the course, through the dusk and dust, two questions fill our minds. What gives those wonderful machines their power of flight? What does it feel like to fly? With the first question we will endeavour to deal in the next chapter; for the second perhaps a little personal narrative may be permitted me.

The first time I had the good fortune to see an aeroplane in flight was at the memorable Rheims Aviation Meeting, in August, I909, the first of flying-meetings and the most noteworthy, because it deinonstrated to the world, in dramatic fashion, the success and the infinite possibilities of the new art.

It was indeed a wonderful occasion, and all through a deliriously exciting week I sat and watched the aeroplanes circling the wide plain of Béthény until I felt that life for me contained henceforward but one desire-to fly 


\section{AT A FLYING-MEETING}

myself in one of those beautiful machines, and experience, if only for one brief space, the glorious gliding freedom that makes the sea-gulls, surely, the happiest of living creatures. Through the mediation of most kind friends, that which I longed for was granted me during the last hour of the last day of that wondrous meeting.

The shades of evening were falling thick on the darkening plain, and a great red harvest moon had already risen high above the distant woods, when I walked out across the course to where my strange craft stood, looming huge and uncanny in the gloaming. It was a Farman biplane, and its pilot was the famous French flyer and constructor, Roger Sommer. Since those days M. Sommer has brought out his own most successful biplane, but at that time he flew a Farman, being, indeed one of Henry Farman's earliest and most notable pupils, who, though he only learned to fly at the beginning of July, Igog, yet by the 7 th of August was the proud possessor of a world's record, which he had taken from the Wright Brothers themselves. Small, light, young, active, quick of movement, and of imperturbable nerve, he is the ideal man for a perfect aviator. From my point of view he possessed but one drawback: he could not speak English; and, alas! my French, which is of the conventional "Please-pass-me-themustard " style, seemed sadly inadequate at this unusual juncture of affairs.

The Farman biplane had also a disadvantage. It was very difficult to get on to, for the lower plane was high above the ground, and there were no steps to assist my ascent. Arrived on the plane, I found a tiny basket-seat for the aviator, obviously not large enough for two, and nothing else; for I was the first passenger of either sex that Sommer had ever carried, and naturally he had not yet turned his attention to the providing of seating accommodation for his friends-whom he now carries, by the 
way, a dozen at a time. So he scrambled up after me and occupied the basket-chair. For myself it is difficult to explain where I sat. I only know that immediately in front of me was Sommer's back, and immediately behind me the very warm radiator of the engine, and that I was wedged in as tightly as possible between the two. Before we started one word of warning was firmly impressed upon me-under no circumstances was I to touch the pilot's arms !

Then a mechanic gave one turn to the propeller, a deafening roar of machinery uprose behind me, and all in a moment we were off over the ground in a mad rush, quicker than any motor-car that I had ever been in. So well provided with springs was the machine that, although the surface of the ground was rough and uneven, there was scarcely any jolting worthy the name, until suddenly what there was ceased entirely, and in its place came a glorious, buoyant, floating sensation, without a parallel and therefore indescribable, but delicious beyond words. I cast one glance below to make sure, but it was needless; such a sensation could belong to but one thing in the world-flight !

It is said that several of the deplorable and fatal disasters that have recently occurred to aviators can be attributed to the feeling of absolute safety that belongs to actual flight, making it appear impossible at the time that an accident can take place. I can well believe it. In my experience of more than one ascent I can state that the paramount sensations are, first, the sheer rapture and exhilaration of the glorious motion; and, secondly, and scarcely less, the feeling of utmost security and safety. Once started there can be not a trace of nervous fear, or only the fear that the flight may all too soon come to its natural close.

Aviators suffer keenly from cold, and no wonder, for 
the draught is tremendous. Even on that hot, breathless summer evening I felt that the warm radiator behind me was by no means unpleasant.

Before me my pilot sat firm and motionless as a rock. His feet and hands were upon the levers that controlled the machine, but he appeared scarcely to move them, neither was there the slightest trace of rocking or rolling; only the swift onward rush. To hold on was ridiculous; I could sit with folded hands. We held no converse; indeed, such would have been scarcely possible above the racket of the engine, but the time came when for a moment I contemplated a remark. We had been flying some minutes, past the brightly lighted grand-stands, round the black and white chequered pylons, when from the darkness on the right-for it was growing dusk indeed now-came looming a monstrous shape which, as it neared, resolved itself into another Farman biplane rapidly approaching. Did Sommer, intent on his steering, see it too? Ought I to tell him? Could I make him hear, or if I made him hear could I make him understand, and what might be the consequences of distracting his attention by digging him in the back? I gave it up and said nothing, and the other biplane shaved past us, but only, it seemed to me, by a very narrow margin; and henceforward I gave myself up to pure delight, and presently, towards the end, some vague wonderings as to whether the shock of touching the earth again would be very severe. I was still wondering when suddenly I noticed that the engine was slackening, and, looking down, I found that we were stopping on the very spot whence we had started, so that we had reached the ground without my even being aware of the fact. When I had scrambled down, with cramped limbs, from my perch, when I had recovered my sense of hearing which, for a few moments, I found I had almost completely lost through the roar of the engine at such 
close quarters, and when I had proffered my heartfelt thanks to my kind aviator in French that I hoped made up in gratitude for what it lacked in grammar, M. Sommer told me that he was going to make no more flights that evening because of the danger, in the gloaming, of running into another machine in the air. I understood better what he meant when next morning, at the hotel in Rheims, old Mr. Farman said to me, "My son says you nearly ran into him last night. Indeed, he described it to me as one of the 'nearest things' he has ever known." So that other big biplane in the air was Henry Farman himself aloft on his biplane, and we really had nearly collided in the sky.

That evening after my flight there were warm congratulations, and strangers requested my autograph, for they said I was the first Englishwoman to fly. Mrs. Cody, a week or two previously, had been taken up by her husband in his famous aeroplane, and was thus the first woman in England to go aloft in a heavier-than-air machine-but they claimed me as the first of purely British nationality. I am glad to think so. Scores and scores of Englishwomen have flown since then, several have piloted, and one at least has even built her own aeroplane. But there is some small satisfaction in being ahead of them, even by only a few weeks ! 


\section{CHAPTER II}

HOW AN AEROPLANE FLIES

"How does an aeroplane fly?" This is our first and most natural question as we see these great heavier-thanair machines speeding across the sky, or circling up into the air, higher and higher, until we lose sight of them among the clouds. How has this miracle of human flight so long desired, so long held impossible, been accomplished ?

To answer this question in simple language is not the easiest of tasks. It would be useless to say, "An aeroplane flies like a bird," for not only would this be no explanation at all, but also, as we can see for ourselves, it would only be partially true. To some extent, certainly, a flying machine flies like a bird; but it does much more, and also much less. Obviously it does not beat its wings up and down as it flies, and to our minds bird flight is inevitably associated with the flapping of wings. It was but natural that when, in bygone ages, man made his earliest attempts at flight, his first idea should be to provide himself with great wings, after the style of the soft plumes which he fitted, most unscientifically, to the shoulders of the angels and supernatural beings of his pictures and statues. But, alas! in this he was doomed to disappointment. Only after long and bitter striving did the knowledge come to him that because of his massive body and his feeble muscles he might never hope to compete, unaided, with the birds. A man of eleven stone in weight would require wings of almost twenty feet in span to support him in the air; but the possession of such mighty wings alone 
would be insufficient. He must also possess enough bodily strength to keep them beating up and down fast enough to prevent his dropping to the ground; and for this exertion he would need a strength he could never attain to-in fact, at least the strength of a horse.

But birds have other means of using their wings than simply beating them up and down, as a very limited amount of observation will show us. "There is a false impression," says Lanchester, perhaps the greatest living authority on the subject, "one that is far too prevalent, that the essence of flight consists in the flapping of wings. Nothing is further from the truth. . . . Very many of the larger birds rarely use the wing-flapping mode of flight at all, but nevertheless it is not said that they no longer fly on that account." Which of us has not watched the seagulls following a ship, tilting their bodies from side to side, but moving no feather of their soft, outstretched pinions? How many times have we not seen the larger English birds, the hawks and kites, the rooks and crows, the pigeons of our towns, not to mention the little swifts and swallows, swooping in long, lazy glides, falling in graceful vol plané, rising again, turning and tilting, in a very ecstasy of graceful movement performed with outstretched and motionless wings, and apparently with no exertion whatever. We read how the great flyers of the southern seas, the albatross and the frigate bird, practically live upon the wing, not touching solid resting place for perhaps a month at a stretch; and yet are unwearied because for the greater part of the time they exert no muscular effort in keeping aloft. To such flights as these we give the names of "soaring." and "gliding," and we find that other creatures besides birds possess a similar power.

Some of us perhaps have seen, in the seas of the Tropics, the flying fish dart from the water and skim from wave 
to wave. They do this in order to escape from some pursuing foe, and their flight is a pure glide, because their wings, which are modified fins only, are not made for flapping. It is said, too, that their glides generally end in a catastrophe, from a "flight" point of view. They leave the water with a sort of leap, and travel perhaps some forty or fifty feet, but they are lacking in what an aviator would call "natural stability," and soon lose their balance and fall back upon the waves with a flop. There are animals, too, such as the flying squirrels of the Malay Islands, which, by the aid of a sort of extended membrane between their legs, accomplish long downward glides through the trees, though they cannot fly horizontally or upwards into the air. Ordinary squirrels, as we may have noticed, spread out their limbs and their bushy tails to the utmost as they leap safely from high branches to the ground.

In this gliding and soaring flight of birds and beasts and fishes, accomplished without wing-flapping, but with the aid of light, outstretched surfaces, man presently found an inspiration for himself; but though he has learnt much from these living examples, he has probably learnt most of all from an inanimate flyer-to which, indeed, they all owe some resemblance-the schoolboy's kite. It is in this familiar toy of our childhood that we find our best analogy to the flying machine, and we shall do well to turn our attention to it now for a little while because, when we have mastered the principles that keep a kite in the air, we shall have gone a long way towards understanding what makes an aeroplane fly.

The all-important part about a kite-practically the whole of it, in fact-is its light supporting surface or "plane." It may have more than one surface; it may have two, or it may have several. It may be a " box-kite " or Hargrave kite, a Bell, Cody, or Baden-Powell kite; it may be a 
" fin-bat" kite with a little plane sticking up in the middle of the large plane; it may be tailless, or the old-fashioned type with the long trail of knotted paper. The surfaces may not even be flat, for there is one kind of kite made in the shape of a hollow cylinder. Whatever its form (and the forms of kite now are legion), the principle remains the same, and the light, supporting surface or surfaces will be the essential part or parts.

Now when a light, flat, or more or less flat, surface is tilted at an angle against the wind, so that the wind can get underneath it, it will be lifted by the force of the wind into the air. This is a fact of everyday observation. We have seen, for example, the dry leaves of autumn whirled upwards into the sky; we have seen loose paper, lying on the ground, carried aloft; we have watched, with smiles, an old gentleman's hat fly upwards from his head in a rollicking March gale; we have experienced, without smiles, a similar accident to ourselves. Again, we know better than to go motoring in broad-brimmed head-gear, so perhaps we may not have noticed, though we can readily understand and believe, that the quicker the motor is travelling, the higher a hat will rise into the sky as it blows off. Next time such an event occurs to us let us console ourselves by reflecting that our hat, for the time being, has simply been demonstrating the principle of the aeroplane.

It was Sir Isaac Newton who first formulated the law that the pressure exerted by a fluid is normal-that is to say, at right angles-to the surface. Air is a fluid, just as much as water is a fluid, only a more rarefied and unstable one; thus if you have an upright plane, for example, and the wind blows upon it, it will move forward in a direction at right angles to itself-that is, horizontally. If the surface is not upright, but at an angle, to the wind, it will still move forward in a direction at right angles 


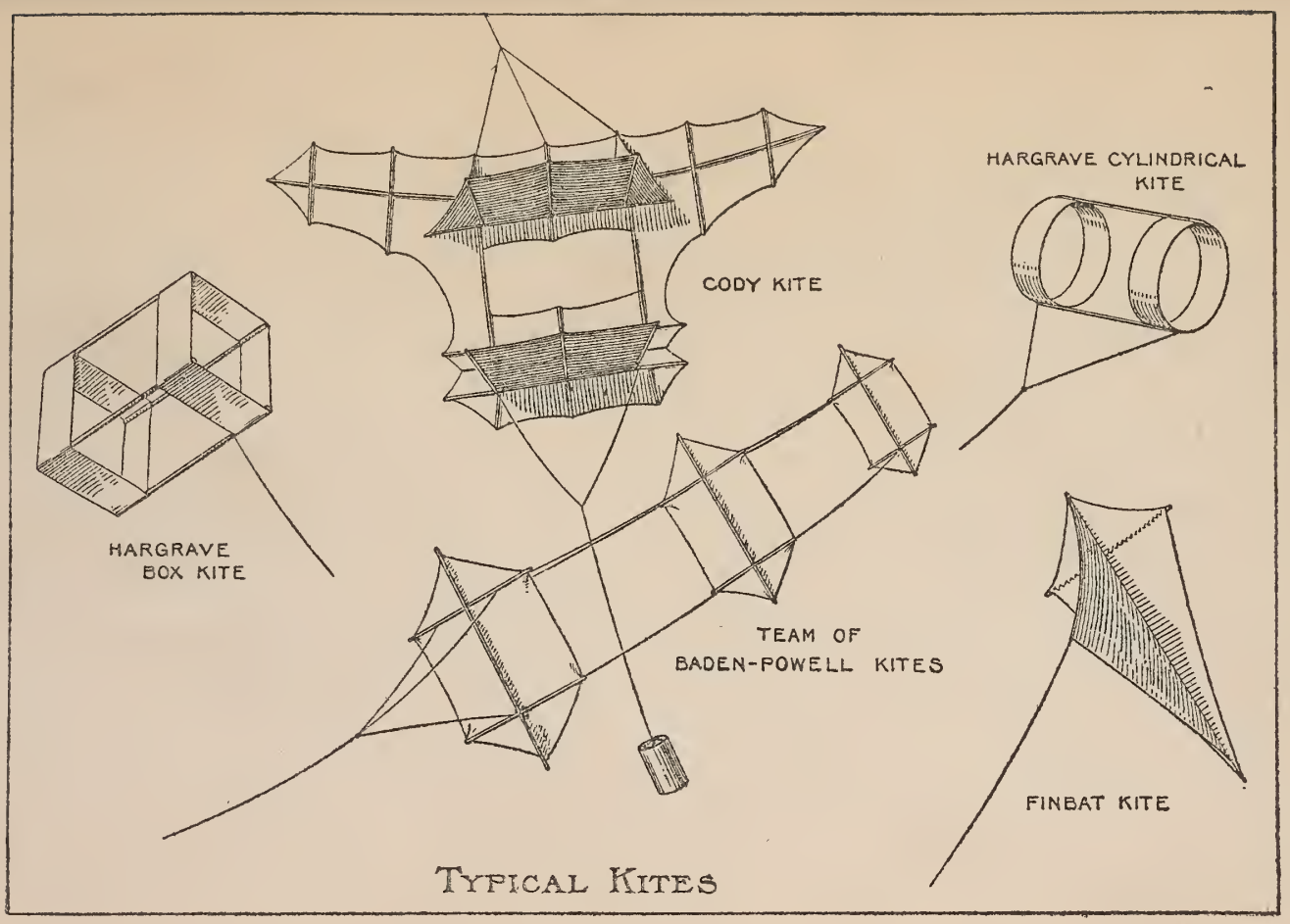


to itself, which means, In this case, that it will rise at an angle into the air.

A little diagram will make this clear:

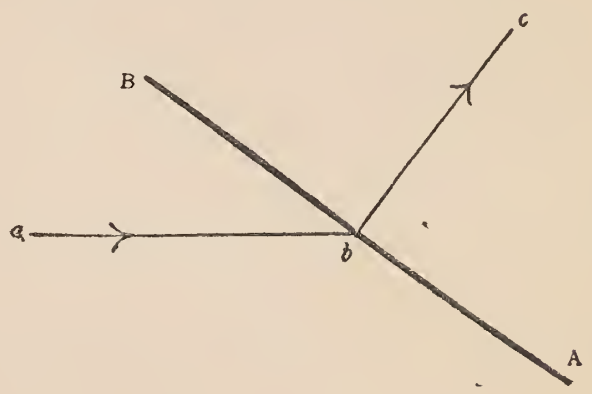

Here A B represents a surface inclined at an angle to the horizon, while the line $a b$ indicates the direction in which the wind is blowing; then $b c$, drawn at right angles to $\mathrm{AB}$, is the direction in which the surface will move under the influence of the wind's force.

The principle that the pressure exerted by a fluid on a surface is normal, or at right angles, to the surface is a law in dynamics, which, as the dictionary will tell you, is "that department of mechanics which treats of force in relation to motion." There is another great branch of mechanics which treats of the forces which keep bodies at rest or equilibrium; this is called statics. Under this heading comes the science known as "aerostatics," that relates to balloons and dirigible balloons or airships, which are kept up in the sky by their gas-bags alone, and are "lighter than air." The science of the "heavier-thanair " machine, which depends on its motion through the air to keep it aloft, is "aerodynamics," and the art of applying it " aviation."

According to Sir Isaac Newton, a light, flat surface or plane-such as a kite-lying at an angle to the wind, will 
be lifted upwards by the force of the wind. But to continue to rise it must be kept at an angle to the wind's direction. A leaf, a runaway hat, or a kite without a string, may rise into the sky, but soon they will be blown upright or tipped over, and then down they will come. The string of a kite, however, is so contrived, and the kite so skilfully balanced, that the pull of the string keeps it continuously at an angle to the direction of the wind; and so long as the wind continues to blow the kite will continue to ascend, if the string will allow it, until the weight of the string becomes too great for the size of the plane and the strength of the wind to support. If, however, the kite-string breaks, or the wind drops, down comes the kite with a run.

The effect of the wind blowing on an inclined plane is clearly shown in a variety of other things besides kites. Take windmills, for example; it is, of course, the wind striking slantwise upon the sails that drives them round. Has the quaint idea ever struck you, by the way, that if a windmill were mounted on wheels, and its sails worked by an engine from inside, instead of being blown round by the wind from outside, the windmill would travel over the country, or at least try to do so ? Again, you have the instance of a sailing ship or yacht, urged forward by the wind ; its motion sideways, or "leeway," being prevented by the resistance of the keel-even as the tendency of a kite to be blown over is prevented by the pull of the string.

Other kite-flying lore, that you will have gathered from your boyhood or girlhood experience, is that a big kite will lift more weight of string than a little kite; and that a stronger wind is required to raise a small, heavy kite into the air than is needed to lift a large, light one. Moreover, you will recall how, if you were flying your kite on a day of light unequal gusts, and the wind failed for a moment or two, your kite would still keep up, pro- 
vided you ran quickly back along the ground dragging the kite, by its string, after you; showing that you could make up for the lack of motion of the wind by imparting motion to the kite itself. Now, suppose you make the kite responsible for all the motion; suppose there is no wind at all to carry it, but that the kite is fitted with an engine and propeller which can drive it rapidly through the air, making its own wind. And suppose there is no string, with a boy at the end of it, to hold the kite at an angle, but instead you so contrive and construct and balance your kite that, of its own accord, it keeps an angle against the wind of its own making; then you will have a kite no longer, but you will have converted it into a veritable flying machine, heavier than air, and yet capable of forcing its way through the sky.

All this sounds simple enough, you will say-why have not men thought of it before? Well, they have thought of it-for many, many years they have known that this was the principle on which to construct an aeroplane; it was in the working out of the principle that the difficulties arose. For it is not enough to know the broad facts of flight; you must know the details also. You must know the best shape for your planes, the best way to arrange them, the best propeller to urge them forward, the best and lightest kind of engine to drive the propeller, the best way to steer and the best way to balance. It is only when you actually come to work on the problem that you begin to realise the extreme complexity of what at first seemed so easy. These questions that I have enumerated are as yet only answered in part. After the work of centuries men have answered them so far that within the last half-dozen years they have made machines that fly. In the future they hope to go on increasing their knowledge until they approach, though they may never attain, the perfect aeroplane. In the next chapter 
we shall learn a little of the history of flight, and the way in which progress has been made; for the present, however, we will just take matters as we find them.

First of all, as to the correct form of the "kite surfaces" or planes. Here at once we are brought up against a new and all-important problem that we have not considered before. The broad, general principles of flight remain, but in practice we find that they are modified by a fresh factor that we have now to take into account -the constitution of the atmosphere.

A light, flat surface, as we have seen, will lift, under certain circumstances, into the air ; but it will lift better still if it is not flat but curved or arched, or "cambered," as the technical term has it. It appears, from experiment, to lift best of all if the curve of the upper side is not placed symmetrically with the curve of the under side, so that as we look at the plane edgewise we shall see that the section of it is like this, with a distinct " hump " near the front edge and tapering off to the back, as in the diagram.

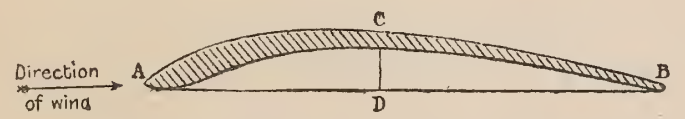

There are a few technical terms connected with the plane of an aeroplane that we shall do well to remember, because we meet with them constantly in all descriptions of flying machines. The front edge of the plane ( $\mathrm{A}$ in the diagram) is called the "entering" or "leading" edge. The rear edge (B) is the "trailing" edge. A straight line drawn from $A$ to $B$, disregarding the curve of the plane, is the "chord." The chord of a plane is its width. The line C D, giving the depth of the curve at its deepest point, is the "camber."

To explain why this particular form of curiously curved plane should be best for lifting purposes we have to enter 
into a realm of great discussion and much experiment, where opinions differ and results are as yet by no means conclusive. Let us content ourselves here with stating the matter in the fewest words and the most general terms.

The behaviour of a plane in the air is affected by the nature of the currents and eddies which it sets up in the air by passing through it. We are familiar enough with the appearance of the extremely complicated currents and eddies made in the water by, say, the blade of an oar or the hull of a moving boat. When an object passes through the air it sets up similar currents and eddies, but far more complicated ones, because air is vastly more unstable than water; and the nature of these air currents is naturally extremely difficult to study since they are invisible to the eye.

When making diagrams and pictures of the flow of water we generally represent it by drawing a number of long lines in the direction in which the water is supposed to be flowing; and those who make a study of the matter have found it convenient to imagine water to be composed of a vast number of minute threads of fluid, arranged side by side, which they call "stream lines." Those who study the movement of the air do the same thing, and imagine the atmosphere to be made up of similar stream lines which, however, are far more easily broken and disturbed than even the stream lines of water.

Now, it is often a matter of great importance that these stream lines, both of air and water, should flow smoothly around a moving body, because if the stream lines are broken they give rise to eddies, and eddies cause resistance. The nature of stream lines is therefore now being carefully investigated. Their study comes largely into the designing of ships, submarines, and torpedoes which have to move rapidly through the water; and you 


\section{HOW AN AEROPLANE FLIES}

can imagine that if it be of importance to consider the stream lines for such a massive object as a battleship, it is vastly more so for such a light and swift thing as an aeroplane. The result of much patient work has been the discovery of what are the best "stream-line" shapes for objects passing through water and air, and one discovery is that stream-line bodies travel blunt end foremost. A fish is a good example of a stream-line body, a torpedo is another. The blunt-nosed section of the plane of an aeroplane, tapering to the back, is best from a streamline point of view, while the peculiar curves of upper and under surface give rise to eddies-exactly how is disputed -which actually help to buoy the plane up.

Experiment has also proved that the best form of plane is not square, but long and narrow. Birds, as we know, have long and narrow wings, and the wings of the soaring birds, such as the albatross, are especially long in proportion to their width. When experimenters come to increase the size of their planes, in order to obtain more lifting power, they find that they have to increase them in span (or from right to left), rather than in width (or from front to back.)

This is because, as experiment has proved, the chief lifting work of a plane is done at the "entering" edge. As the plane passes through the atmosphere it is continually entering upon fresh undisturbed masses of air which support it during the extremely small fraction of a second that it is passing over them. The front edge enters first upon this undisturbed air, pressing it down and forcing it into all sorts of currents and eddies; and the rear part of the plane, which passes over the same air immediately afterwards, gets a sort of "back-wash" from the front, and so, having only disturbed air to press upon, is not able to obtain so much support. For this reason, then, the entering edge must be as long as possible, and to 
increase the width of plane behind is inexpedient beyond certain narrow limits. The most usual proportion is to have the span of the plane about six times as great as the width. To use the technical term, the " aspect ratio" is 6 to $\mathrm{I}$. The aspect ratio of an aeroplane- a term very frequently met with-means simply the relation of the total length of the plane to the chord.

The effect produced on the air by the passage through it of a curved plane is shown in our frontispiece. An apparatus has been invented by Professor Hele Shaw in which stream lines are represented. by fine threads of coloured glycerine, and by observing the way in which these threads group themselves round various objects placed in the line of flow much valuable knowledge has been gained. Our frontispiece shows photographs of results obtained by this apparatus; but in looking at them we have to remember that they represent a fluid moving very slowly, while in the case of an aeroplane the air is moving extremely quickly. Nevertheless the pictures are very instructive, especially that of the section of an aeroplane, showing the smooth, unbroken flow of the stream lines about the blunt leading edge, and down the curving upper and under surfaces.

As is but natural, a great deal of knowledge about the best shapes and sizes of planes has been gathered from observations of the wings of birds. This is as it should be. Nature's heavier-than-air flyers have been navigating the skies so long and so successfully that they must surely know the best way of doing it. The study of their flight has been carried to such a pitch of perfection that it has become a matter of mathematics. The famous Mr. Lanchester, already referred to, set himself, at one time, to work out, mathematically, the flight of the albatross from what he knew of its weight, size of wing surface, etc. He had already done this most successfully in 


\section{HOW AN AEROPLANE FLIES}

the case of other birds, such as the swift and swallow, his results proving in accordance with ascertained facts. But somehow the albatross refused to come into line. According to his calculations it could not be anything but a most unstable and unsatisfactory flyer. For long he puzzled, and then the solution came to him: the bird must use its feet as a kind of extra tail. This point had never been suggested by naturalists before, but after looking up the whole of what he calls "the albatross literature" Mr. Lanchester found, in the first place from a photograph, that the bird flies with its legs extended behind, and its large webbed feet, placed together, make an important addition to the spread of its tail, and give it just the extra stability that his calculations had shown was needed.

We have said that the most efficient form of plane is a long and narrow one-a fact specially demonstrated in the wings of the albatross, the span of which is no less than fourteen times the width (i.e. the aspect ratio is I4 to I). But in the case of a large flying machine a long and narrow plane may well prove unwieldy; so the designer simply cuts his plane in half and mounts the halves one above the other as a "biplane." By this means he finds that although he loses a little lifting power, owing to the tendency which the wind has to slip out from under the planes at the ends (for he now has four ends instead of two), yet the loss is more than counterbalanced by the convenience. Certain aviators and constructors of aeroplanes, notably Mr. A. V. Roe, have cut their planes into three and made successful "triplanes," but beyond this number the multiplication of the planes has not proved advisable.

The angle at which the planes of an aeroplane are placed is naturally a matter of great importance. The more you tilt the planes up the greater resistance they 
will offer to the air, and the more power you will, therefore, need to drive them along. Aviators have a particular term for this air resistance : they call it "drift." It is the force that you feel on a windy day when you stand still and the wind blows you, or on a calm day when you hurry along on a bicycle and make the wind yourself, and it is exerted horizontally. But, as we have seen in our kite, the force of the wind on a suitable surface, set at an angle, has a tendency to "lift" it as well as to "drift" it, and the result is that the plane partly lifts and partly drifts, and so goes slantwise up into the sky. If it lifts more than it drifts, it goes up at a steep angle; if it drifts more than it lifts, it rises at a small one. In the flight of every aeroplane there is "lift" and "drift" in varying proportions, and the great aim of both the aviator and the aeroplane designer is to obtain the greatest amount of lift and the least amount of drift from his machine.

Every aeroplane has what is known as its "flying angle "- that is, the angle at which its planes are inclined to the horizontal. This angle is also called the "angle of incidence." An aeroplane of a fixed weight flies at a fixed speed at a fixed angle of incidence, and you cannot alter one of these things without altering another. If you add to the speed of a flying machine without altering its weight or its angle of incidence, you do not make it go faster in a horizontal direction: you make it rise higher. Similarly, if you cause it to go slower by "throttling" or partly shutting off the engine, you will only succeed in making it descend. It follows from this, therefore, that every aeroplane has its own natural speed. You can alter this speed by altering the area of the surface. If you make the planes smaller, you decrease the lifting power, and the machine must therefore travel faster if it is to keep up in the air. It is for the same reason 
that, as we recall, a small heavy kite needs a stronger wind to fly in than a big light one. It is for the same reason that little birds and insects beat their tiny wings much faster than the long-winged albatross or eagle.

An ordinary one-seated Blériot monoplane, for example, has a smaller spread than a Farman biplane, and is bound therefore to travel quicker. This does not mean, however, that it must have a more powerful engine, because it is less solidly constructed and carries less weight and offers less resistance to the wind. In speaking of the speed of an aeroplane, by the way, we must always remember that we mean speed in relation to the air it is passing through, not the ground that it is covering. If it is travelling with the wind, it will obviously cover more ground than if it is flying against it, although all the while it is passing through the air at exactly the same speed. A flying machine travelling at forty miles an hour with a twenty mile wind behind it will pass over the ground at sixty miles an hour. If it is going against the wind, its land speed is but twenty miles an hour. If a machine moving at forty miles an hour encountered a head wind of forty miles an hour, it would, theoretically, simply hover over one spot. If the head wind were sixty miles an hour, it would, also theoretically, travel backwards, relatively to the earth, at twenty miles an hour. I say theoretically because in reality it would probably be smashed to pieces. Flying in a high wind is, at present, an exceedingly dangerous proceeding; but with time it will tend to become less so. A great deal will depend upon the speed. It has been mathematically demonstrated that a flying machine, to be safe, must have a speed at least twice as great as any wind it is going to encounter. The faster the machine, therefore, the safer. A few years hence, when aeroplanes can travel at $\mathrm{I}_{50}$ and 200 miles an hour, when they are made more stable, and aviators have grown 
more experienced, aerial travel will be safe in any wind that blows.

So far in speaking of dynamic flight we have taken our analogy from objects, as birds and kites, which rise upwards from the ground. But there is another way of approaching the matter which leads ultimately to the same conclusions, but by a somewhat different paththis is by considering the behaviour of bodies which fall downwards from a height.

We all know the old experiment where you take two exactly similar sheets of paper and drop them from the same height, and one will reach the ground quicker than the other simply because you have crumpled it up into a ball, while you allow its fellow to flutter down wide open. Similarly we are all familiar enough with a parachute display, in which an aeronaut drops from a balloon at a great height, but reaches the ground in safety because he (only it is generally a "she" !) is attached to an enormous species of umbrella which expands during the fall and brings the parachutist gently and slowly to earth. In each case the resistance of the air is the reason for the slow descent and, in the case of the parachute, so large a surface is offered to the air that the resistance of it is sufficient so to retard the fall of a heavy human body from a great height that it comes down at a comparatively slow and even rate, instead of quicker and quicker as it otherwise would.

The planes of an aeroplane are, of course, not large enough to act as a parachute to the great weight of structure, engine and aviator that an aeroplane carries. It would not be possible to construct them large enough and light enough for such a purpose, nor would there be any point in attempting it. In the early days of flying there were many people who said, "The aeroplane must always be intensely dangerous because, if the engine stops in the 
air, there is nothing to save it, and it must instantly fall to the ground like a stone." We sometimes meet people who say so still, but they are growing fewer every day as knowledge increases. As we saw for ourselves at our flying-meeting in the first chapter, an aviator may stop his engine at any height and glide safely and easily at a uniform speed to earth.

Because, as has been demonstrated mathematically and proved by experiment with falling bodies, a plane moving horizontally will glide, not fall straight, to earth, and the faster the plane is moving horizontally at the time that it begins to drop the longer it will take to come down. An aeroplane whose engine is stopped suddenly, whether purposely or no, in the air, is travelling rapidly horizontally at the time, and glides down in "vol plané" at a "gliding angle" which varies with each machine, and at a speed which is the same as its ordinary flying speed, and does not increase. Of course if, through a collision, for example, the aeroplane has no "way" on it when its engine stops, or it loses its balance and turns over in the air, a terrible tragedy will probably ensue, but this will be an "accident" pure and simple.

As we shall learn in the next chapter, it has been through experimenting with man-carrying "gliders"aeroplanes large enough to carry a man, but without motors - that a very great part of our present knowledge of the principles of aviation has been obtained. As there is no motive power in a glider, it has to be launched from a height, or shot, catapult fashion, into the air, to begin with, in order that it may make its glide. After discovering, by actual experiment, the best form that a glider should take, the next step has been to add an engine and propeller to drive it through the air, and the result has been the complete aeroplane.

And when he has constructed a machine that will 
rise and fly the great aim of the aviator is, naturally, to give it stability.

A passenger on a ship at sea knows, frequently from painful experience, that the vessel can perform a considerable number of motions. It can go forwards and it can go backwards; it can also turn to right and left. But it does not, unfortunately, stop at this. It can, and does, also roll from side to side, and pitch from end to end. An aeroplane in the air can achieve all these movements, and two more besides, for it can rise and fall. The aviator has to see that his flying machine duly performs such of these motions as he desires, and does not indulge in the others meantime "on its own."

The aim and object of aeroplane constructors at the present time is to make a machine that shall have "automatic stability" ; that is, a machine that shall balance itself in the air largely, at least, of its own accord, and shall not compel the aviator to keep his hands on the levers, and his mind and nerves on the alert to the extent which has, up till now, been necessary. An aeroplane passing through the sky is liable to be struck by all kinds of unexpected side gusts, to meet with ascending and descending currents, strata of air of different densities, dangerous "wind pockets" - sort of holes in the air, of mysterious origin, where suddenly the resistance seems to fail. The speed of its own engine will also vary, causing, as we have explained, the aeroplane to have a tendency to rise or fall. With all these difficulties to contend with the pilot needs indeed every assistance in keeping his balance that improved construction can afford him.

To preserve "longitudinal stability"-that is, to prevent "pitching" from end to end-nearly all aeroplanes nowadays are provided with a tail. As the birds have found out, a tail, carried out at some distance from the wings or main planes, has a considerable steadying effect, 


\section{HOW AN AEROPLANE FLIES}

checking any tendency to dip up and down. Within certain limits the farther back the tail is placed the more effect does it have.

The aviator also corrects the pitching of his machine by means of his horizontal rudder or "elevator"-a smaller movable plane, or planes, placed horizontally, either out at the front or the back of the main planes. In the original Wright machines there is no tail at all, and horizontal stability depends entirely on the manipulation of the elevator, in this case a biplane one in the front. But in the later Wright aeroplanes tails are fitted and the elevator, as part of the tail, is put at the back.

To preserve lateral stability -or to prevent rolling from side to side-a variety of means have been adopted. One way is to have on the machine vertical or upright surfaces which offer a resistance to the air if they heel over, and so help to check the tendency. The original Voisin machines, in the early days of flight, had several of these vertical planes or "panels" between the main planes, making the whole thing look like a box with compartments"cellules" as they were called. But it was found that the disadvantages these panels entailed outweighed their usefulness, and they are now done away with for the most part, and vertical planes are used only for steering purposes, and generally placed in the tail.

Another plan is to employ what is called " the dihedral angle "-that is, so to place the main planes that they form a very shallow $\mathrm{V}$ with the body of the machine. This also gives a steadying effect, but again the advantages are apt to be outbalanced by corresponding drawbacks.

An aeroplane shows a great tendency to tilt over as it turns to right or left in the air. In sweeping round, the outer tip of the plane has to travel farther and, therefore, faster, than the rest of the machine. To travel faster 
means, as we have seen, to rise higher, and the consequence is that, unless something is done to prevent it, the wing tip will rise until the whole machine is tilted at an angle which may become dangerous. To guard against this various devices are employed. One of the most popular is what is known as "feathering " or "warping" the wings or planes. The extreme tips of the planes are made flexible, and as the pilot makes a turn in the air he "warps" or flexes one or both of the rear edges of his wing tips, causing them to offer greater or less resistance to the air, and so keeping the machine on a more even keel.

The celebrated Wright brothers were the first to employ this warping system, and in their machines the warping is combined with the turning, so that the same movement that steers to right or left also flexes the wing tips. It is in respect to this point that the Wrights claim their famous patent-the subject of so much discussion and litigation.

But the effect of warping may be brought about in other ways. In many machines the planes are made perfectly rigid and immovable, but at the back of them, or between them, are placed movable flaps or small surfaces known as "ailerons" - a term which those who object to the use of French words are endeavouring to replace by "balancers." These ailerons serve exactly the same purpose as is achieved by warping the wing tips, and tend to preserve lateral stability. But when all is said and done the stability of an aeroplane in the air is largely a question of speed. A swiftly moving flying machine - like a swiftly moving bicycle-is far less easily upset than one moving slowly. Therefore, again, we may prophesy that the safe aeroplane of the future will travel extremely fast.

To steer to right or left the aviator has a rudder of one or more vertical planes, generally placed at the back 


\section{HOW AN AEROPLANE FLIES}

and forming a part of the tail. To steer up and down he has his elevator which, as we have said, is a movable horizontal plane or planes placed either well in front of the main planes or forming part of the tail at the back. Some machines have both front and back elevators which move in conjunction. All these steering planes are worked by levers which the aviator controls with his hands or feet. Exactly how he does it in the leading types of machines, how he rises from the ground and alights again at the end of his voyage, as also the outlines of the construction of biplane and monoplane, we shall learn in a later chapter when we once more return to the actual flying-ground, this time with a clearer understanding of what we shall see there. 


\section{CHAPTER III}

\section{HOW MAN LEARNT TO FLY}

Ir is time now for us to turn back to the pages of past history and learn from them how, slowly, through the ages, man has won his way, by painful and laborious stages, by lavish sacrifice of thought, time, skill, and very life itself, to his present conquest of the air.

The beginning of human flight, like the beginning of all things, fades away into vagueness and legend, and it is impossible to tell where romance ends and fact commences. There is the usual cloud of mere fancy and conjecture, and mingled with it all manner of impossible statements, gravely recorded with the dogmatic cocksureness of the days before "scientific doubt" came into vogue. But amid all the jargon of the old writers about "flying chariots," "little imps in earthern pots," " upward attractions," and the like, by which they pretended they had solved the problem, we find here and there unmistakably the germ of the great discovery, and come upon men whose eyes could see many generations ahead of their time.

One of these was certainly that wonderful philosopher, Roger Bacon, the learned monk. Born seven hundred years ago, in the reign of King John, he not only turned his mind to such matters as the re-invention of gunpowder, the properties of lenses, and so forth, but he studied the question of flight also, and suggested the use of "a large, hollow globe, wrought extremely thin, so as to have it as light as possible" and "filled with etherial air or liquid fire." 


\section{HOW MAN LEARNT TO FLY}

Obviously a glimpse of the future was vouchsafed to him, but it was to be more than five hundred years before his dreams came true.

It is pretty certain that some notions of gliding flight, and of the properties of the parachute, were known in the Middle Ages, since there are many records of men who fitted "wings" to themselves and then jumped from great heights, and came to earth without much damage. Some say that the idea of the parachute originated with Leonardo da Vinci; it is certain that that wonderful genius, who excelled in so many things besides painting, paid a great deal of attention to the question of flight, and left behind him many notes and sketches of ingenious wing-driven flying machines.

But matters did not progress very fast, for as recently as I69I we have Bishop Wilkins of Chester gravely enunciating that flying was a mere matter of practice to which a man should be brought up from his youth, "trying first only to use his wings in running on the ground as an Estrich or tame Geese will do, touching the earth with his toes, and so by degrees learn to rise higher till he shall attain unto skill and confidence." The learned bishop also recommends a flying chariot worked, rather vaguely, with a spring, in which a man might travel with ease about the world by the wonderfully simple plan of rising into the air, waiting for the earth to turn round beneath him, and then descending upon the desired spot! These were the ideas of learned men only two hundred years ago.

Less than a century passed, and men thought they had solved the problem. They had, indeed, succeeded in rising into the skies. Once again the old story may be told of two brothers, paper-makers by trade, Stephen and Joseph Montgolfier by name, sitting over their winter fire in the little French town of Annonay, one November night of the year I782. They are watching the smoke of 
their logs curling up the wide chimney, and the idea occurs to one of them that if a paper bag were filled with smoke it, too, might be made to rise aloft. Immediately they set to work to make the experiment; a little fire is made in a small tin tray, a paper bag is held over it. But though the bag fills out and struggles to rise, so that the deeply interested brothers see that they are on the eve of a great discovery, yet the smoke in the bag always gets too cold before there is enough in it to lift the bag from the table. Then, in the nick of time, the door opens and an old widow woman, their neighbour, attracted by the smoke issuing from the window, enters and stands watching their fruitless efforts. Woman-like she grasps the difficulty and solves it. "Why don't you tie the bag on to the tray ?" she says. The name of that widow woman is unrecorded, yet deserves to be inscribed in letters of gold; for it is through her timely suggestion that the first balloon in history rises and flutters to the ceiling.

It was only a very few months later that a large and magnificently decorated Montgolfier balloon was sent up before the King and Queen of France, and an enormous crowd in front of the royal palace at Versailles. It carried aloft the first living aerial passengers-a sheep, a cock and a duck. Wild was the excitement and great the delight when the travellers returned to ground uninjured. Forthwith the cry arose that men should take their place, and King Louis XVI.-whose head was yet safe on his shoulders-made the thoughtful proposal that two criminals, lying under sentence of death in the gaol, should be sent for a trial trip in a balloon. "What!" cried in indignation Pilâtre de Rozier, a French gentleman who stood by, "shall vile criminals have the honour of first ascending into the sky? Never!" That honour he claimed for himself, and shared with a French nobleman, the Marquis d'Arlandes. The occasion was a memorable one, and the 
first human voyage in cloudland, on November 2I, I783, is an event that has never really been equalled in the wonderful history of aerial travel. For not only was the machine an untried one, and desperately dangerous, carrying as it did a blazing furnace slung close beneath the silken envelope, but the very nature of the atmosphere aloft was absolutely unknown. In those days men were afraid to climb the smallest mountains-the Alps were untrodden, and even our English fells unexplored. As far as de Rozier and his companion knew they might be suffocated at even a few hundred feet above the earth. But they went up gallantly, standing on a wicker gallery alongside the fire which they constantly fed with bundles of fuel; while in their other hands they held each a big wet sponge, with which to mop out the flames whenever, as frequently happened, the silk caught fire.

Surely never was a more hazardous voyage, for they passed right over the heart of Paris, where to land would have been impossible; but after half an hour it ended safely in a field some five miles away.

By this time ballooning was thoroughly "in the air" in every sense of the phrase, and unmanned ascents had already been made with balloons inflated with the recently discovered "inflammable air," later to be known as hydrogen. One Charles was the author of this new idea, and henceforward the rival air-craft, "Montgolfier" and "Charlier" made frequent ascents. Pilâtre de Rozier, indeed, tried to combine the two, and put a fire balloon beneath another filled with hydrogen gas. The inevitable happened, and poor de Rozier perished-earliest victim of the new-found art.

Balloon ascents became more and more frequent, and spread from France to every civilised country of the world. James Tytler, a Scotsman, made the first ascent in the British Isles, going up from Edinburgh in a Montgolfier, 
in August, I784. His ascent was not a very successful one, and was eclipsed by the voyages of Vincent Lunardi, a young Italian, who the following month made his first journey in a gas-balloon from London, amid wildest excitement, and landed near Ware, where an aged stone with a long inscription still marks the spot.

Four months later the Channel was crossed, from England to France, by M. Blanchard, a Frenchman, and Dr. Jeffries, an American. The crossing of the Channel has ever been a great event in the early days of all kinds of aerial travel. Enthusiasm was now at its height, and nothing was too extravagant or far fetched to be said of the new discovery. Men declared that a new kingdom had been given them to conquer; that now they would be able to pay visits to the sun and the moon and the fixed stars-in fact, they would even be able to take Heaven itself by storm !

But disillusionment came quickly. The great defect of the balloon soon manifested itself-the impossibility of steering it. The old inventors were loath to believe it. They took oars aloft with them and perspired freely in working them up and down, but to no purpose. They hoisted sails out at the side of the car, and the wind caught them and slewed the balloon round, but did no more. Reluctantly at last they came to see that a balloon in the air is like a drifting boat on the water, carried idly along by stream or tide, and unable to be steered unless by some means made to go faster or slower than the current that bears it.

Thus it has followed that the spherical balloon, in all its century and a third of existence, has made next to no progress, for progress is practically impossible. Charles Green discovered that ordinary household gas might be used for inflation instead of the much more costly hydrogen ; lesser details of valves and "ripping panels," and so forth, 
have been elaborated; but otherwise matters are unchanged and the days of the usefulness of the balloon are wellnigh over. It lingers now mainly for exhibition purposes, and as the means to a very delightful sport.

Nevertheless, we should be very grateful to the old balloon, for it has done grand work in the past. It has proved of the greatest service in times of warfare, most notably in the siege of Paris, when it formed the only means of communication between the beleagured Parisians and the outside world. It has been used extensively as a means of scientific research, as witness the many scientific voyages of Glaisher and Coxwell, and the late Rev. J. M. Bacon. It was Glaisher and Coxwell, by the way, who, in the year I862, performed the unrivalled feat of ascending to a height of seven miles into the air ; the greatest height that man has ever reached, in a balloon, up a mountain, or in any other fashion. Their voyage was a terrific one, and they barely escaped with their lives yet they managed to survive, and their record stands unchallenged. Lastly, the balloon has been used for exploring inaccessible tracts of the earth's surface ; the most famous attempt being the ill-fated voyage of Andrée and his two companions towards the North Pole in I897.

So presently men began turning their attention to the dirigible balloon or airship, and very soon they found that the only way effectually to steer a balloon was to fit it with an engine and propeller which should drive it through the air faster than the wind would bear it. But here at once they were met with a difficulty-in those days insurmountable. There were no engines in existence light enough and at the same time powerful enough for the purpose. A Frenchman of the name of Giffard was the first to achieve any success in a dirigible. This was in the year 1852 ; but the only engine he could get for his purpose was a little 3 -horse-power steam engine, weighing, 
without its fuel, nearly a quarter of a ton! It is not wonderful that Giffard's experiments did not lead to any great result. Nor did the next fifty or so years see any startling progress in airships.

And then came the motor-car, and at once all was changed. For with the coming of the all-conquering car came also those light, petrol-driven, "internal-combustion" engines that have made, not only the modern airship, but the flying machine also, alone practicable.

The first man to grasp the aerial possibilities of the new invention was that wonderful Brazilian genius, Santos Dumont. He had long been an ardent aeronaut, and as soon as motoring came into vogue he naturally-keen sportsman that he is-took it up enthusiastically. And as he rode his early motor tricycle about the country the idea occurred to him that he might combine his two hobbies together, by fitting the engine of his tricycle into his balloon and making an airship. There followed those wonderful and wildly adventurous voyages that demonstrated to the world the success of the new project, and the extraordinary pluck of its originator, and culminated in the winning of the great prize offered by Monsieur Deutsch for an airship flight around the Eiffel Tower. Santos Dumont made his first experiments in the year I898. From that time onwards the progress that has led to the giant Zeppelin craft, and to the great fleet of magnificent airships at present owned by the nations of the world, has been rapid and uninterrupted.

Again the papers declared that the heavens at length were conquered, and that now at long last man had come into his kingdom of the air. But there were those who looked with no great favour or enthusiasm upon the dirigible. They pointed out that progress in that direction was limited, and that already the "lighter-than-air" followers were getting to the end of their tether. To 


\section{HOW MAN LEARNT TO FLY}

add to the strength of airships meant to add to their weight; to add to their weight entailed adding to the size of the great gas-bags that held them aloft; to make these enormous balloons capable of forcing their way against even a moderate wind they must be made stronger, therefore heavier and larger. This was arguing in a circle. They were the "heavier-than-air" men who said these things, the men who were even then experimenting with the earliest aeroplanes; but presently even Santos Dumont himself was declaring that " to drive a dirigible balloon through the air is like pushing a candle through a brick wall." Aeronauts were divided into two great schools. At first the lighter-than-air folk had it all their own way, for their craft sailed in the air, and their rivals remained persistently on the ground. But now the day has come when the tables are turned, and the aeroplane -the true flying machine-seems in a fair way ultimately to drive the airship from the field.

As to who was actually the first man to rise from the ground in a heavier-than-air machine opinions differ. There is a story that it was Sir George Cayley's coachman. Sir George Cayley was a scientific baronet who flourished in Yorkshire about a century ago. He was a man of great attainments, and a special leaning towards aerial matters, and it is said that had others only seen as clearly as he did and followed his advice, Wellington would have had a dirigible balloon to help him win the battle of Waterloo. He was a man far in advance of his time, and he made himself a flying machine driven by some ingenious sort of internal combustion engine of his own invention. He put his coachman into it to try it on the ground, but presently, to everybody's surprise, the thing began to lift, and the poor aviator was so frightened that he jumped out and broke his leg. I like to believe in this little legend, for the humble coachman is a fitting 
companion for the nameless old heroine of the first Montgolfier balloon.

Anyhow, Sir George Cayley had a very fair understanding of the problems of dynamic flight. So had Thomas Walker, a painter of Hull, who, in the year I8Io, published "A Treatise upon the Art of Flying by Mechanical Means." But the most famous early pioneers of the heavier-than-air school were three other Englishmen living in the first half of the nineteenth century-Henson, Stringfellow, and Wenham.

There are experts of the present day who do not hesitate to assert that these men are the undoubted originators of the aeroplane, tracing the conception of the monoplane to Henson's model of 1840 , and the biplane to Wenham's experiments fifteen years later. This is certainly a comforting doctrine in these days when the backwardness of our countrymen in aeronautical enterprise is dinned into our ears morning, noon, and night. It is possible that we rather overdo our self-depreciation. Modesty is as becoming in a nation as in an individual, but there is no point in carrying it to extremes. In the case of the monoplane actual pictorial proof is forthcoming.

Henson and Stringfellow were two friends living at Chard, in Somerset, about the year I840. They were both engineers, and exceedingly interested in the problem of flight, and between them they evolved the idea of a mechanically driven flying machine-Henson being chiefly responsible for the design of the aeroplane, Stringfellow for the specially light steam engine that was to drive it. So enthusiastic did they become over their idea that they took out a patent, and formed a company called "The Aerial Steam Transit Company." The public grew excited, and the papers of the time were full of accounts and pictures of the project. All the same no one seemed inclined to risk any money, and beyond a not very successful 


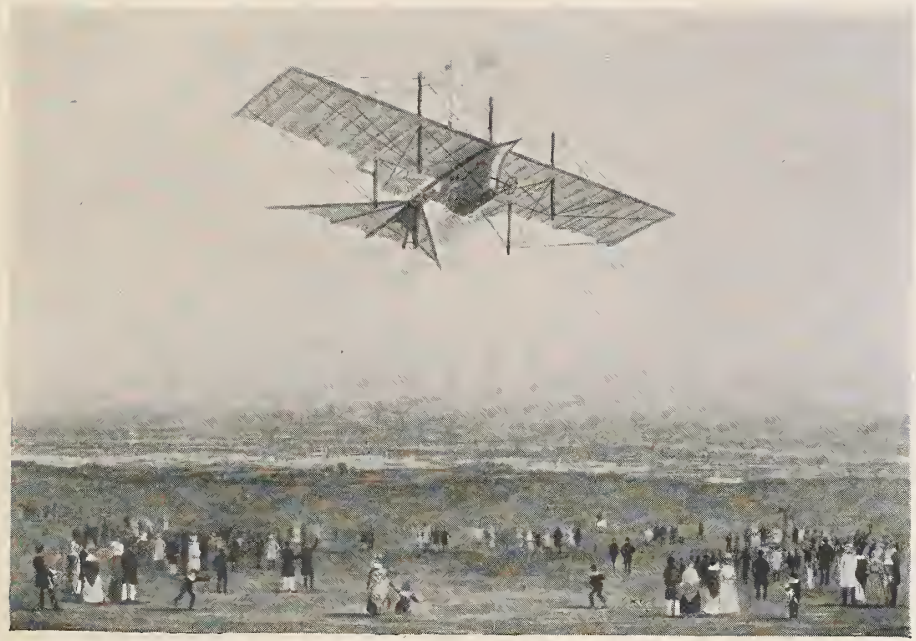

HENSON'S (PROPOSED) FLYING MACHINE-1840. (From an Old Print.)

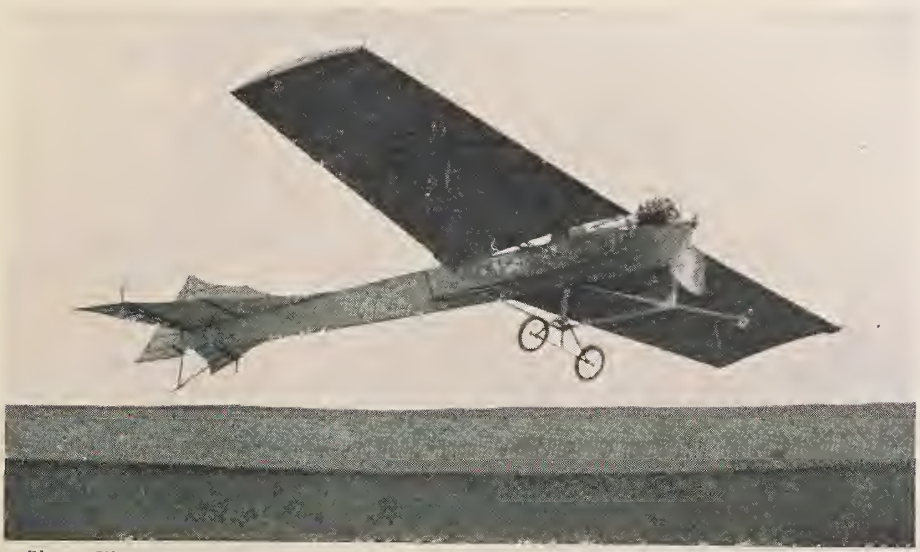

Photo: Illustrations Bureau.

LATHAM'S "ANTOINETTE" MONOPLANE-1910.

A COMPARISON OF SEVENTY YEARS. See pages 45 and 79 . 

model nothing came of it. The days were all too young for the coming of the aeroplane; and yet a glance at Henson's machine will show that it contained more than the germ of success. Compare the picture of his craft with a photograph of the Antoinette monoplane, one of the most magnificent flying machines of the present day. The resemblance is quite extraordinary, and we cannot doubt that had poor Henson but had, in his day, seventy years ago, the famous Antoinette motor to work with, the pictures of the period would have represented not dreams but realities.

Henson presently emigrated to America, a disappointed and impoverished man. Stringfellow in later years continued his experiments and achieved the honour of producing the first engine-driven model aeroplane that ever flew. It has remained for later generations to estimate the work of these men at its proper value. Models of their machines are now in the South Kensington Museum, and their names are honoured as true pioneers of the conquest of the air.

Francis Wenham was also an engineer who turned his thoughts to the mysteries of flight. Fifty years ago he read a famous paper before the Aeronautical Society in London, which showed that he had mastered the principles of the aeroplane as thoroughly as we have at the present day. Later he made experiments with light engines, shapes of planes, etc., that are now classical, and undoubtedly his work has had great effect in inspiring later discoveries. Wenham died in I908, and it is pleasant to think that he lived to see the realisation of those dreams of his which he did so much to bring true. Since the days of these three pioneers perhaps the most famous English worker has been Mr. Horatio Phillips, whose experiments, made some twenty years ago, on the best forms of planes, settled once and for all the shape which gives the most 
lifting power for a given area. The form of entering edge of the blunt-nosed "humped" section that we noticed in our previous chapter is due to him, and called by his name -the "Phillips entry." It has been said of him that he has done more work in the cause of aviation than any living Briton.

And now, all over the world, there began to be felt stirrings of the coming movement, and the idea of flight wrought more and more in men's minds. In Australia, Lawrence Hargrave commenced experimenting with kites, and presently evolved the now familiar box kite-a noteworthy event in the history of aviation, for it led directly to the aeroplanes of Santos Dumont and the Voisin brothers-the first French machines to fly.

But as we saw in the previous chapter, there is another way of approaching the question of dynamic flight, and that is by studying the behaviour of bodies falling from a height. As far back as 1854 Captain Le Bris, a French sailor, made what he called an artificial albatross-a kind of enormous model bird with wings fifty feet in span and weighing ninety-two pounds. With this he made a most daring experiment by dropping down a quarry one hundred feet deep, and was certainly lucky to escape with only a broken leg. Several years later Lilienthal, a German engineer, constructed for himself a soaring machine or "glider" on which he could jump from a height and glide to the ground. His apparatus took the form of two huge wings, with a big, curving tail behind, and for his experiments he had an artificial hill made from earth that was being dug up for a canal in the suburbs of Berlin. From this hill he took his leaps, learning thereby many important facts-the best shape and size for the wings, the best way to balance and steer them, and so forth. So proficient did he become that he could glide for four hundred yards at a time, but one day he lost his balance in the 


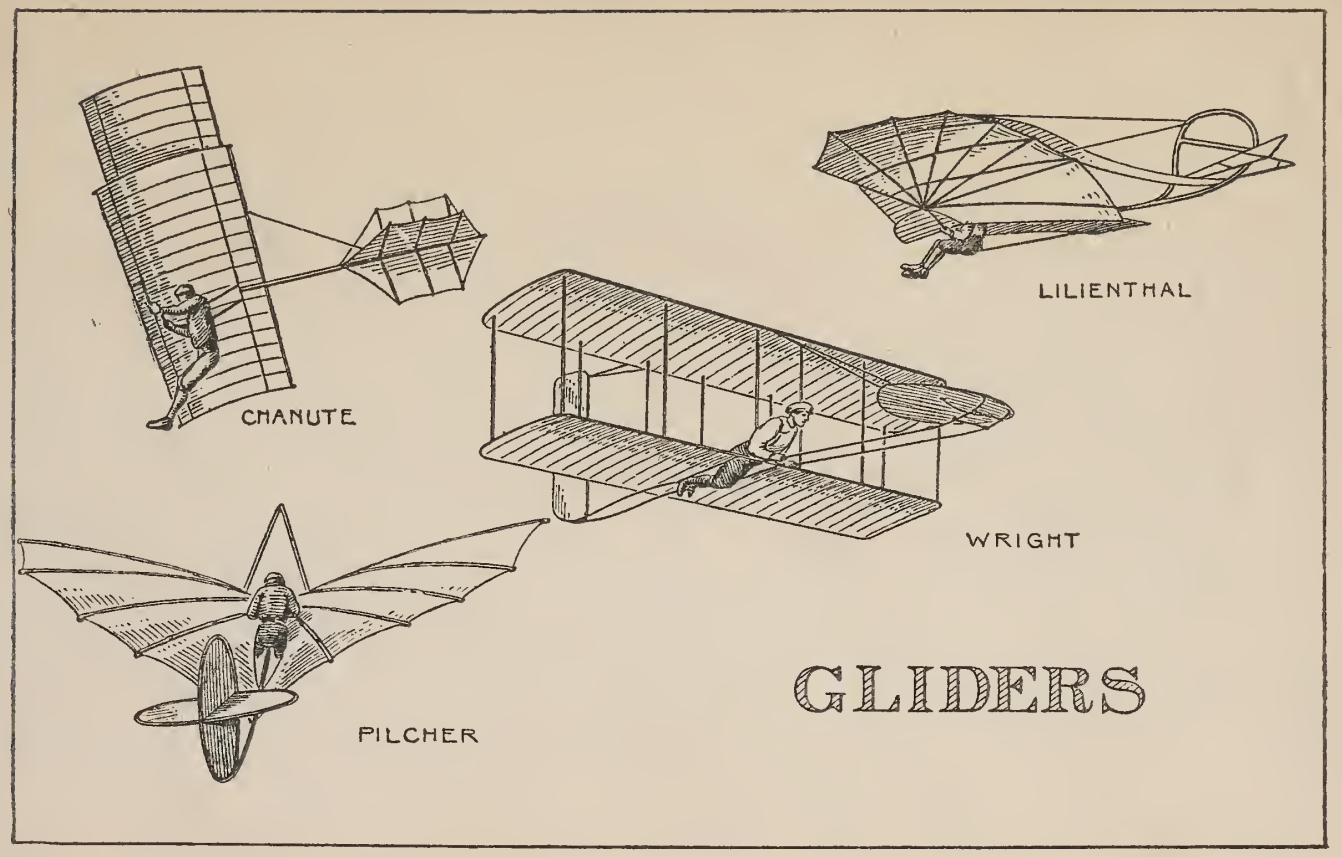


air and, falling fifty feet to the ground, broke his spine. His mantle fell on a young Englishman, Percy Pilcher, also an engineer, who continued the gliding experiments with great success until he also fell with his machine from a height and was killed. Pilcher and Lilienthal were true pioneers of the cause for which they laid down their brave lives. Their work, more perhaps than any others, helped on the great movement in its early days, and though they perished as martyrs, yet their sacrifice was not in vain, for by the successes, but yet more by the failures, of its devoted labourers the conquest of the air has been achieved.

Lilienthal died in 1896 , and Pilcher three years later. About this time most important work was being done by two celebrated Americans, one in the United States, the other in our own country. Sir Hiram Maxim, whose name will ever be a household word by reason of his famous gun, turned his giant brain to work on the subject of flight, and produced a mighty flying machine which is often considered to be the first that ever flew. It was of enormous size, weighing over three tons, and containing 4,000 square feet of supporting surface; and to drive it Maxim produced a steam engine of 360 horse-power, which made a new record for lightness; for in those days (r892) the petrol motor had not yet dawned upon the horizon. The great craft ran on wheels, and was mounted on a double railway line, while a little way above the track were placed other rails upside down, so that the wheels, if they lifted, would run under these and be prevented from rising too high.

It was not Maxim's intention to allow his tremendous machine to rise free in the air until he had mastered its balancing. (Even with the aeroplanes of to-day the budding aviator spends some time running his machine about on the ground- "rolling" he calls it-before he 


\section{HOW MAN LEARNT TO FLY}

ventures to leave the earth.) And Maxim used to run his craft at forty-two miles an hour down the track, by which time it would have left the lower rails and be running along the underside of the upper ones. But shortly an upper rail broke, and the impatient monster rose free into the air for its first but, alas ! its last flight, for immediately it lost its balance and in falling was smashed to pieces.

Sir Hiram Maxim did a vast deal of invaluable experimental work on the lifting power of planes driven at different speeds, and at the same time, but quite independently, the late Professor Langley, in America, was working on the same problem. Their results went to prove that planes inclined at a small angle and driven at high speed have far more "lift" than had before been supposed, and that the faster they travel the more lift they get for the same expenditure of power. Both men also made many investigations concerning the shapes of planes, etc., and Langley experimented largely with engine-driven model flying machines launched from a house-boat moored on the waters of the broad Potomac River.

Thus, in one way and another, by varying methods and in different parts of the world, men were gradually and painfully gathering the knowledge which was presently to be put together by those who reaped the benefit of their discoveries. For let it ever be borne in mind that aviation is no new invention, suddenly evolved by a master genius, but the result of years and years of patient toil on the part of devoted workers, many of whom never lived to see the reward of their labours, and whose very names are now scarce known to those who profit by the results of their work.

The next link in the chain was forged by Octave Chanute, a famous American engineer. He took up Lilienthal's and Pilcher's gliding experiments at the point where those ill-fated pioneers laid them down and, building on $\mathrm{E}$ 
their work, elaborated more and more improved gliders that ever drew nearer to the successful aeroplane. By experiment he learned a great deal about the balancing of these craft, and he introduced the "two-decker," or biplane type in place of Lilienthal's monoplane wings. Long before Chanute's recent death, he was enthusiastically acclaimed on both sides of the Atlantic as the "father of modern aviation."

An early French pioneer must also be mentioned. During the "nineties" Monsieur Ader, a well-known electrician, produced three wonderful flying machines. The first, it is recorded, flew, or hopped, for I64 feet, on October 9, I890-which is before Maxim or any other aviator left the ground. The last and most successful, "L'Avion," flew 300 yards in 1897 before a committee of army officers appointed by the French Government. "L'Avion" was a most weird-looking creature, with wings like a huge bat, and two propellers in front, with blades resembling giant quill pens-they were, indeed, made to imitate feathers. That Ader really did fly is now apparently established beyond question, but at the time he hardly seems to have received fair treatment. His feats were discredited and the Government refused him further assistance; he was considered a "crank" and a visionary, and, deeply disappointed, he threw aside his work, on which he had spent a million francs. But a later generation has done him better justice, and at a banquet held in Paris, on New Year's Eve, IgIo, where all the guests were aviators who had won their pilot's certificates, Ader, by a charming and graceful suggestion, was invited to preside. There, surrounded by Paulhan, Leblanc, Rougier, and almost a hundred other famous flyers, all of whom were proud to call themselves his disciples, the old man must have felt at last that he had entered into his own. 


\section{HOW MAN LEARNT TO FLY}

But now at length, in the fullness of time, there dawned on the world an event that, in a moment, lifted the great problem of flight from realms of mere speculation and theory into active reality. This was, of course, the coming of the light, petrol-driven, internal-combustion engine, which, as we have explained, appeared on the scene with the advent of the motor-car. Now at last the great engineers of the world found it worth while to lavish brains and money on the evolving of engines which should combine least weight with greatest efficiency. That which the struggling heavier-than-air investigators could not afford to do for their experiments, was brought about to satisfy the luxury of the wealthy and great.

It was certainly curious that now when success was actually at hand, England, who had done so much to sow the seed, should lag behind and leave two other great nations, America and France, to reap the fruit. It is also a curious coincidence that just as two brothers, Stephen and Joseph Montgolfier, were the authors of the first balloon, so, a century and a quarter later, two other pairs of brothers, a French and an American, were mainly responsible for the earliest aeroplanes.

The American pair were those celebrated men Wilbur and Orville Wright. Amid all the world's heroes of aviation these two brothers will ever stand out from the rest, if only because of their remarkable characters. Patient, silent, and doggedly determined, they did their wonderful work in strictest seclusion and secrecy until success was won, and all was ready; and then they launched their great discovery on the astonished world as a veritable thunderbolt, and left the nations gasping with amazement at what had been accomplished without their knowledge.

The Wright brothers were bicycle manufacturers in Dayton, a small town of Ohio, U.S.A., and they say that 
their interest in aeronautical problems dates from the day when they read in the paper an account of the death of Lilienthal. It seemed to them that insufficient knowledge alone was to blame for his disaster, and they calculated that in all his five years of experimenting he had only spent some five hours in actual gliding through the air. If in that brief time he had learnt so much, what might not be achieved by steady continuous work under favourable conditions? The brothers determined to try their hand at further investigation, and they hit at last upon an ideal spot for the purpose, a sandy spit of land on the sea coast in North Carolina, where a steady wind, such as they needed for their experiments, blows constantly from the Atlantic; where sand hills of a hundred feet and more gave splendid jumping-off places, and where, absolutely remote from the haunts of man-for the place is almost a desert-they could carry on their work without fear of spying or interruption.

They began experimenting with a Chanute glider which they presently modified and improved. They did away with the tail behind, they put an elevator on in front, and they caused the aviator to lie flat on his chest on the lower plane instead of dangling his legs below, as in all previous gliders. Their glides became more and more successful, and presently Mr. Chanute himself came and spent a week with the brothers in their Robinson Crusoe camp the other side of nowhere. He was impressed exceedingly with what he saw, and coming to Europe soon afterwards told the aeronautical workers there what wonderful things were being done in America.

England, except for one or two enthusiastic souls, was frankly indifferent, for all her former interest in flight seemed to have died out of her; but France was quite tremendously excited. Several Frenchmen were working on the problem at the time; one was poor Captain Ferber, 


\section{HOW MAN LEARNT TO FLY}

afterwards one of the first victims of aviation; another was Blériot, one day to be the hero of the monoplane, but not for several more years of toil and frequent disappointment; a third was Esnault-Pelterie, another early flyer, and a fourth M. Archdeacon, a man of means, and immensely enthusiastic over the new art, the dawn of which he saw was rapidly approaching. Chanute's accounts filled him with excitement. He wrote a sort of manifesto to his countrymen. He said that the great triumph was coming, was coming very quickly, and it behoved France to bestir herself lest the nation which produced the first balloon should lose the honour of producing the first flying machine also. "Gentlemen of science," he ended, "to your compasses! You, patrons of learning, and you, also, gentlemen of the Government, put your hands in your pockets-or indeed we are lost!" And he himself and his friend, M. Deutsch, set the example by subscribing 50,000 francs for a prize to the first aviator to fly a circular kilometer (about five-eighths of a mile).

But it was all too late. On December I7th, I903, Orville Wright, at Kitty Hawk, his lone Atlantic flyingground, flew 852 feet on a machine to which a petrol motor, designed and made by the brothers themselves, was now attached. Two years later, at their own home in Dayton, one of them flew eleven and, the following month, twenty miles, which he covered in half an hour. The aeroplane had arrived!

But the Frenchmen did not know that they were beaten, or at least would not believe it. The Wright brothers were keeping their work very dark until they should have perfected it. Only the vaguest rumours came from the far Atlantic coast or the little Ohio town. Even the most credulous hardly knew what to think, while the sceptical merely smiled and talked of "Yankee tall stories." Meanwhile the work in France was pushed on apace, and Arch- 
deacon began special experiments with kites and light motors, assisted by the brothers Voisin.

Gabriel and Charles Voisin are the third famous pair of brothers in the history of aeronautics, and their work has been not a scrap less important, though perhaps less widely recognised, than that of the others. Some of their first experiments were with huge box kites towed about by a motor launch on the River Seine, and Gabriel Voisin got many a ducking, and once at least came very near drowning over the business. Gliding experiments with Chanute gliders came next, and finally the brothers constructed a biplane, driven by a petrol motor, in appearance exceedingly like the box kites from which it had drawn a good deal of its inspiration. A young French sculptor, Leon Delagrange, ordered the first of these machines; Henry Farman, a Parisian Englishman, a racing cyclist and later a racing motorist, born of English parents, but naturalised as a French subject, secured the next. But to naither of them, nor yet to Blériot, now working with the aid of the Voisins on his eighth monoplane, came the honour of making the first practicable aeroplane flight in Europe. That triumph was snatched from them all by that wonderful man Santos Dumont.

Santos Dumont is a genius of a meteoric sort, suddenly blazing in the sky with some wonderful new feat, then fading into obscurity only to shine forth again in quite a different direction. He never seems seriously to work out the results of his marvellous inspirations. After having, in startling fashion, indicated a new line of progress he leaves it to others to follow up if they please, and turns his brilliant mind to something quite different. Not content with being the pioneer of the modern airship, he sought for fresh worlds to conquer, and desired to be the pioneer of the flying machine also. In wondrous fashion he succeeded. He began his experiments only at the 
beginning of 1906, but by August his strange machine had actually hopped from the ground, and that autumn the European press was, for the second time in his life, waxing delirious over him, this time as "The First Man to Fly!"

His aeroplane, which he called "The Bird of Prey" -why is not very evident, for it resembled no bird that ever flew out of nightmare-was a weird-looking craft indeed, built up, it seemed, of several box kites all strung together. Its main double-decker planes were tilted up at a considerable angle; there was no tail, but in front a big box-kite elevator; so that the thing appeared to fly tail foremost or, as someone said, like a duck with its neck outstretched. On a light, open framework in the midst, mounted on bicycle wheels, was the 50-horse-power Antoinette motor, driving the propeller at the back, and the sort of wicker wastepaper basket in which the aviator stood. In the early attempts the aeroplane, after being run along the ground for a hundred yards at twenty-five miles an hour, hopped, when the elevator was tilted up, a few feet at a time, but on October 24, I906, Santos Dumont flew for seventy yards, and the following month for more than three times that distance, and would doubtless have flown farther yet had not the wildly excited spectators got in the way, as is their cheerful wont, and compelled him to come down. By these flights he won several prizes offered for the first aeroplane successes and, what was vastly more important, stirred the indifferent, incredulous world to the amazed realisation that what it had hitherto sneered at as a fantastic dream had actually, in a moment, become reality.

The next record belongs to Blériot, whose long labours and extraordinary perseverance were cheered by a little flight in the spring of I907. For a long while Louis Blériot was known as the inventor of the fine acetylene motor- 
car lamp which bears his name, and also as a hopeless "crank," working year in year out and wasting a once handsome fortune on the totally impracticable idea of a monoplane, when everybody knew that a biplane was the only machine that could possibly hope to fly. "Another Blériot Smash!" became a stock piece of news for the papers, and people were not surprised; only contemptuous and mildly pitying, making little jokes about how the mad inventor would certainly establish a " record," but it would be for the number of his accidents alone. Meantime Blériot worked steadily on, gleaning fresh knowledge from each disaster, and winning through the long years of bitter disappointment and hope deferred with a brave heart and a courage and confidence that never failed.

At the same time the Voisin aeroplane-a large, heavy biplane with a big box tail-was getting on. Delagrange was the first to order his machine, but Farman was the earliest to leave the ground. In October, I907, he flew first 300 yards, then 800 , and three months later accomplished the circular kilometer that won him the DeutschArchdeacon prize. Delagrange followed him closely, and the two alternately beat each other's records, in friendly rivalry, all that spring.

Then, indeed, France declared, with much flourish of trumpets, that her sons had achieved the conquest of the air, and the other nations of the Old World acclaimed her triumph. Not so the New World. "I guess you needn't be so proud," said America to France. "We have two men right here who have been flying for years, and one of them has flown twenty miles!" France was contemptuously incredulous. She described the brothers Wright by a beautiful new word that she had taken from the expressive American vocabulary, but had altered for herself. She called them "Bluffeurs."

This was not all the French nation, of course. Some 


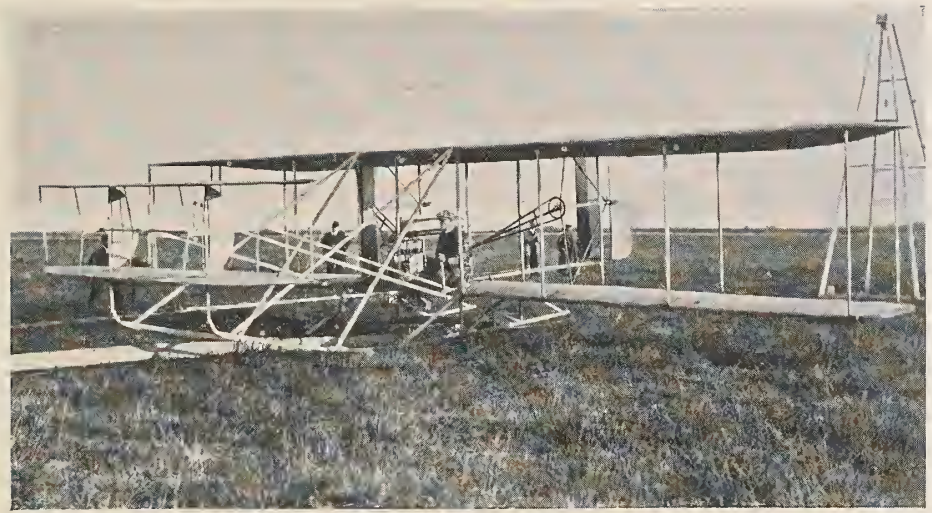

Photo: Illustrations Bureau.

THE FIRST AMERICAN BIPLANE.

Wilbur Wright Ready to Start.

See pages 57 and 70.

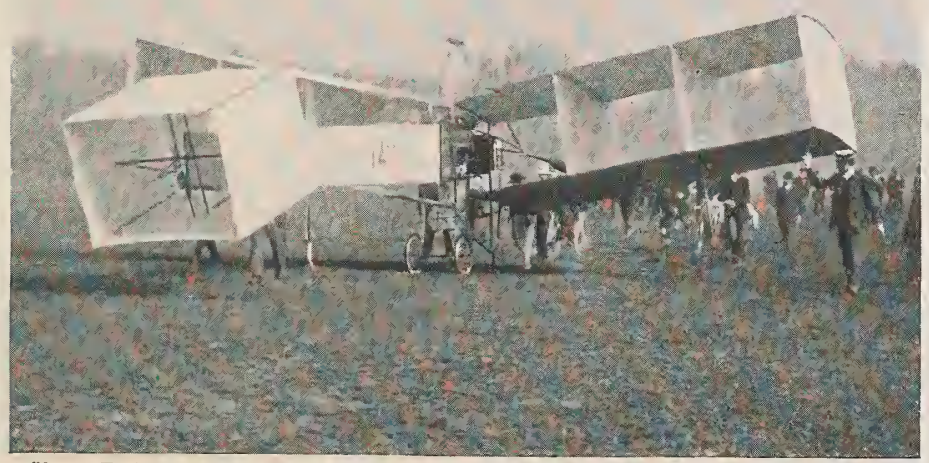

Photo: Topical.

THE FIRST FRENCH BIPLANE.

Santos Dumont's "Bird of Prey."

See page 55.

THE FIRST AEROPLANES THAT FLEW. 



\section{HOW MAN LEARNT TO FLY}

had reason to be better informed, some had actually met the mysterious brothers when they came to Europe to approach the foreign governments with their new invention, and those who had come in contact with these strong, silent men had been impressed at once by their transparent sincerity. Moreover, the Wright brothers had really themselves to thank for this incredulity. They had tried their very utmost to keep the world in ignorance until the time should be ripe for complete disclosure. That hour at length had arrived. "You don't believe us?" said the brothers to the nations, "You want proof ? Well, then, you shall have it!"

During the summer of 1908 Wilbur Wright came with his machines to France. Orville took other machines to Fort Meyer, in Virginia, in his own country; and simultaneously, on either side of the Atlantic, the two commenced flight, not of a few minutes at a time only as the Frenchmen had so far done, but of an hour or more at a stretch, in an original and far-perfected biplane, and with an ease and skill that demonstrated from the first moment the justice of their proud claim to be the first men satisfactorily to solve the problem of the ages.

With the triumph of the Wrights, in September, Igo8how short a while ago!-the first stage of the history of flight comes naturally to a close. 


\section{CHAPTER IV}

\section{THE AEROPLANES OF TO-DAY}

Now with fresh knowledge, with a clearer understanding of the broad principles of flight, with a fair idea of how those great principles came to be discovered and turned to account, let us return once more to the aeroplanes themselves, and examine them in greater detail and with more intimate care.

For this purpose we want to see them not merely in the air but at close quarters on the ground, to go near them and examine them at our leisure. Let us repair, therefore, not to an aviation meeting, but to a permanent flying-ground, where practice is always going on, where the great schools connected with the various famous machines train their pupils, and where the experimenter and constructor works out his new designs. At the present moment there are several of these "aerodromes" in different parts of Great Britain, and others are springing up with mushroom rapidity in every direction as the new art develops and spreads.

First, in order of precedence, comes the Royal Aero Club's Flying-Ground at Eastchurch, in Sheppey-an almost ungetatable but, once reached, ideal spot among the low-lying flats of the Thames estuary, with endless stretches of level grass, broken only by narrow watercourses, and far from the madding crowd and its unwelcome interruptions. Here is the wonderfully complete aeroplane factory of that intensely clever constructor and inventor, Mr. Horace Short, the long ranges of the members' hangars, 


\section{THE AEROPLANES OF TO-DAY 59}

and everything that is needed in the way of repairing sheds and so forth. Here in delightful seclusion and pleasantly unconventional picnic fashion, a little coterie of enthusiastic aviators-many of them men of means and leisure-carry on their work, united by a common interest and the freemasonry of sport.

Next comes Brooklands. It was a stroke of pure genius that led to the conversion of the central plain enclosed by the famous motor track at Weybridge, that travellers on the South Western are so familiar with, into a popular aerodrome where, at a reasonable distance from London, but secluded by the great track from interruption, the flying men can pursue their labours. There were many difficulties to contend with at first and even now. The River Wey still meanders through the course, and a sewage farm obtrusively thrusts itself into notice, and seems to exert a magnetic influence on the aeroplane of the beginner. But the ground is very rapidly being improved, its thirty to forty hangars are fully occupied and the scene of busy activity; and a visitor from town who chooses only a moderately fine afternoon is certain of seeing first-class flying on any day of the week.

Yet more accessible from London-only six and a half miles from the Marble Arch, in fact-is the fine new Hendon Aerodrome, where the Blériot, Grahame-White and Valkyrie schools have their headquarters. The "British and Colonial Aeroplane Company," who turn out the famous "Bristol " machines, claim that they have the best flying-ground in Great Britain on Salisbury Plain. The distinction of being one of the worst belongs to Laffan's Plain at Aldershot, where Mr. Cody and the military aviators contend with trees and cross currents and long grass and stumps and fences that no doubt in the end terid to make them into specially efficient flyers, but are certainly embarrassing to the beginner. Besides these, 
there are other aerodromes in the New Forest, at Huntingdon, Wolverhampton, and Shoreham, near Liverpool, in Yorkshire, and other places too numerous even to enumerate.

It is to none of these flying-grounds, however, that we are going to pay our visit, but to an idealised aerodrome, a skilful blending of the lot, where all the chief types of aeroplanes are gathered together, and all the hangar doors are standing wide, so that nothing shall interfere with our careful inspection of their contents.

Outside one of the sheds, all ready for its flight, the engine and polished-wood propeller shining in the sunlight, the snowy spread of the great planes all fresh and new, stands a Farman biplane, most famous of the present day two-decker flying machines, and undoubtedly, with her light, graceful build, a thing of beauty. The main planes are thirty-five feet long and six feet six inches wide. They are placed six feet six inches apart, for it is customary to make the distance between the planes of a biplane, known technically as the "gap," the same measurement as their width. In this particular machine the two main planes are both of the same size, but in "racing" Farmans the lower plane is cut much shorter than the upper one, and in what is called the "military type" the upper plane is made of extra length. The planes are mounted on a simple framework, about five feet high (what a long way up it seemed when I had to scramble up it that night at Rheims!), which is known as the "chassis" - a much more expressive term than its English equivalent "carriage." Affixed to the chassis are the four small rubber-tyred wheels on which the aeroplane runs along the ground to gather speed for its flight. But between each pair of wheels, and most ingeniously strapped to their axle by broad elastic bands, is a long, curving wooden sledge-runner or "skid"-for all the world like 


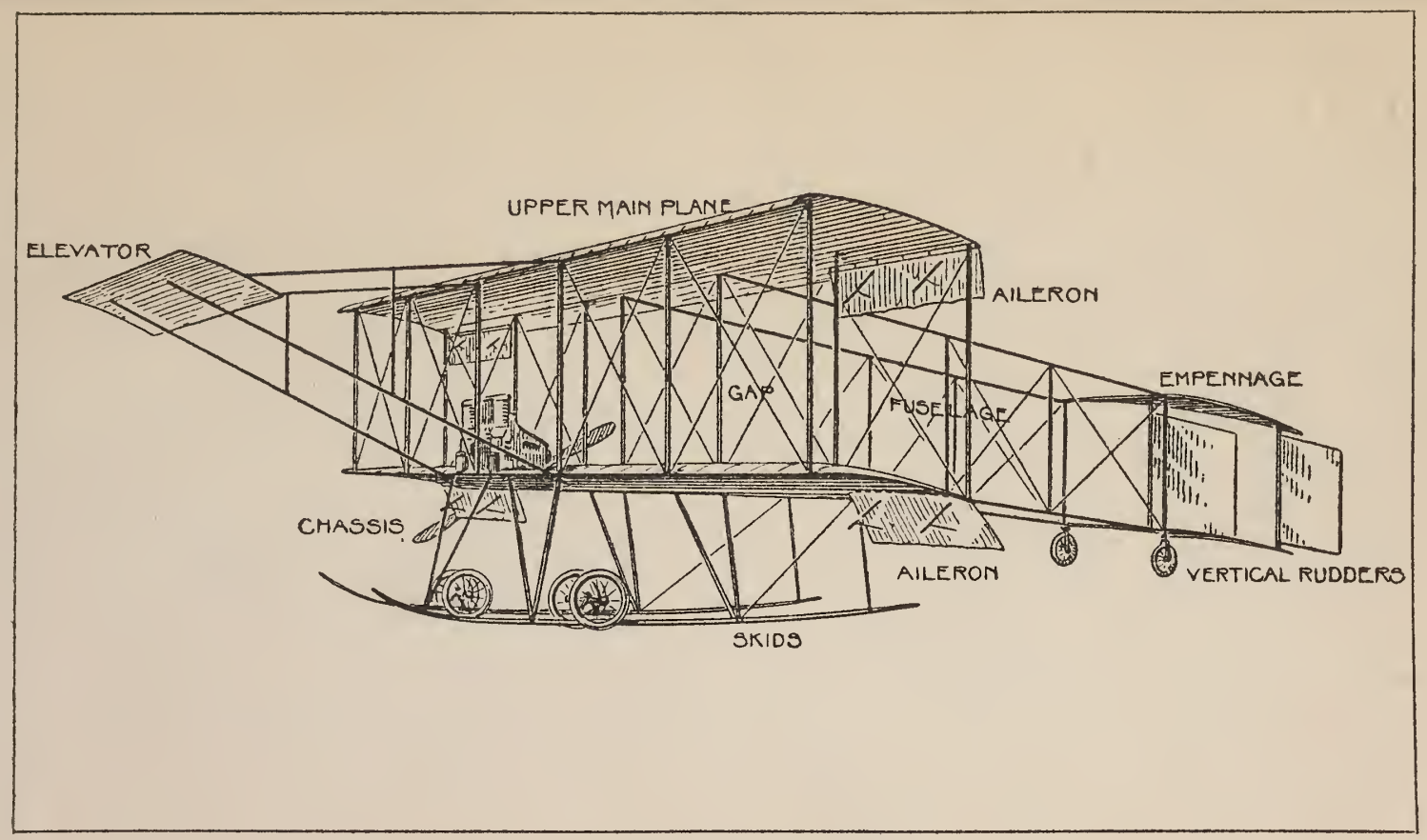

THE FARMAN BIPLANE. 
an alpine sportsman's "ski" - which is one of the great features of the Farman machine. These skids have proved of the utmost value in landing. Landing after a flight, especially on rough or uneven ground, frequently puts a great strain on the chassis, and time and again wheels are torn off, the framework is broken, the aeroplane topples over sideways and injures the planes, and a successful flight ends in a very complete smash. A strong and efficient chassis is, therefore, an all important part of an aeroplane's construction, and the long, broad skids on which the machine rests when the shock of the fall forces the wheels upwards have proved most effective.

From the upper and lower main planes stretch four long out-rigger spars, gradually converging together, which form the body or frame-called by the Frenchmen the "fuselage" -and carrying, some fourteen feet behind, the tail, to which it is often convenient to give its French name of "empennage." The Farman tail is a biplane, and its two almost square planes are about 6 feet 6 inches in span, while hinged between them, and projecting out behind, are two exactly similar movable upright planes, which are the "vertical rudders" ; by moving these the aviator steers his course to right or left, and for this purpose controlling wires from the rudders are carried to a bar, placed below the pilot's seat, which he works with his feet.

Stretching out from the front of the main planes are other long slender outriggers, which carry the elevatora single horizontal plane fifteen feet long. In recent Farmans this elevator is connected with a small hinged flap at the rear of the top plane of the tail, the action of which tends to depress the tail at the same time that the elevator raises the front of the machine. It is with the elevator, as we have already seen, that the aviator steers up and down in the air, and the wires which control it are fastened to a lever placed to his right hand. Thus the 
pilot of a Farman biplane steers to right and left with his feet, and by moving a hand lever to and fro tilts his machine up and down in the air. But, as we remember from our second chapter, he requires to do more than this. He needs that balancing movement which is supplied in some machines by "warping" the main planes, and in others by the little movable surfaces called "ailerons" - literally " vinglets" - a word. which, as we have said, has been translated by the English term "balancers."

The main planes of a Farman are made immovable and cannot be warped; the machine, therefore, is fitted with ailerons. As we look at the two decks we notice that their trailing edges are not continuous, but a small portion of the rear part of the planes hangs from each end in a loose flap, dangling down, as somebody said, like clothes on a line. There are four of these flaps altogether, two on the upper plane, two on the lower. When the aeroplane is at rest they dangle loosely down as a sort of valance, but when the machine is in flight the wind raises them level with the planes so that they are no longer noticeable. These flaps are the ailerons, and the wires that control them are brought to the same lever at the pilot's right hand which controls the elevator; only whereas to move the elevator he works the lever to and fro, to control the ailerons he pushes it from side to side-this arrangement leaving his left hand free for the regulation of the engine. Everything is now done to make the "controls" of an aeroplane as simple and few as possible, and to render their movement as nearly as may be what a man might be expected to do by instinct in his natural efforts to keep his balance. Balance, indeed, as on a bicycle, soon becomes instinctive, but the aviator has need ever to keep his wits about him. Poor Mr. Rolls once said that his first impression of flying was 
like trying to drive a motor-car which was skidding in all directions at once.

The seat for the pilot is in the middle of the front of the lower plane, and at his back are the tanks of petrol and lubricating oil. Now let us run round behind and look at the engine.

It is that wonderful French motor called the "Gnome" -most famous of all aeroplane engines, winner of wellnigh all the great races, and largely responsible for the enormous progress in aviation during the last two years. Seven cylinders radiate out from the centre like the spokes of a wheel; but whereas in an ordinary engine the cylinders are stationary while the main shaft revolves, producing the work, in the "Gnome" it is the shaft which is stationary, and round it the seven cylinders force themselves to revolve, doing the work by their own revolution. The big screw propeller, eight feet in diameter, is fixed rigidly to the cylinders, and revolves with them. The ordinary "Gnome" is rated at 50 horse-power, weighs only $I 67 \mathrm{lb}$., and runs at very high speed, making $I, 200$ revolutions in a minute. To keep it properly lubricated is a matter of supreme importance; pure castor oil is used for the purpose at the rate of two gallons an hour, and the engine consumes four and a half gallons of petrol in the same time.

One of the great advantages of the " rotary" engine is that it needs no flywheel, making its own, in fact. Another is that the passing of the cylinders so rapidly through the air keeps them cool and prevents overheating. Overheating is a great trouble with aeroplane engines, which have to work continuously at top speed. Motorcar engines are only called upon occasionally to exert their greatest powers; aeroplane engines must do so all the time, for flight is like one long effort to climb an endless hill. The ordinary type of petrol motor is generally cooled by 


\section{THE AEROPLANES OF TO-DAY}

causing water to circulate through " jackets" surrounding the cylinders. The water heated by its passage through these jackets is cooled again by passing through a series of tubes, known as the "radiator," specially constructed to present a large surface to the air. But in spite of all efforts there is a great tendency to overheating in the high-speed flying-machine engines, and the water circulation presents an extra complication liable to go wrong, to say nothing of the additional weight it entails.

The engine of an aeroplane is its most vital part; it answers to the digestion of a mortal, and can be equally touchy and troublesome. There is scarce an aviator in existence who has not spent long hours of exasperation and maddening delay over "engine trouble"; even as, in the early days of motoring, the driver spent the most of his time under the car on his back in the mud. In this case also time will bring its cure. The making of efficient engines is now absorbing the attention of many British firms, for in these days of great prizes for "AllBritish " aeroplanes this is becoming a matter of importance. There are several very fine and reliable English aerial motors now on the market, but as far as the flying-machine engines of the world go the "Gnome" is very easily first favourite.

And now a few words as to the propeller, whose two finely polished blades we shall see, if we look into them, are built up of different layers of wood-generally walnut -most skilfully put together. Several inches thick at the axis, or "boss," the blades thin off to a paper-knife edge at the tips, and are very carefully curved in a special manner. The designing of screw-propellers for aeroplanes is a most important and complicated matter, concerning which many experiments are now being made, and much has yet to be learnt. The principle, as we all know, is the principle of the screw ; but just as it needs a very different 
shape of screw to screw its way through water than for boring through a solid material such as wood, so it needs yet another form for screwing in a highly elastic fluid like air. The proper shape for the screw propeller of a ship is all wrong for the screw propeller of a flying machine.

Every propeller has its particular "pitch" - that is, the distance it would travel forward in one complete turn supposing it were screwing into something solid such as wood. In turning round in air, which is elastic, it does not travel anything like so far, and the difference between the distance it ought theoretically to travel, and the distance it actually does travel, is called its " slip." The problem for the designer of aerial propellers is so to shape his blades that he gets the greatest amount of "thrust" for the least amount of air resistance. It is like the problem of "lift " and " drift," and the law of the entering edge comes into it, so that a long, narrow propeller blade is found more efficient than a short, broad one. The "thrust" of a propeller may be described as the force with which it drives the air backwards, or urges the aeroplane forwards.

Propellers being so delicately made and revolving at such a terrific speed are specially liable to injury. The most extraordinary and unlooked for accidents happen to them. At the Lanark Aviation Meeting a workman's pocket-knife lying on the ground was sucked up by a revolving propeller and gashed a great piece out of the propeller blade. An ordinary pin from a passenger's dress has been found firmly embedded in the wood, and a lady's woollen cap, blown off during a flight, actually made a chip in the edge. On several occasions dogs have run into revolving propellers on the ground, and the result has been equally fatal to propeller and dog. A number of spare propellers is a necessary part of every aviator's 
outfit and, needless to say, these beautifully constructed articles are a costly item !

There are endless little details about the construction of a Farman biplane to interest an expert examiner, and even our non-expert selves may notice a few more points. We see that the planes are covered with a specially closely woven cotton fabric very carefully and smoothly stretched, and all the spars and ribs on the under sides are neatly enclosed in pockets of the same material, so that sharp edges and roughnesses are avoided; in fact, everything about the machine is as smooth and polished as possible. This is to reduce what is known as "skin friction." Air is a sticky fluid, even as treacle is sticky. Little particles of air lodge on any roughness or inequality on a surface passing through them; other particles stick to these, and the result is a certain amount of friction, the tendency to which is to retard. Many experts at the present day, indeed, hold that this skin friction is so small that it need not be regarded; nevertheless most aeroplane constructors aim at having everything about their machines as "slippery" as possible.

Another thing we shall notice about the main planes, which are not flat but "cambered," is that the leading edge is made solid and firm, with a spar inside, while the trailing edge is only the thickness of the material and flexible. The wooden framework of the aeroplane is mostly composed of ash, and to reduce the head resistance as much as may be there are as few struts and spars and wires as can possibly be done with. It is curious how much resistance a wire will offer, thin as it may be. Wires vibrate while flying in the air, and it is said that they cause the same resistance as if the space they vibrate in were solid.

Henry Farman, the inventor of this famous biplane, was, as we have seen in the previous chapter, the second man 
in Europe to fly; but he served his apprenticeship and made his first records on a "Voisin." At the back of one of the sheds here, covered with dust, its engine taken out of it, its canvas all black and oil-stained with long service, lies one of the original Voisin machines. From it we can see whence Farman borrowed his inspiration, and where he made his improvements. It looks heavy and rather clumsy, mainly because of the upright "panels" or "curtains" which box the main planes in at either end, and divide them into "cellules" in the middle. The use of these curtains rendered ailerons unnecessary, but they added tremendously to the head resistance. There are no skids on the chassis, and the outrigger spars in front that carry the elevator are covered in with canvas, forming a queer sort of prow. The chief points on which the Farman machine departed from the original Voisin was in the use of aileron flaps, the employment of skids and the doing away with the curtains.

Of variations of the Farman type biplane there are simply no end. Henry Farman's own brother, Maurice, has one variety which proved successful enough to make the world's "distance" record, in I9I0, with a flight (by Tabuteau, a Frenchman) of 365 miles. Latterly the Farmans have amalgamated, forming between them perhaps the most renowned aeroplane firm in existence, and yet another pair of famous aeronautical brethren. Sommer, one of Farman's very first pupils, presently brought out his own most popular aeroplane, founded on his master's, but with differences and improvements, one of which is that the skids are prolonged and turned upwards until they meet the elevator in front, suggesting the rockers of a very " safe " nursery rocking-horse. Then in England we have that very successful biplane, the "Bristol "-manufactured by the British and Colonial Aeroplane Company (under the directorship of Sir George White) at the town 

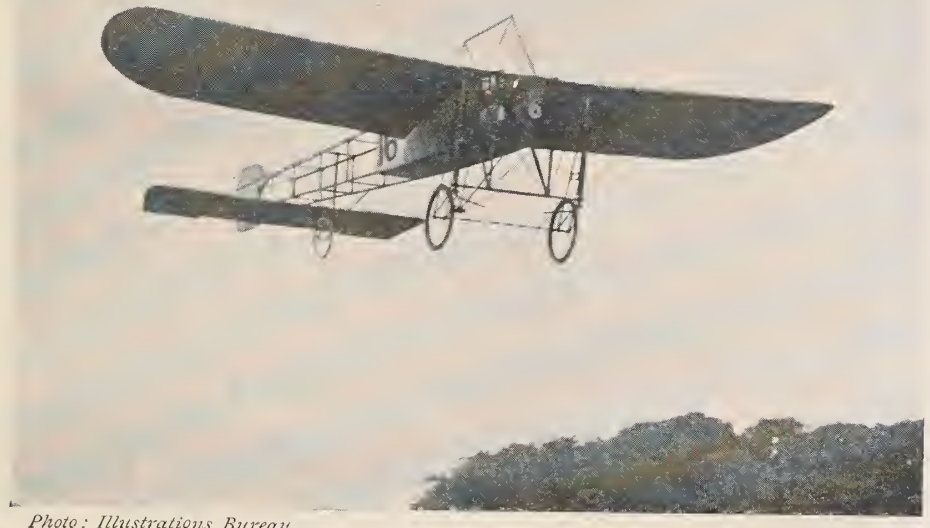

A BLÉRIOT MONOPLANE IN FLIGHT.

See page 6.

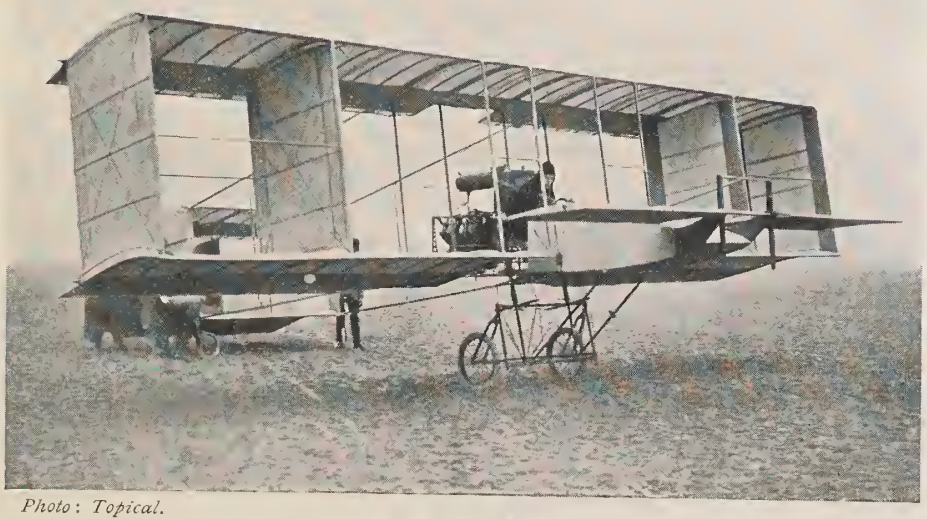

THE FIRST BRITISH AVIATOR.

Moore-Brabazon on a Voisin Biplane.

See pages 68 and 86. 


\section{$+$}


of its name, and tested and taught chiefly on Salisbury Plain. Grahame-White has his "Baby," which is on Farman lines; the Humber firm produce a biplane approximating to the "Sommer"; the de Haviland Military biplane is somewhat after the same style; Messrs. Short Brothers, at Eastchurch; make a very fine, and in many ways absolutely original, Farman-type machine, as do several other British constructors. Quite one of the most successful and interesting of the biplanes made in this country is designed by Mr. Howard Wright (not to be confused with his American namesakes). It is one of his machines that is even now rising into the air at the other end of the aerodrome, and coming towards us across the sky. At first glimpse we think it a Farman, but as we catch it in profile we note its peculiar tail, not biplane but crossshaped monoplane, with vertical and horizontal surfaces bisecting each other, and when it presently lands close beside us we notice its many other distinctive and original points. It was with this All-British machine that that fine flyer, Mr. Tom Sopwith, flew I69 miles from Brooklands over the Channel, across France, into Belgium, breaking British records galore and winning Baron de Forest's $£ 4,000$ prize. It is this machine also that $\mathrm{Mr}$. Sopwith uses for calling on the King at Windsor Castle for afternoon tea.

We have studied the Farman flying machine carefully, for it is the most famous and successful of European biplanes, and from it the greater number of biplane constructors have drawn their inspiration, even as Farman himself drew his from the original Voisin, the parent of them all. It will be instructive to turn next to an equally celebrated biplane which owes nothing to French ideas, the American aeroplane of the brothers Wright-the first aeroplane to achieve successful flight.

In a shed at our ideal flying-ground we may find a 
specimen, old and toil-worn it is true, but perfect, of this original Wright, that set the whole world agog in the summer of I908. The first glance will show us how curiously it differs from its European rivals, and for this difference the reason is not far to seek. The French and American aviators approached the problem of the flying machine by two different paths. The Frenchman started with his machine on the ground, and tried to make it rise, the American began with his in the air and strove to keep it there. As we have seen, Wilbur and Orville Wright commenced with gliders with which they jumped off sandhills and glided to earth. Later, when they got so far as to fit an engine into their gliders, they still did not start with wheels to gather speed along the ground, but shot their aeroplanes, catapult fashion, bodily into the air.

The catapult system was ingenious and simple. The aeroplane was placed on a little trolley made to run on a low wooden rail laid along the ground. At one end of the rail was a wooden derrick about fifteen feet high, generally called the "tower," to the top of which a heavy weight was pulled up. The rope to which the weight was fastened was attached to the aeroplane in such a way that, after the engine had been started and was running at full speed, the dropping of the weight gave a sudden extra impetus to the machine, already straining to be off, and shot it at tremendous speed down the rail, at the end of which it left its trolley and mounted in the air. Later it was found that by having a longer rail the use of the tower could be dispensed with. Yet more recently, wheels have been fitted in the usual way, and the rail abandoned altogether; but this being one of the old-type Wrights that we are examining there are no wheels, and the machine rests low on the ground on its long sledge-runners alone.

One of the most noteworthy features of this old Wright 


\section{THE AEROPLANES OF TO-DAY $7 I$}

is the big elevator, thrust ten feet out in front, of biplane form, and with two queer little half-moon shaped upright surfaces, generally known as the " blinkers," fixed between the two planes. Another tremendously important point is that the machine has no tail, the big pair of upright movable planes carried out at the back being the rudder and nothing more. This absence of tail made the early Wright biplanes peculiarly lacking in automatic stability, and left the balance to depend on the pilot far more than in the case of the French tailed machines. A Wright was, therefore, a difficult machine to learn, but once mastered it was claimed that the aviator had it more completely under control than was possible in any other form of aeroplane. Nevertheless, as time has passed, the American biplane has come more into line with European ideas, and a tail has been fitted behind the rudder. It was the breaking of an experimental and inefficient tail, not designed by the Wright brothers, that led to the terrible tragedy of the death of Mr. Rolls, on a Wright machine, at the Bournemouth flying-meeting, in July, I9ro.

This American aeroplane has two propellers at the back of the main planes, driven by chains off the fourcylinder 25 horse-power engine, and revolving in opposite directions. The aviator sits on the front of the lower plane, balancing the engine placed on the opposite side of the centre line, and any passenger carried is put in the middle, as is also the petrol tank. This is cleverly thought out, since the weight of a passenger and of the petrol carried is a variable quantity, but placed in the middle the balance cannot thereby be affected. The steering is done by two hand levers, of which one works the elevator up and down, and the other, as has already been explained, turns the rudder to right and left and by the same movement warps or flexes the rear tips of the main planes.

This being an ideal aerodrome, arranged for our special 
benefit, we are not unduly surprised to find beside this ancient and historic biplane Mr. Ogilvie's "Baby Wright" that created so much interest on its first appearance in England at the third Aero Show, in IgIr, and won him third place at the Gordon-Bennett race in America the previous autumn. What a beautiful little machine it is, and what a contrast it offers to its elder brother (or should we say grandparent?)! The biplane elevator has gone from the front altogether, and its duties are performed by a single horizontal plane placed behind the vertical rudders and forming a tail. The long skids are cut short and fastened between two pairs of wheels in the usual style, for towers and starting rails are now things of the long ago. On the front framework of the chassis are two small, fixed triangular planes, taking the place and title of the old "blinkers," their purpose being to provide a sort of pivot about which the machine turns when steering to right or left. This biplane is a baby in truth, for its two little decks give no more supporting surface between them than the wings of a small Blériot monoplane ; it is tremendously rapid (Brookins, in America, is said to have attained a speed, independent of the wind, of eighty miles an hour on a similar craft), and its attraction is tremendously enhanced-to the feminine eye at all events-by its beautiful finish. In the olden days the Wright brothers cared little indeed for polish and appearances; strength and efficiency were enough for them, and their solid grey-painted machines were rough and ready. The dainty little craft before us is, if anything, too spick and span with its silver plating, its bright varnish, and its seat upholstered in delicate French grey. It seems all too beautiful to be splashed with oil and dulled with use.

This is the American quarter of our flying-ground, for in the very next shed is a "Curtiss" biplane, the next most famous flying machine hailing from the United 


\section{THE AEROPLANES OF TO-DAY}

States. There is something very light and symmetrical

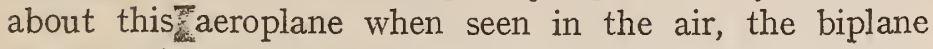
elevator thrust specially far out in front on slender spars, balancing the cross-shaped tail put equally far out at the back. Between the main planes, partly projecting beyond their ends, are two lesser movable planes-the aileronsand the control of them is original, for they are connected with a lever forming the back of the pilot's seat; and the natural movement of the aviator's body, as he instinctively sways to right or left in his efforts to keep his balance, moves the ailerons in the desired way. Glenn Curtiss, the inventor, a particularly calm, nonchalant Yankee, brought his biplane to the first Rheims meeting, in Ig09. Everyone there was exceedingly impressed by the lightness and elegance of its build, its faultless appearance, its shining metal and polished woodwork. It was far and away the smartest-looking aeroplane in all that great show, and the sun glittered gaily upon it as it darted round the course like an arrow from a bow. For it was "smart" in every sense of the word, and bore off to America the Gordon-Bennett Cup-the blue ribbon of the air-which Grahame-White had the luck to bring to England the following year.

So far we have confined ourselves strictly to biplanes, keeping to the last the undoubtedly more fascinating monoplanes; for elegant and graceful as these big box kites can be, they lack the peculiar charm of the machines whose appearance and flight recall some living object, insect or bird. Here, being pushed from its hangar at this moment, comes one of the famous Blériots, "No. XI., type Calais-Douvres," as the catalogue has it, for it was on a machine like this that its inventor flew the Channel on that never-to-be-forgotten day of July, I909, that crowned his weary labours and made him in an hour the hero of Europe. What a tiny thing it looks, especially 
after the big biplanes! A Farman machine is forty-three feet from nose to tail tip, and thirty-five feet in span; its total flying weight is I,050 lb. ; its price, with a Gnome motor, EI,I20. A small Blériot from front to back is twenty-three feet, and in span twenty-nine. Its flying weight is $550 \mathrm{lb}$., and its price, with an Anzani engine, $£ 480$. Can we wonder at its attraction for the would-be aviator of sporting instincts but limited purse?

So completely does a monoplane differ from a biplane that we must run over our flight vocabulary again in describing it. First of all the long, tapering fuselage, or body, which is partly covered in with canvas, rests on a chassis made largely of steel tubes like a bicycle, and mounted on two large bicycle wheels. There are no skids, but instead, to break the shock of falling, the frame-work of the chassis contains two arrangements of very strong elastic bands, known as the "shock absorbers."

On either side of the front of the body spread the two wings, which form the main plane, and are hung from a framework of steel tubes on the top of the fuselage called the "cabane." These wings are blunt and rounded at the tips like a bird's, arched or cambered, and, unlike the Farman machine, are double surfaced; that is to say, the fabric which smoothly covers the upper and under sides is held apart by the framework in between, and the wings have therefore a very appreciable thickness, being over three inches in the thickest part. They taper away, however, at the back, and give that humped stream-line curve with blunt end foremost that we are now so familiar with.

The tail, or empennage, consists of a vertical and an horizontal plane. The centre part of the horizontal plane is fixed, but the two ends are movable up and down and form the elevator; in the newer type of machine, however, 


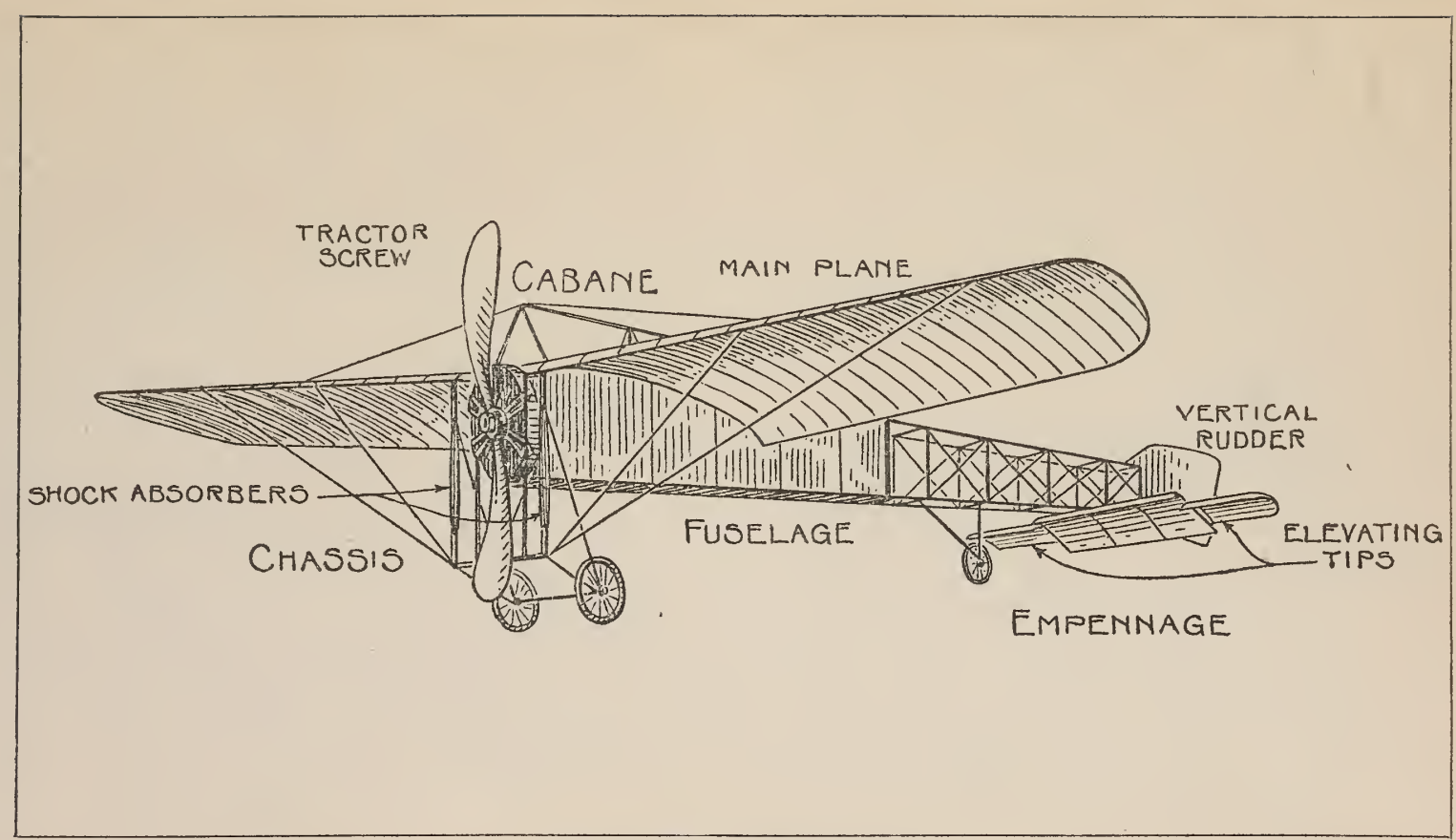

THE BLERIOT MONOPLANE. 
the elevator is a hinged flap placed behind the fixed tail. The vertical plane is the rudder, and is worked by the feet of the aviator, who sits in the front of the body, between the wings, in a seat which suggests that of a canoe. In front of him is a curious-looking arrangement, to which the control wires are attached; it is rather like the dome of a big electric bell, with a pillar coming out of it carrying a little steering wheel on top. It is, as a matter of fact, known as the "cloche" (French for bell), and working it to and fro moves the elevator, and from side to side warps the wings. The pilot works this cloche with his left hand, and his right is free for the control of his engine. The engine itself is right in front of him, and foremost of all is the big screw propeller which, because it is placed in the front of the aeroplane, and so draws it forward instead of driving it from behind, is more correctly termed the "tractor screw."

The ordinary Blériot monoplane is single seated, but a year after his cross-Channel flight Blériot brought out an enlarged edition to carry two people, the aviator and a passenger. There is a Blériot two-seater even now getting ready for a flight outside a shed at the end of the "street." I point it out to you with a thrill of pleasant reminiscence, for one autumn day of IgIo I was the lucky passenger.

It was at Brooklands. My craft had the words "Big Bat" painted in blue on the rudder, and my pilot was Mr. Graham Gilmour, who, despite his youthful appearance, is one of the most experienced and skilful of British aviators.

What a delightful voyage it was, and what a contrast -in comfort, at any rate-it presented to my biplane flight with Sommer a year before! I climbed into the body of the machine from underneath by a sort of trap-door arrangement-in quite dignified fashion by the aid of a chair. I emerged into what in size and shape might have been a boat, only the sides, of canvas, were so high all 


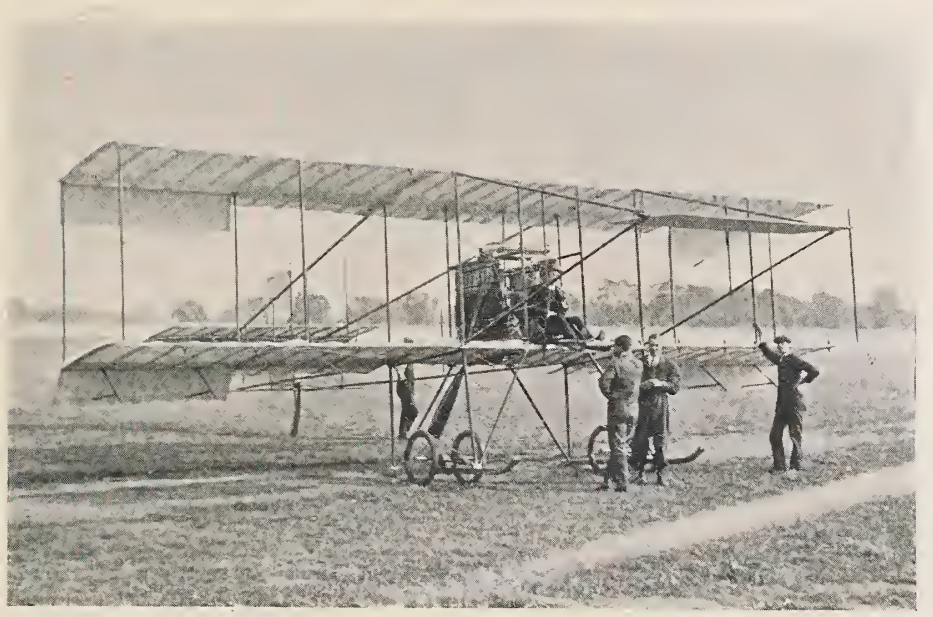

THE HOWARD-WRIGHT BIPLANE.

See page 69

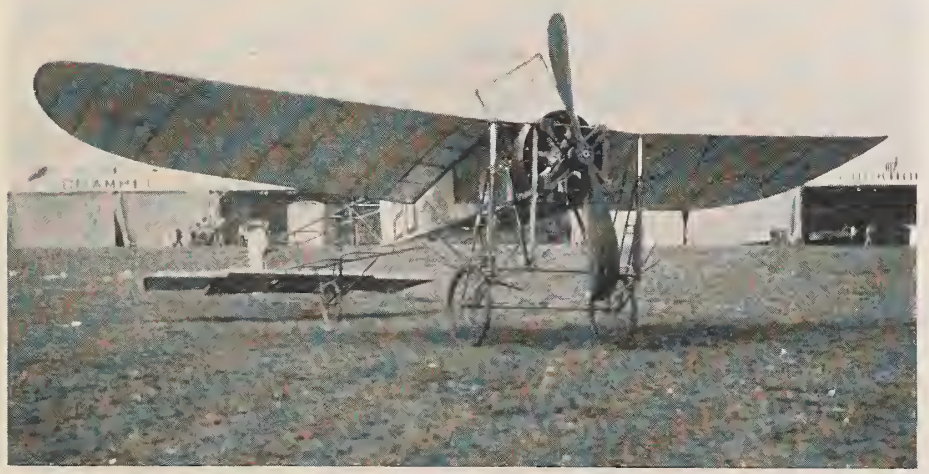

A BLÉRIOT MONOPLANE WITH A GNOME ENGINE.

See page $\%$.

BIPLANE AND MONOPLANE. 
1 


\section{THE AEROPLANES OF TO-DAY}

round that I could only just look over when sitting, in a comfortable seat, by my companion's side. On either side spread the wide expanse of smooth white wings. In front the great propeller-blade cut a good slice out of the horizon. The best view was looking backwards over the pigeon-shaped tail.

By way of keeping me quiet, I suppose, Mr. Gilmour gave me an aneroid to hold and read, and also an indiarubber tube with a bulb at the end like a scent spray, which I was to squeeze when I saw the fluid in a little glass gauge in front fall low. The object of this I discovered was the regulation of the flow of lubricating castor oil to the engine. Then the propeller was turned sharply, the "Gnome" engine started immediately with its loud, dull, even purr, and the half-dozen assistants held on manfully to the giant bird to hold her back until the engine was running free. Mr. Gilmour raised his right hand in the recognised signal for "Let go!" or "Lachez tout!" as the Frenchmen say (to call out would, of course, be useless in that tremendous uproar), and in a moment came a headlong rush over the grass with our tail held well above the ground. I recognised the movement of the "cloche" that flapped the tail elevator downward and pointed our nose to the sky, so I knew the moment when we began to rise from the earth almost before I felt the glorious, buoyant, floating sensation that is like nothing else in the world, and for which no proper adjectives have yet been invented.

But this time I could appreciate it all so much the better because I enjoyed it in comfort; not to say luxury. The wind swept the top of my head, but the rest of me was cosily sheltered by the high surrounding walls. The engine was well screened away and shut out in front. It had need to be, for a "Gnome" working at full speed spatters its gallons of evil-smelling, burnt castor oil like 
a St. Bernard dog shaking itself after a bath; aviators have actually sometimes found their vision distorted by a thin film of oil gathering on their eyeballs. So quickly was the propeller turning that it was, of course, absolutely invisible, and we looked clear out through it at a landscape only a little darkened by its presence.

Round and round the Brooklands course we went, rising higher and higher in a splendid spiral. "Next time round and we'll go out," said Mr. Gilmour-for I found with delight that we could speak to each other quite easily. And so in the next circuit we left the track and sped out over the green fields, the wooded parks, and happy homesteads of peaceful, prosperous Surrey. The panorama was the vast, flattened expanse that the balloonist knows so well. The straight waters of the Basingstoke Canal were very noticeable, the railway tracks, and the many acres of pine woods; while straight ahead of us a setting sun sank gloriously among a few rosy evening clouds. It was magnificent indeed, but Mr. Gilmour said there was more wind aloft than he cared about, and bade me notice the way the machine shivered now and again to a cross gust. He told me to read the aneroid as, after several miles across country, he turned her nose for home. I read I,000 feet, and told him so, whereupon he did a strange thing-at least, at the moment I certainly thought it so. Without a word of warning he suddenly leant forward and shut the engine right off, at the same moment tipping down the nose of the machine until I almost slid off my seat on to the floor, and down we plunged through the sky. Just for one fraction of a second I must confess I fairly gasped. Had the young man suddenly been seized with homicidal mania ? Then of course I recollected, and I hoped my voice was quite nonchalant and even as I asked, "Is this vol plané ?"

It was, and a glorious dive we had, from I,000 feet 
high to within quite a short distance of the ground, before my aviator switched on the engine again and put her back on an even keel. "Do you like swooping ?" he asked. I said I thought so, and so he forthwith proceeded to treat me to an exhibition of trick flying, swooping to within a few feet of the earth, then swinging up again in approved switchback style, making right and left turns and figures of eight in the air, and other aerial gymnastics until one knew not whether most to admire the skill of the pilot or the magnificent way in which his great monoplane obeyed his behests. It was almost half an hour before we landed back in front of the sheds-one of the most delightful and thrilling half-hours I think I have ever spent.

We shall find several fine English variations of the Blériot type monoplane in the sheds of our flying-ground, made by the leading British firms, and we shall also discover some highly interesting French monoplanes of different makes. Probably we shall be most struck with the great Antoinette, with its boat-shaped, polished body tapering to a sharp prow, its huge-span square-tipped wings set at a distinct dihedral angle, its pretty and striking empennage of intersecting horizontal and vertical planes. It will strike us, however, that the two little steering wheels at the sides, one working the elevator the other doing the warping, are not so convenient or easy to learn as the levers and cloche of the other machines, and a big spoon-shaped skid which sticks out in front of the chassis looks as if it would give trouble on rough ground.

Almost equally elegant and beautifully constructed, its long, graceful body built on the lines of a racing skiff, is the "Hanriot" monoplane. Monsieur Hanriot's son, Marcel, is its most famous exponent, known as the "Boy Aviator," because he was but fifteen years old when he won his pilot's certificate-the youngest aspirant to that 
honour. The "Boy" was a great popular "draw" at the Lanark meeting of IgIo, and folks came prepared to gush over him with the sentimental wonder that an infant prodigy excites. But they were disappointed. Marcel at fifteen and a half was a full-grown man in height and breadth, and in solidity, coolness, and imperturbability could give points to any aviator present. He flew quite magnificently and as if he had not a nerve in his body. Only in his smooth, round, youthful, impassive face was his boyishness apparent.

The clever red-winged "R. E. P." monoplane (the design of M. Esnault-Pelterie) will absorb our attention awhile; and we shall linger some time in the hangar where -it only takes up one corner-stands the tiny "Demoiselle," the invention of that most original genius, Santos Dumont. It is the smallest and lightest of monoplanes, so small that it can be packed up quite easily upon a motor-car for transport. Two backward-sloping wings form a sort of. arbour under which the aviator sits, strapped to his seat, only a few inches above the grass when the machine is on the ground, while the engine is placed right above, perched actually on the top of the planes. The ingenious and distinctive tail consists of an horizontal and vertical plane crossed, but rigid and moving together on a universal joint, that is to say, a joint that will allow the tail to be set in any position. The lever which controls the warping of the wings is fastened by a tape to the back of the pilot's waistcoat (he has to wear a special one for the purpose), and he works it by swaying his body from side to side. The planes are painted yellow ochre, and the machine is known to its friends as the "Angry Wasp," or the "Infuriated Grasshopper." It looks a most dangerous craft to drive, and only a few extra skilled and daring pilots venture to fly it, though its inventor uses it for paying afternoon calls. It not infrequently finishes its 


\section{THE AEROPLANES OF TO-DAY 8I}

flight by turning completely upside down and lying on its back with the aviator's legs in the air.

There is another French monoplane here which has a distinctly uncanny look about it, the "Nieuport." It is a peculiarly efficient machine, for in March, IgII, it managed to carry off all the world's distance and duration records with one or two passengers, and also to attain a speed of sixty-eight miles an hour with an engine of only 30 horse-power. To avoid head resistance the whole fuselage is covered in and curved in careful stream-line form, and the result is a plump, rounded body, with a well-developed "crop," low on the ground, which bears an almost terrifying resemblance to a monstrous bird-a dreadful blind bird, for, oddly enough, it is the absence of eyes that at first strikes one so strangely. Later, when we see it in the air, we forget all about this odd impression and are filled only with admiration at the swift, powerful motion; and when, at the close of the flight, a descent is made in vol plané, we perceive at once that we have here a glider of quite exceptional powers. The Wright machine which, as we have seen, is a very fine glider, can glide down at an angle of $I$ in 8 ; the Bréguet biplane can manage I in I2; but the Nieuport gliding angle is I in 20. It is claimed for this monoplane that if the engine stops at a height of $I, 320$ feet, the pilot can choose his landing place inside a radius of five miles.

The Bréguet machine which we have just mentioned is in a hangar over the way, and at our first glance through the open door we think it is dismantled, for its great planes are folded together over its back like the wings of a resting butterfly. A mechanic standing by smiles at our look of disappointment. "It will be ready for flight in ten minutes," he says. We don't believe him, but, behold forthwith he and his companions seize the folded wings and, almost at a touch it seems, they straighten 
out into a biplane of a most original and interesting kind. Except for the ribs of the wings, the framework is constructed entirely of steel tubing in place of wood; and while all the biplanes we have seen so far have screwpropellers at the back of the main planes, the Bréguet has a tractor screw in the front like a monoplane. The tail of crossed elevator and rudder moves on a universal joint; there are no ailerons, and though the wings are made to warp it is claimed that the machine is so stable that warping is rarely resorted to. Monsieur Bréguet, the inventor, is quite one of the pioneers of flight, for his experiments go back to the days when Blériot and Voisin were making their earliest machines. He shared with them the amused scorn with which their efforts were greeted. His own machine for a long while went by the name of the "Flying Coffee-Pot" (though in truth the resemblance is far-fetched); but after much experience and long and patient endeavour he has undoubtedly succeeded in producing what he aimed at-a successful aeroplane intended especially for military purposes.

Hours are slipping by as we wander happily from shed to shed, and it is time to be turning homewards; but before we go let us step across to this group of hangars and take a hurried glance at their contents, for this is the specially British quarter of the aerodrome, and among the aeroplanes it contains are some of peculiar interest and originality.

One hangar we notice is larger than the rest; it had need be, for it houses Cody's " Flying Cathedral," admirably described by one expert as "like its inventor, large and strong and sturdy, and evidently determined to 'get there." " Cody himself says that "What Cody does is Cody pure and simple," and his boast is no more than the truth. He designed his machine in the first place for military use, to carry an artilleryman and a Maxim 


\section{THE AEROPLANES OF TO-DAY}

gun, if need be, so that his special aims have been size and strength, and he has certainly achieved them, for his machine is the heaviest aeroplane in the world, has carried 2,300 pounds into the air, while the chassis on one occasion charged a fallen tree and cleared it unscathed. In form the Cody machine is a great biplane whose main planes are forty-six feet in span, with cross tail behind, and an elevator in front made in two parts, which can work in unison, when they form an elevator pure and simple, or one may be tilted up while the other is dipped down, and in this way they can be used to help the balancing action of the ailerons placed in the gap between the main planes. This is only one of the clever and original ideas about the machine which we have now no time to particularise. We may mention, however, one other point, described by an admirer as a "true Codyesque touch." An aviator in flight suffers most severely from the cold of the terrific blast that sweeps past him. Mr. Cody has so arranged the radiator of his engine above the driving seat that, though it in no way impedes his view, all the hot air from it is blown down upon the pilot, while small subsidiary offshoots from the main radiator are placed in front of the foot-board to keep his toes warm!

The shed next door contains a unique example of a triplane in the original three-decker machine which $\mathrm{Mr}$. A. V. Roe, its inventor, calls the "Avroplane," after his own name. Roe was certainly one of the three first men to fly in England, and to him are due the first flights made on an "All-British" aeroplane-accomplished, moreover, with an engine of only 9 horse-power, a record hard to beat. Note how narrow are the planes which he mounts in three tiers at the front of the long, tapering monoplanetype body. The chord indeed is only 3 feet 6 inches, and there is consequently an enormous amount of entering edge to a comparatively small surface, which gives a great 
deal of lifting efficiency. Latterly Mr. Roe has been constructing Avro biplanes as well as triplanes, and has met with quite extraordinary success in his acknowledged aim of producing a light, cheap machine that shall fly with very little power.

Our last glimpse, as the day declines, is of the wonderful "Valkyrie," the invention of Mr. H. Barber for the Aeronautical Syndicate. It is a large and handsome craft before which we stand and consider a moment, trying to make up our minds which is the front, for this is an example of what is popularly known as a "tail first" aeroplane, an expressive but unscientific phrase, since it is obvious that a tail must always be behind. Perhaps it would be more correct to describe the Valkyrie as a tailless monoplane with a leading plane in front of the main planes; unless we like to regard the main planes themselves as a tail to the large leading plane which is fixed well ahead of them on this most paradoxical craft. But if puzzling to define, the Valkyrie is admirable to drive, and flies strongly and well, and is, despite the large area it seems to cover, uncommonly light and steady. This aeroplane began coming prominently into notice in the summer and autumn of IgIo, and since then the large and flourishing "Valkyrie School" at the Hendon Flying-Ground testifies to the merits of this All-British design.

Many sheds yet remain unvisited when we turn our unwilling steps towards home. We wish especially it had been possible to linger longer in the British section and to exhaust its treasures; but this would be a very long task, for we have seen enough to realise that our countrymen are rapidly making up for lost time, and as aeroplane designers and constructors, as well as aviators, already fairly hold their own in the conquest of the air. 


\section{CHAPTER V}

\section{RECENT HISTORY}

THE recent history of flight may be considered to begin with Blériot's crossing of the Channel.

The Wright brothers made their sensational appearance in Europe and America during the summer of I908, and for many months afterwards they bulked so large in the aeronautical world that they dwarfed everybody else into insignificance. The French flyers went steadfastly on with their work, but their successes passed unnoticed. Of what interest was it to that all-important person, "the man in the street," that a Frenchman called Blériot had flown seventeen miles, when the same paper that modestly recorded the fact blazoned, in huge headlines, that Wilbur Wright had flown for ninety, and had been specially visited by the King of Spain and King Edward of England. It was of less interest still to him to hear that America contained other flyers beside the wondrous brothers, and that gentlemen of the names of Graham Bell, Herring, Baldwin, McCurdy, and Curtiss had been making quite successful flights with machines of their own design. The average individual disregarded such chronicling of small beer altogether. He was only interested to read about what Orville had for breakfast, and whether Wilbur did or did not possess what some reporter had described as "a bird face."

The man in the street, who is an Englishman-probably a Londoner-was also feeling a good deal vexed that his country was taking no share in this marvellous new art 
of aviation, of which the papers were so full. For some time he had tried to comfort himself with reflecting that Henry Farman, though a naturalised Frenchman, was born of English parents, but he could put forward no sort of claim to the American triumphs, and he felt vaguely indignant at what was really the fault of his own apathy and indilference.

Nevertheless, though late in the day, England was beginning to wake up. The first All-British aviator was Mr. Moore-Brabazon, who learnt to fly a Voisin biplane in France during December, Igo8. The first observed flight in this country was made the following month at Aldershot in a big aeroplane constructed for the British Army by Mr. Cody, in those days still an American subject. Mr. Cody had for many years experimented with large kites of his own design. One night in I903 he performed a daring feat. He harnessed one of his kites to a light boat and, after waiting some while for a favourable wind, started at eight o'clock on a November evening from Calais, and all alone, for he quickly out-distanced his escort, through the darkness, was towed by his kite across the Channel, reaching Dover at five o'clock the next morning. He has been for many voyages in the sky carried aloft by several kites harnessed together, and these "man-lifting" kites of his were presently adopted by our own military authorities for use in the British Army. From kite construction Mr. Cody passed naturally to the making of aeroplanes, and achieved several successful flights in the early months of Ig09. But shortly the War Office withdrew their support, leaving Mr. Cody to carry on his experiments at his own expense.

In March of this year the first British Aero Show was held at Olympia, in London, and though it contained far too many examples of freak machines that would never under any circumstances leave the ground, and though 


\section{RECENT HISTORY}

the critics sneeringly said that there were "more liars than flyers" to be found there, yet much public interest was aroused, and fair promise was given of progress to come.

The Wright brothers had it all their own way for the better part of a year, and their record flights stood unchallenged right up till August, Igog. During the greater part of that time Henry Farman seemed to have disappeared from the field. It was known that he had parted from the Voisin firm, and it was said that he was building a machine of his own; but practically nothing was heard of him until suddenly, in the summer, he reappeared with a wonderful biplane, and immediately the tables were turned. My kind friend, Monsieur Sommer, bought one of the first of the new machines on the 4th of July, learned to fly it in a day, and on August the 7 th beat Wilbur Wright's record (of the previous December) by a flight of two hours and twenty-seven minutes. But already before this, some wonderful events had happened that had brought the flyers of Europe once more to the fore.

There was, and is, in France a well-known firm of engineers known as the "Antoinette" Company, makers of a particularly famous light petrol-motor of that name. This firm had for years been experimenting with monoplanes, and during the spring of Igog they produced a machine designed by Monsieur Levavasseur, a gentleman whose appearance suggests irresistibly the "Ancient Mariner," or the Skipper of

\section{". . the schooner 'Hesperus' \\ That sailed the wintry sea."}

This exceedingly clever man invented a monoplane known, from the company, as the "Antoinette," and for aviator he was lucky enough to secure the services of a very skilful and daring young sportsman of partly English 
parentage, Mr. Hubert Latham. The combination of aeroplane and aviator was particularly fortunate, for both were splendid of their kind; some most successful flights were made, and before long it was announced that Latham was shortly going to make an attempt to win the prize for $f_{£} I, 000$ offered by The Daily Mail for the first aeroplane crossing of the Channel. By July his Antoinette was ready and housed on the French cliffs near Calais, and he himself, watched over in fatherly fashion by Levavasseur, was waiting for a favourable moment to cross the twedty odd miles of blue water that means so much, in different ways, to so many people. Excitement grew, but the weather of a notorious summer displayed its worst qualities; the crowds of reporters and spectators that blackened the Dover cliffs grew weary of watching an empty sky, and the scoffers and incredulous, of whom there was no lack, went about saying, "I told you so! He'll never do it." They continued to say it, though with less conviction, when, on the Igth of the month, Latham actually made a start, but after getting some eight miles out to sea his engine failed, and he sank gently into the water, where he was presently picked up, sitting on his floating aeroplane and calmly smoking a cigarette.

There followed a great surprise and, I think, the most dramatic event in the history of aviation.

After nine years of the most wonderful perseverance, after the squandering (so his friends thought) of almost all his fortune, and the expenditure of Heaven knows how much thought and energy and patient labour, Louis Blériot had at last produced a monoplane that proved, in several fine flights, its inventor's long-deferred success. Blériot had achieved his aim, and yet it seemed to him that now, at the eleventh hour, the fruits of his labours were to be snatched from him. Although, as we have seen, he was one of the very earliest heavier-than-air 
experimenters, and the first of all to take up the monoplane, yet his name, outside aeronautical circles, was practically unknown, while all the world was now talking of Latham and the Antoinette, whose triumph would utterly eclipse his own renown. Blériot determined to make one last desperate bid for the luck that had so long evaded him. $\mathrm{He}$ must get across the Channel before his rival. $\mathrm{He}$ was in great pain at the time with a badly burned foot and ankle, the result of a petrol explosion; he walked with crutches and had to be lifted into his machine, but he could not afford to wait for recovery. Immediately after Latham's first failure he sent in his notice of entry for the prize, and came with his little monoplane-far smaller than the Antoinette-to Calais. It was a brave venture, but fickle Fortune is a woman, and with a woman's well-known partiality.

On the night of July 24th Latham retired to bed wearied with the strain of long weeks of watching and anxiety, but having given orders that he was to be aroused immediately the weather-still most unfavourable-showed any signs of improvement. At two o'clock Monsieur Levavasseur got up and looked at the sky, and at three also, but saw no sufficient reason to disturb the tired sleeper. But at five o'clock Latham was awakened with a vengeance by the unwelcome tidings that his rival had already started. "Impossible !" he cried as he scrambled into his clothes and ordered out his machine in a wild attempt to give chase. But while the aeroplane was making ready came the tidings that the Channel was flown; and though the bitterly disappointed aviator, after despatching, in true sporting spirit, a wire to the victor"Sincere congratulations! Hope to follow you shortly. LAтHAM"--thought yet to make a crossing, the wind was now so high that Levavasseur peremptorily forbade him even to attempt to start. 
For Blériot had seen the chance of a lifetime and had snatched at it. Kept awake by pain and excitement, he happened on the one half-hour of calm between two days of raging storm. At half-past four he was off; thirtyseven minutes later that Sunday morning he was on the cliffs of Dover, shaking hands with an astonished policeman - the only man in England to see him land. Swiftly the news spread throughout the world: the Channel was crossed! Blériot had triumphed! The Frenchmen had once more established themselves in the van of aeronautical progress: London was beside herself, Paris was frankly delirious, and Blériot became in a moment the hero of Europe. But there was a deeper meaning still in the historic flight, which remained after all the excitement of the moment had fizzled out. England at last was thoroughly awakened; the scoffers were silenced, and even the most sceptical were forced to own that the conquest of the air was now an accomplished fact.

Two days later the indomitable Latham made another magnificent attempt to follow Blériot across the Channel. He all but succeeded, but by the most cruel fate his engine failed him at the very last moment, and he fell into the water actually in the sight of the 40,000 spectators at Dover who were already cheering his success. He was promptly rescued, but his face was badly cut by the glass of the goggles he was wearing, broken in the fall. By his splendid pluck and by his cruel disappointment he had earned the sympathy and admiration of all.

The next great event in the aeronautical world was the Rheims Aviation Week-first of flying-meetings, and probably the most famous that will ever be held. This wonderful meeting brought the progress of flight before the public notice in a way that had never yet been done. Until then, although everyone had read of the flying men and their marvellous machines, only a very few had been 
privileged to see them. Here, for more than a week, on the broad plain of Béthény, outside the ancient Champagne City, hundreds of thousands of delighted spectators, drawn from all the world, beheld, with their own eyes, under most favourable conditions, the marvels they had scarce believed in.

We saw almost all the great leaders of flight, and all the famous machines. We saw Henry Farman, a lithe, athletic, bearded man, much better looking than his photographs, slogging round the course hour after hour in a record flight that was wonderful for endurance, but very uninteresting to watch because he flies so low, generally only just clear of the ground. Farman suffers from giddiness if he rises to any height, and on the one occasion when he attempted high flying landed quite shaken and overcome. We saw Glenn Curtiss, the American, dart like an arrow through the air on his light, glittering craft, and win the Gordon-Bennett Cup. We saw the hawk-nosed Blériot, his faithful wife's arm around him, pale and bandaged and looking very ill, poor fellow! after his machine had caught fire in the air and brought him down thirty feet to earth - a mass of leaping flames. We saw the Comte de Lambert and poor Lefebvre on Wright biplanes that suggested in their flight, as somebody said, a cross between a partridge and a reaping machine. We saw a record made on a Voisin biplane by one Louis Paulhan, said to be a promising flyer. We saw, and frantically applauded, a round-shouldered young man, with a scarred face and a cigarette, whom we knew to be Hubert Latham. But we applauded him yet the more when we watched him in the air, driving his proud and beautiful dragon-fly, with consummate grace and skill, through the pelting rain and flickering rainbows of a sudden thunder shower. All this and much more was to be seen that wonderful week. One curious point I 
noticed at this meeting and have marvelled at on other occasions-the behaviour of the birds. During a balloon or airship ascent not a bird is to be seen, for the strange, unwieldy gas-bags scare them far away. Not so the swift and noisy aeroplanes. All up and down the plain at Béthény the birds were flying, actually alongside the machines, not alarmed, evidently, but keenly interested in the strange new flying creatures that had invaded their realms, and in which they seemed to recognise some sort of kinship to themselves.

There was only one English aviator at Rheims, Mr. G. B. Cockburn. To this far-seeing pioneer, be it ever remembered, belongs the honour of purchasing the very first Farman biplane ever affered for sale; and of causing to be fitted to it, for the first time, and against the advice of Farman himself, the famous Gnome motor. At the Rheims meeting Mr. Cockburn piloted a Voisin, with which he did not have much luck, and I think no one at that time would have believed that, only a year later, an Englishman was to carry off the Gordon-Bennett Cup. The wonderful interest excited by the Rheims Week of course led to imitation, and flying-meetings were advertised from all over Europe. Within six weeks two were taking place simultaneously in England, at Doncaster and Blackpool. It was almost a pity that they were arranged so hastily, for they came at a time of equinoctial gales, and were very much spoilt thereby. Moreover, England was hardly ready for such displays; certainly the English aviators were not, and there was a sad exhibition of All-British machines that absolutely refused to leave the ground and gave cause for " the enemies to blaspheme."

Nevertheless, there was some magnificent flying. At Doncaster were Sommer, and Delagrange and Le Blon; at Blackpool, Henry Farman, Paulhan, and Latham-and the latter covered himself anew with glory by taking his 


\section{RECENT HISTORY}

Antoinette out in a gale of forty miles an hour and steering it, despite the frantic protests of the crowd and his brother aviators, around the course. It was a daring feat and a successful, but other flyers were not so fortunate, and death now began taking heavy toll of the brave heroes of the air. Up to September, Igog, the only victim of the aeroplane had been Lieutenant Selfridge, an American, killed in a fall with Orville Wright a year before; but now with the great increase of flying, and with undoubtedly the greater recklessness thereby engendered, disasters began inevitably to increase. The first to fall was Lefebvre, almost the most popular aviator at Rheims; the second was also a Rheims flyer, poor Captain Ferber, one of the first experimenters with heavier-than-air machines in France. Before long another most famous pioneer, Leon Delagrange, was gone, and then his friend and companion at Doncaster, Le Blon. Nor were these all, and inevitably the foolish cry was raised-we hear it still-that flying was too dangerous for man to engage in, was wicked, contrary to nature (whatever that means), and "ought to be stopped." Those who speak thus forget, or wilfully shut their eyes to, the fact that no great progress in invention is ever made without sacrifice of human life, for the world will have come to a sad pitch of decrepitude and senile decay when its young men are deterred by thought of personal risk from enterprise and daring sport. The time is shortly at hand when aviation will be as safe as other forms of rapid travel. Even now in its experimental, and therefore most dangerous stage, it offers no greater risks than many callings and the more adventurous sports. This absolute fact is frequently denied by those who draw their information from newspapers, who find that their readers prefer the harrowing chronicles of disaster to mere dull records of success, and cater for them accordingly. The average man remembers that thirty aviators have 
been killed in a year; he does not realise that two or three thousand have met with no serious mishap. As a matter of fact statistics drawn up by experts show that aviation is-even at the present time-less risky than mountaineering, and certainly vastly more useful.

The autumn and winter of Igog saw a number of young Englishmen take up the new art, among them the very flower of British sportsmen. The Hon. C. S. Rolls, Cecil Grace, Captain Dickson, Grahame-White, Frank McClean, Lieut. Gibbs, Mortimer Singer, Alec. Ogilvie, Graham Gilmour, and several others learnt to fly either in England. or in the schools now springing up in France. British aeroplane designers and constructors also began coming into prominence. Much of this enthusiasm was due to the splendid and patriotic encouragement of The Daily Mail, who strove to do for this country what wealthy and public-spirited men had already done in France by offering large prizes for aeronautical enterprise. Blériot, as we have seen, won their $£ I, 000$ prize for the first crossing of the Channel; on October 30, I909, Moore-Brabazon easily carried off another $£ I, 000$ offered for a circular flight of a mile on an "All-British" machine, his biplane being made, somewhat on Wright lines, by Mr. Horace Short, at Sheppey.

There still remained the most magnificent prize of all - $\{$ I0,000 for an aeroplane journey from London to Manchester. The Daily Mail had announced this record prize as far back as the autumn of I906, immediately after Santos Dumont succeeded in leaving the ground, and scoffers said that the paper was perfectly safe in advertising an enormous reward which it would never be called upon to pay. In truth, for many months the winning of the prize looked a very remote event. Even the wonderful Wright brothers declined to attempt it and gave it as their opinion that many vain efforts would be 
made before the tremendous feat was accomplished. In September, I909, Mr. Cody, encouraged by a splendid cross-country flight of forty miles, announced that he was going to make the venture, and preparations were made and much excitement aroused; but a bad bout of the peculiarly virulent ill-luck that seems to attack all aviators in turn laid him low then and for many months to come. In the meantime he became a naturalised Englishman, commenced a new machine, and, like Mr. Micawber, "drew back for a spring."

When, in early April, I9I0, Claude Grahame-White made his formal entry for the $£$ I0,000 prize, people were not particularly thrilled. The aeronautical world knew this young Englishman as a promising aviator who had learned in France to fly first a Blériot and then a Farman machine. The general public only recollected that, according to the papers, he had made a wager to fly up the Thames to London and had not done it; and "the man in the street" continued to sneer bitterly that "Englishmen were no good at flying!" When, on the morning of Saturday, April 23rd, the man in the street saw on the red posters of The Daily Mail that GrahameWhite had started for Manchester, and when a few hours later he learned that this real English flyer had actually reached Rugby, his first stopping place, and had flown seventy-five miles at a stretch, he first rubbed his eyes with astonishment and then he wanted to shout with pride and patriotism because the great prize was going to be won-and by one of his own countrymen!

There followed another dramatic surprise, recalling the Channel flight of nine months before. After an hour at Rugby, Mr. Grahame-White continued his flight and, despite a freshening breeze, fought on as far as Lichfield. There another halt was perforce made, and there disaster overtook him, for a gale of wind blew his machine-a 
Farman biplane-over as it stood, insufficiently secured, in a field, and so damaged it that it had to be taken back to London for repairs. By the following Wednesday it was ready for the air again, and a fresh start was immediately announced; but meantime a fresh competitor had appeared on the scene.

Louis Paulhan, a young Frenchman who, after a varied career as tight-rope walker, sailor, and airship mechanic, had developed into an aviator, first won his spurs at the Rheims Meeting where, for one day, he held the world's record with a flight of two hours and forty-three minutes made on a "Voisin." He flew in England at the first Blackpool meeting, and afterwards gave some magnificent exhibition flights near London. While in this country he expressed his intention of trying later for the London to Manchester prize, but in the meantime he went to America and while there made another record by flying over 4,000 feet high-by far the greatest height that had yet been attained in an aeroplane. Coming back to France, the news presently reached him that Grahame-White had designs upon the great English award that he had already marked as his own but considered himself scarcely ready for. However, Grahame-White's action decided him; it was a case of now or never, so he forthwith packed up his new racing "Farman" and came to England.

Paulhan's machine did not reach its starting place, at Hendon, until the morning of the Wednesday when Grahame-White's damaged aeroplane was ready for flight again. All day long he laboured with his mechanics putting it together-" assembling" it, as is the favourite term. At 5.30 in the afternoon, after eleven hours' continuous work, with no trial flight and without fuss of any kind, he quietly got into the air and flew II7 miles to Lichfield, where he landed after a flight of two hours and fifty minutes. 

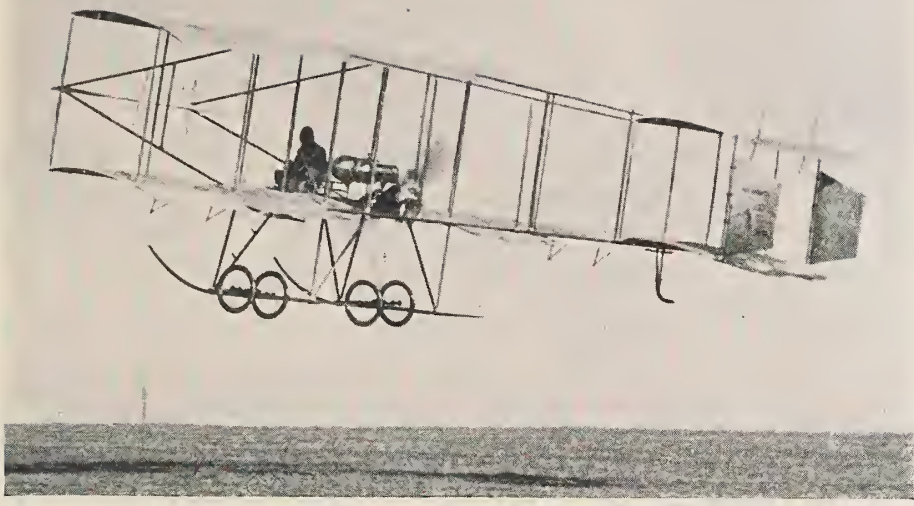

THE "BRISTOL" BIPLANE IN THE AIR.

See page 68.

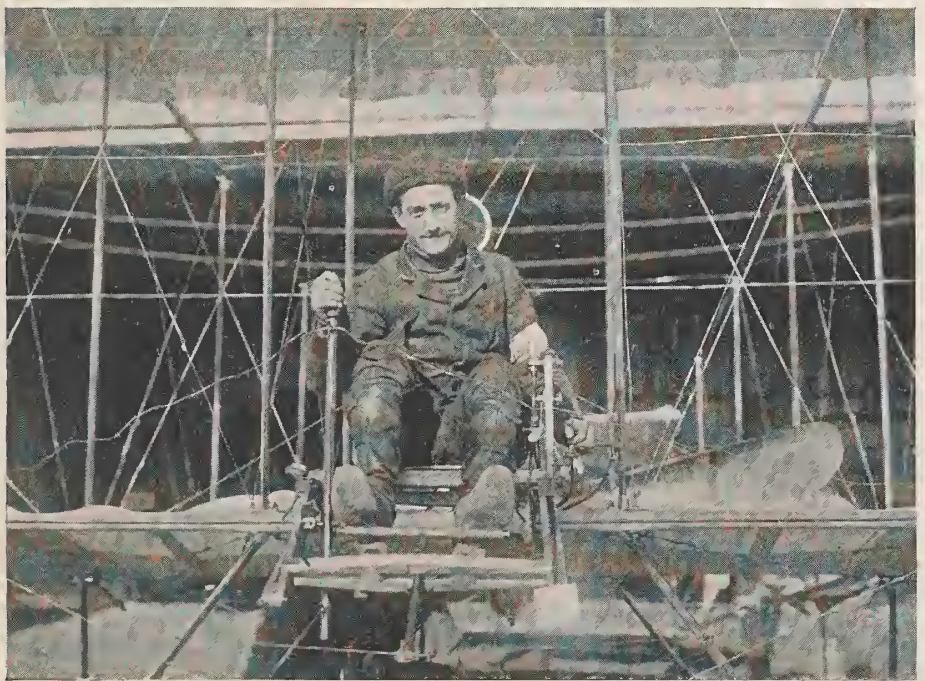

Photo: Illustrations Bureau.

THE CONTROLS OF A FARMAN BIPLANE.

Paulhan on his London to Manchester Flight.

See pages 62 and 96. 

Only a few miles away from Hendon, at Wormwood Scrubs, that afternoon, Grahame-White had decided that, in view of the gusty wind that was blowing, he would wait until the calm hours of the early morning for his start; and he himself turned in to rest for a few hours, to be ready for his exertions of the morrow. Like Latham, a year before, his sleep was disturbed by the unwelcome tidings that his rival had started; like Latham he immediately followed in pursuit, and got as far as Roade, sixty miles from London, where darkness compelled him to descend. He started again next morning, almost before it was light, and an hour ahead of Paulhan; but engine trouble brought him down ten miles short of Lichfield, and before the necessary repairs were finished came the crushing tidings that the Frenchman, starting at half-past five, had reached the goal, and Grahame-White was the first to lead the cheers that announced his rival's wellearned victory.

Later events in the world of aviation are too fresh in the recollection of everyone for recapitulation. Every week has seen the papers devoting more space to purely British achievements, and less to the exclusive glorification of the foreigner. After the French meeting at Tours, in May, I9Io, when Captain Dickson carried off $\mathrm{I} 8,000$ francs in prize money, it was no longer possible to say that as flyers our own countrymen lagged behind the other nations, and their splendid performances at Wolverhampton, Bournemouth, Lanark, Blackpool, Leopardstown, and elsewhere covered them with fame, which culminated in a blaze of glory when Grahame-White went to America and returned with the Gordon-Bennett Cup.

Comte Jacques de Lesseps made the second crossing of the Channel in May, but twelve days later the Hon. C. S. Rolls flew the double journey from England to France and back again in a Wright biplane. The longer and much $\mathrm{H}$ 
more hazardous passage of the Irish Channel-known by evil repute as a place of most fickle and treacherous winds -was all but accomplished on September IIth, by Mr. Robert Loraine, the actor-aviator. By a stroke of cruel ill-luck his engine, which had been giving him trouble most of the hour and a half that he was aloft, failed utterly a few hundred yards short of the Irish coast, off Howth Head, Dublin Bay, and his Farman biplane landing in the sea, floated but turned turtle, and Mr. Loraine, diving from under her, swam to the neighbouring Bailey Lighthouse. The plucky actor came in for a tremendous ovation on his first appearance soon after in a play with the (unintentionally) appropriate title of "The Man from the Sea."

The tragic death of Mr. Rolls, at Bournemouth, saddened not only the world of sport, of which he was one of the brightest stars, but the whole British nation, who loved him dearly. Equally sincere was the grief when the brave and modest Cecil Grace disappeared with his Bleriot into the fog lying heavy on the cold, grey, December sea, never to be heard of more. Another tragedy-a foreign onetouched all hearts. Many Englishmen had seen and marvelled when George Chavez, the Peruvian, at Blackpool and Lanark, rose upwards on his Blériot, like a lark, soaring higher and higher till he became the merest speck in the clouds, whence he would descend again in thrilling and spectacular spiral vols planés, alighting, as a feather, on the grass. All had admired his matchless skill and nerve aloft, and had smiled to note his boyish light-heartedness when, between his flights, he and his fellow-aviators romped about the field like merry children. In September, I9I0, he entered, unwisely, for the prize offered for the crossing, by aeroplane, of the Alps, at the Simplon Pass, between Switzerland and Italy - a cruelly dangerous competition that should never have been 
instituted. By a marvellous combination of skill and daring, he achieved what was thought to be the impossible, and soared safely over the terrible mountains which, at the Pass, are 6,600 feet high. But, exhausted no doubt by the awful strain, and numbed by the cold, he came to grief at the very moment of landing on the Italian side and died, pathetically, in the hour of his victory, of injuries which no one expected to prove fatal. Poor Chavez, alas! was only one of many aviators who fell victims to the new art on the Continent; nor was the loss to the American nation less severe. Within only six weeks, at the close of the year, came the deaths of three of their most famous flyers, Johnstone, a daring "Wright" exponent, Moisant, who had flown from Paris to London with a passenger the previous August, and Hoxsey, who perished in the descent after attaining the world's record altitude of II,474 feet, or two and a quarter miles high.

Among the victims of severe accidents which, happily, did not prove fatal, may be mentioned the Baroness de la Roche, the first lady aviator to win a pilot's certificate, who had a bad fall at the second Rheims Meeting in July; the Hon. Alan Boyle, who was pitched on his head in an unfortunate landing at Bournemouth; and Mr. G. A. Barnes, at Folkestone. In October Leon Morane, a very skilful French flyer, who had stirred the crowds at the Bournemouth Meeting to immense enthusiasm by his magnificent performances, started with his brother from Paris on a two-seated Blériot to win the Michelin Grand Prix of $£ 4,000$ offered, a good many months before, for a flight, with a passenger, from Paris to the summit of the Puy-de-Dôme, a peak of the Cevennes, 5,860 feet high, and over 200 miles away. The conditions were specially exacting, because the whole distance had to be traversed in less than six hours; and unusually dangerous to boot, 
since the only possible landing place on the summit of the mountain is of very small extent, practically only about I50 yards square, bounded on three sides by precipitous descents, and on the fourth by a wall of cliff; moreover, the mountain is frequently shrouded in sudden fog. No wonder some while elapsed before an aviator felt sufficiently sure of himself and his machine to risk the venture.

The first to attempt it was Weymann, an American, who, after a magnificent flight, lost his way in a mist and came down only some ten miles short of the goal. This was in September, and the attempt of the brothers Morane the following month was more disastrous, for when only a few miles from Paris their machine, from some not very well-explained cause, fell heavily, and they both met with most severe injuries. It was on the third attempt, on March 7th, IgII, that the great prize was won, by $M$. Eugène Renaux and a passenger, on a Maurice Farman biplane, flying at fifty miles an hour, without accident and with but one stop on the way.

But perhaps the most sensational accident of all was the collision in the air at the Milan meeting on October Ist, Igro, between Captain Dickson and M. Thomas. The circumstances were ex raordinary. Thomas was flying an Antoinette, whose great wings shut out from the aviator the view directly downwards. Dickson was on a Farman, the upper plane of which effectually hides the sky immediately uproards. Dickson was rising into the air, Thomas was descending. Had the positions been reversed no accident would have happened, for both would then have seen each other; as it was the horrified spectators beheld the two machines crash together in mid-air and fall in hideous ruin to the ground. Almost by a miracle both men escaped with their lives, though Captain Dickson's injuries were well-nigh fatal. 
In August great excitement was aroused in France by the Circuit de L'Est-a cross-country race of 500 miles, won by Leblanc, who flew the distance, on a Blériot, in twelve hours spread out over several days. This was the first of the great town-to-town circular races which are now such a feature of aviation and are taking the place of flying-meetings, and the less sensational record making round an aerodrome. These cross-country races are likely to do splendid service in the progress of the art, because they tend to encourage not only speed in aeroplanes but, what is vastly more important, reliability as well. In these town-to-town trips, lasting several days, the slower but more dependable machine has an even chance against the faster and more showy rival that will only do its best for a short while, or when it has a mind to; for in this case "the race is not to the swift nor the battle to the strong, but time and chance happeneth to them all."

The end of IgIo saw much fine flying all over the world made in attempts to win the several big prizes that expired with the last day of the year. One of them was Baron de Forest's $£ 4,000$, won, as has already been told, in such fine style by Mr. Tom Sopwith. Another was the Michelin award for the longest flight made by a British aviator on an all-British machine. I think everyone in England was delighted when this honour fell to Mr. Cody, who, starting in the chill early morning of December 3Ist, flew around Laffan's Plain for four hours and forty-seven minutes, during which he probably covered nearly 230 miles, though he was officially credited with $I 85 \frac{1}{2}$. His machine was his own design and construction, and was driven by a British Green engine. No one has had a more varied aeronautical career than Mr. Cody, made up of triumphs and most bitter disappointments. He has been both the hero and laughing-stock of a most fickle 
public, who alternately lauded him with extravagant praise and then, forgetting his past successes, taunted him in the time of ill-fortune when his "Reaping-and-binding Machine," or " Flying Cathedral," as they styled it, declined to leave the earth. But in spite of undeserved ridicule, discouragement, serious injury, and accidents that nearly cost him his life on several occasions, he persevered with his work, happily optimistic and serenely confident of himself and his big machine. I remember at the first Rheims Meeting a conversation I had with poor Captain Ferber, himself one of the first pioneers of aviation and shortly, alas! to be one of its earliest victims. "You in England don't appreciate what a good man you have in Cody," he said. "He will do great things." And subsequent events have proved this true.

A noteworthy feat in aviation of the early months of IgII was the magnificent flight from London to Paris accomplished by Prier, the young French instructor of the Blériot School at Hendon. Leaving the aerodrome at I.37 on April I2th, he flew without a stop to Issy-lesMoulineaux, outside Paris, which he reached at 5.33 , having covered 250 miles in just under four hours-much of which time he was travelling at seventy miles an hour -beating the best train and boat time by three hours.

To attempt to state the world's records in aviation would be a useless task, knowing full well, as I do, that even before these pages see the light such records will already be broken and out of date. Instead I will just give a few figures of a single year-Igro-showing the progress that has been made in one period of twelve months both in England and throughout the world. It will at least be useful for comparison in future times.

First, for our own country. At the beginning of I9I0 England had practically no bona fide aviators, and only 
some half-dozen men who had flown at all. By the end of the year Great Britain possessed thirty-eight pilots who had obtained the certificate of the Royal Aero Club, and twelve others who had French certificates, making fifty in all. Her sons had flown at seventy-five miles an hour, for four and three-quarter hours at a stretch, for I 85 miles on end round a course, and 169 across country (and sea), had crossed the English Channel several times, and the Irish Channel once, and had won the GordonBennett Cup.

For the rest of the world, Henry Farman, on his own machine, at the end of I909 held the World's Record for distance and duration with a flight of four hours and seventeen minutes, during which he traversed (officially) I37 miles. He made a brave endeavour at the close of IgIo to hold it again, but though a continuous flight of eight hours and thirteen minutes gave him the duration record, he was beaten in distance by Tabuteau, on a Maurice Farman biplane, who covered 365 miles in seven hours forty-eight minutes. The speed record belonged officially at that time to Leblanc, who flew, in America, with a racing Blériot, at sixty-seven miles an hour, though Radley one afternoon at Lanark attained, on the straight, nearly seventy-six miles an hour. A year's progress in high flying was marvellous. On December Ist, I909, Latham broke all previous records and astonished the wide world by rising $I, 550$ feet into the air. A year later poor Hoxsey, in his last fatal ascent, reached II,474 feet, though in view of the fact that his recording apparatus was injured in the subsequent fall that caused his death, the official record was judged still to remain with the Frenchman Legagneux, who not long before had attained I0,746 feet. As to passenger flights, at the end of April, I9I0, Sommer covered himself with glory when he mounted four souls, including himself, into his own machine, and took them for a five 
minutes' flight. Less than eleven months later Bréguet made his biplane, most appropriately known as the Aero-bus, lift twelve; but two days following Sommer, not to be outdone, and troubled with no superstitious scruples, succeeded somehow in packing thirteen on to his aeroplane, and yet even with this unlucky number came to no mishap. 


\section{CHAPTER VI}

\section{THE AEROPLANES OF TO-MORROW}

WHAT are likely to be the future developments of the aeroplane, and what effect will the conquest of the air have upon the civilisation of the world ?

There is always the temptation for each one of us to play the prophet. It is easy work, and we think it sounds clever. If we are right we can go about saying, "I told you so!" (surely the greatest pleasure in life). If we are wrong the chances are that other people have not heeded what we said, and will not remind us of our blunders. There is no particular merit therefore in prophecy, in general, but in the case of aviation it is certainly interesting, and may prove instructive, to consider the paths along which progress is likely to be made in the near future.

The last few years have seen tremendous advances in the science and art of flight, but we are still a very long way from attaining the summit of our ambitions, the perfect flying machine. All over the world great numbers of men, and more and more every day, are working on the problem, and these workers may be divided into two great branches, the practical and the theoretical. The practical man labours in his workshop and on the flyingground, constructing and testing his machines, buying his knowledge, often painfully enough, from actual personal experience. The theoretical man spends his days at his desk, covering endless pages with abstruse mathematical calculations; or in well-appointed laboratories carrying 
out delicate experiments with infinite patience and care. There has been a foolish tendency of late for these men to sneer at each other. The practical man says, and no doubt truly, that if the problem of flight had been left to his theoretical brother alone no aeroplane would yet have mounted into the sky. The theoretical man repliesequally justly - that if more attention had but been paid to his labours and less had been left to " the light of nature " and "the rule of thumb," an infinite amount of waste of time and money and life itself might have been spared. Such bickering is pure folly, for it is self-evident that the services of both men are needed for the task, and the successful aeroplane constructor and flyer is he who in equal measure combines theory and practice in his work.

The practical part of the business is carried out, as we know, in countless workshops and on open spaces and aerodromes throughout the country; the theoretical part is best illustrated at a place like the Aeronautical Department of the National Physical Laboratory at Teddington. A visit there will show us many interesting and wonderful things.

We shall see, in the special shed erected for it, the "Whirling Table" -an apparatus for testing the efficiency of different shapes of aerial propellers at various speeds. The only way of accurately testing a propeller is by making it travel rapidly through the air, and the whirling table at Teddington consists of a giant arm, some fifty feet long, which is made to rotate at tremendous speed, carrying at the end of it a model of the propeller to be tested. As the great arm sweeps round the room the "thrust" of the propeller is recorded by a most ingenious automatic electric signal.

In another room we find what is known as a "Wind Tunnel" - a long chamber, carefully sealed from the outside air, along which a great fan forces a tremendous 


\section{THE AEROPLANES OF TO-MORROW IOך}

draught of wind. Little models of different forms of planes are hung in this current of air, and from their behaviour the "lift" and "drift" of each can be determined. In the same room as the wind tunnel we are shown a long, narrow tank through which a stream of water is made to flow at a uniform pace. In this water small objects are submerged, careful note is made of the resistance they offer, and the best stream-line forms are thereby determined. In the laboratory there are also various apparatus for ascertaining the strength of the materials, fabric, wood, and metal of which an aeroplane is constructed, and for testing aerial engines; while outside the buildings are two lofty "Wind Towers," sixty feet high and a hundred yards apart, from which the behaviour of the wind may be observed. It is impossible to doubt that the results obtained by the careful use of such splendid appliances as these must prove of the utmost value.

The chief progress in aeroplane construction during the last year or two has been in the direction of increase of speed, and it is certain that the flying machines of the future will travel much faster yet. But increased speed, though it solves many difficulties, is not everything. Engines must be made more reliable, aeroplanes must be given more automatic stability, and rendered safer and more easily controlled; there must be a general increase in efficiency. At the present moment the majority of biplanes and monoplanes are very wasteful of their energy, and do far less with their horse-power than ought to be possible. There is unlimited scope for experiment and improvement in almost every detail of construction.

One of the dreams of the flying-machine designer is the invention of a plane which can be made larger or smaller at will while in the air. If it were only possible for an aviator to vary the size of his planes in flight he would 
have vastly more control over the speed than he at present possesses. The fact that its speed can be varied so little is one of the present drawbacks of the flying machine; other points against it being that it cannot hover over one spot nor rise straight upwards from the ground into the air. At the present moment a good many inventors are at work upon the problem of what they call a "Helicopter" -a flying machine which shall be driven by propellers placed horizontally-or "working in an horizontal plane" as is the more correct way of expressing it-so that they shall screw their way vertically up into the sky. These propellers are usually supposed to be made capable of being tilted in order to give a forward as well as an upward motion, and in many designs there are no planes or supporting surfaces at all to the machine, which is to keep itself in the air simply by virtue of the lifting action of the propellers; while in other forms the helicopter idea is combined with the aeroplane. There are other inventors still who seek to imitate the birds by imparting a flapping motion to the wings of their aeroplanes, which they style "Ornithopters." Yet another set of men make their wings rotate, and produce what they are pleased to call "Gyropters"; but so far mechanical difficulties have proved too great, and no particular progress has been made with any of these "opter" machines.

It seems a pity that the moment a new discovery or invention comes to light the first question we ask is not "How will this benefit humanity?" but " How can it be used in time of war?" However we may deplore it, the fact remains, and we may strive to console ourselves by thinking that the more the art of war is perfected, the more terrible and destructive its weapons are made, the less likely the nations will be lightly to embark upon it.

This applies particularly to the use of aeroplanes for purposes of bombardment. The other day I heard Sir 


\section{THE AEROPLANES OF TO-MORROW IO9}

Hiram Maxim-who, of all men, should be justified in giving an opinion-discussing this very matter. $\mathrm{He}$ pointed out that, at the present moment, the greatest range at which our most powerful modern artillery can bombard a town is, say, nine or ten miles at the very outside. But, he said, there exist even now aeroplanes that can carry many pounds weight of nitro-glycerine or other high explosive in addition to their pilots; that starting from a base, say, thirty miles away, could speed at fifty miles an hour to the town, camp or fortress to be attacked, drop their charges and return for others, not once, but many times over, in a few hours. A town therefore may now be regarded as open to bombardment from any distance. "Would the sovereigns and potentates that play the war game," said Sir Hiram, "be so eager to commence hostilities, if they knew that within a few hours of war being declared the enemy's aerial craft might be dropping bombs on their own castles and palaces!"

Nor would the aeroplane or airship so bombarding be necessarily running very special risk. Their attacks would probably not be made in clear daylight skies, but under cover of night, or in times of mist and cloud. As the Duke of Argyll expresses it, "It would be as useless to try to hit an aeroplane in the dark as to fire a shell at the siren of a ship in a fog." Even in daylight it is at any time a difficult matter to hit a swiftly moving object directly overhead, and it must ever be borne in mind that shells fired vertically upward would, if they missed their aim, return and explode among those who fired them, so that to open fire upon an airship or aeroplane at close quarters would be at least as dangerous to one party as the other. Furthermore, it is to be remembered that an aeroplane might be hit a good many times over, with ordinary weapons, without being brought down. A rifle shot that disabled the pilot or engine, or put the 
machine out of control, would, of course, be fatal, but the planes might be fairly riddled with bullet holes without much harm being done. After all mere personal risk counts for very little in warfare. If a nation at war can cheerfully risk a battleship costing a couple of millions and containing a thousand souls, is there any doubt that she can venture an aeroplane costing a couple of hundred and carrying one man, or two at the most ?

A far stronger argument against the employment of aeroplanes in bombardment than the mere risk run is the comparatively little damage that they can do. To drop a bomb with any precision on a desired spot from a swiftly moving flying machine at a great height would be probably quite impossible; moreover, modern warfare has proved that the effect of high explosives is very much less than might be expected, since the damage they do is limited to such a very small area. A ton of dynamite dropped on a building, says one authority, would shatter everything to dust in the place where it fell, but outside a very small radius it would do very little harm at all beyond breaking the windows. The chief terror would lie in the moral effect, which, indeed, is likely to be very great, especially in a town of defenceless civilians.

We cannot plead, as some folk are ready to do, that aerial bombardment is forbidden by the rules of civilised warfare. At the last Hague Conference the right of hostile aerial craft to retaliate in case of resistance was fully recognised. An airship or aeroplane fired upon by an army or a fortress is perfectly entitled to reply by dropping explosives from aloft. There is also another point to bear in mind. Bombardment, by any means whatever, of undefended towns, villages or dwellings is forbidden in the most emphatic terms; but how can we define the word "undefended" when it comes to aerial matters? London may be considered undefended, and yet if but one 


\section{THE AEROPLANES OF TO-MORROW III}

shot were fired by one of her millions of inhabitants at an enemy's aerial craft hovering overhead, that craft, airship, or aeroplane, would immediately be entitled to make the most terrible reprisals. This is a fact that should be impressed on all. As Colonel Capper has pointed out, "One ignorant yokel with a gun might bring about the destruction of a whole town."

Nevertheless, it hardly appears likely that in the next European war-far may it be!-aeroplanes will be used for purposes of attack or transport, for these are hardly their functions. But that they will be employed in battle is certain, and their duties will be no less important. Swift-flying machines will carry aides-de-camp, maybe the general himself, from end to end of the extended field of battle. For scouting and reconnoitring their use should be untold. Every detail of the opposing force, or of the enemy's country, will be seen and noted by trained military aviators, and their observations signalled by wireless telegraphy (with which experiments in connection with aeroplanes are already being made). It is not needful to go very high to see enormous expanses of territory. "With specially constructed field-glasses," says one authority, "at an altitude of half a mile or less it would be possible to survey, in clear weather, a far greater range of territory than the greatest guns of the day could possibly fire over." It was Wellington, I think, who said that the genius of the successful general lay in knowing what was on the other side of the hill. In the fights of the future hills, even mountains, as a means of concealment, will count for nothing.

For naval purposes the aeroplane may be no less useful. One of the greatest risks run in modern naval warfare lies in the presence of unseen dangers, sunken mines and submarines, lurking beneath the waves. Now it is a curious and interesting fact, and likely to prove a very 
important one, that from a considerable height above the sea-say 500 or 600 feet-objects below the water become visible even when the surface is rough and broken. What a chance for an aeroplane we have here! One of the most important experiments at present being carried out with flying machines is the fitting to them of appliances that shall make them capable of descending safely upon the water, and yet more vital, of rising from the water into the air. Already splendid progress is being made. On January 26th, IgII, Glenn Curtiss, the famous American aviator, with pontoons or hollow "hydroplanes" fitted in place of wheels to a Curtiss biplane, rose from the waters of the Bay of San Diego, California, almost as easily as from the ground, and descended again upon the waves, not once but several times over with equal success. The importance of this experiment cannot well be overestimated.

There is another warlike function of the aeroplane, none the less possible because it reads like a terrible nightmare. Presumably in the next war of highly civilised nations the giant airships of their airy navies will sally forth on dread errands of destruction, and the chief weapons used against these aerial foes will surely be the swiftly moving flying machines, swarms of which we may picture launching themselves upon a huge and less agile dirigible balloon, harassing it, out-manœuvring it, driving it upwards into the sky in vain attempt to escape its tormentors, until finally an aeroplane, rising above, has the airship indeed completely at its mercy; and safely, and at its leisure, wreaks its vengeance on the mighty, defenceless gas-bag below, and by firing, exploding or harpooning it, sends the whole craft hurtling to earth in sickening annihilation.

As to the peaceful possibilities of flight they are infinite, and it were futile to try to enumerate them. One effect 


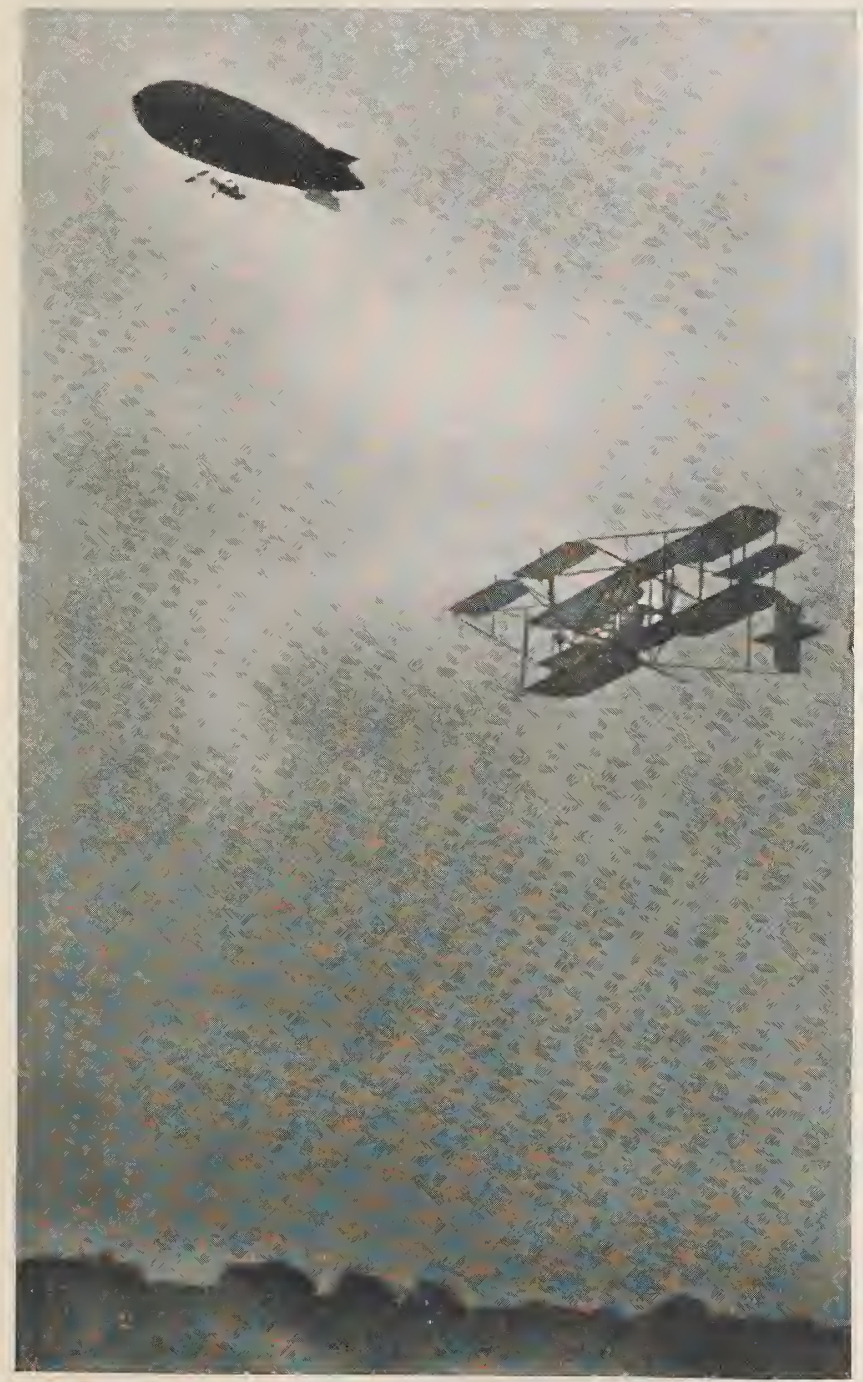

Hhoto: Topical.

THE WARFARE OF THE FUTURE?

The "Beta" Airship and the Cody Aeroplane Flying at Dusk.

See page 112 



\section{THE AEROPLANES OF TO-MORROW II3}

of the general employment of the aeroplane, says an authority, will be the universal adoption of Free Trade, for the very simple reason that tariffs will presently prove impossible to enforce. Certainly, at the present moment even, if the aviators of the Continent chose to embark upon smuggling with some light commodity such as, say, saccharin, the Custom House officers would find themselves at a distinct disadvantage. Precautions against this sort of thing will certainly have to be taken before long.

But enough of idle speculation, pleasant enough to indulge in, but serving no particular purpose. Most of us will live long enough to learn for ourselves if our dreams come true; for events move quickly now along the paths of progress, but in aviation quickest of all. One thing I think we may safely prophesy-that when our descendants in future generations, those

\section{". . yet unmoulded tongues}

Far on in summers that we shall not see,"

have need to recall the opening years of the twentieth century, they will refer to them, not merely as the Edwardian period, not at all by titles that belong to political watchwords and party strifes, that now seem so momentous, but will then have shrunk to their true perspective, not by the names of great men even-of whom there are all too many (or too few)-for such distinction, but they will call them simply "the days when man first learnt to fly." 


\section{GLOSSARY INDEX}

Aerodrome. A flying-ground, 3.

Aerodynamics. The science that relates to the "heavier-thanair" flying machine, 20.

Aeronaut. One who navigates the air, 20.

Aeronautics. The entire science of aerial navigation, 20.

Aeroplane. A heavier-than-air flying machine, having one or more fixed planes or supporting surfaces, 3 .

Aerostatics. The science that relates to lighter-than-air aerial craft; i.e. balloons and airships, 20.

Ailerons, or Balancers. Small, movable, horizontal surfaces for maintaining the balance of an aeroplane, 34,63 .

Airship. A dirigible-balloon; a lighter-than-air craft capable of being steered in the sky, 4 .

Angle of Incidence. See Flying-Angle.

Aspect Ratio. The proportion of the "span" (q.v.) of a plane to its "chord" (q.v.), 26.

Aviation. The art of flight with a heavier-than-air machine, 20.

Aviator. The pilot of a flying machine, 20.

Biplane. An aeroplane with two main planes placed one above the other, 4 .

Blinkers. Small, fixed, vertical planes at the front of an aeroplane which assist horizontal steering, 7I, 72 .

Cabane. A framework of steel tubes on the top of the fuselage of a Blériot monoplane, from which the wings are hung, 74 . 


\section{GLOSSARY INDEX}

Camber. The maximum distance between the "chord" (q.v.) and the surface of a curved plane, 23 .

Chassis. The "carriage" on which the body of an aeroplane is mounted, 60 .

Chord. The length of the line joining the "entering" (q.v.) and " trailing" (q.v.) edges of a "cambered" (or curved) plane, 23.

Cloche. The bell-like control of a Blériot monoplane, 76 .

Curtains, or Panels. Upright planes placed between the main planes, "boxing" them in, and perhaps dividing them into compartments or "cellules," $33,68$.

Dihedral Angle. A term meaning that the planes are arranged in the shape of a wide $\mathrm{V}, 33$.

Drift. The horizontal resistance experienced by an aeroplane passing through the air, 28.

Elevator. A movable horizontal plane, or planes, by which an aeroplane is made to rise or fall in the air, 33.

Empennage. The tail of an aeroplane, 62, 74 .

Entering or Leading Edge. The forward edge of a plane (or of a propeller blade), 23 .

Flexing. See Warping.

Fuselage. The body, or frame, of an aeroplane to which the planes, etc., are attached, 62, 74 .

Flying-Angle. The angle at which the planes of an aeroplane in flight are inclined to the horizontal. Also called the "Angle of Incidence," 28.

Flying Machine. A heavier-than-air machine for flight, 4.

Gap. The space between the main planes of a biplane or multiplane, 60.

Glider. A flying machine, but without a motor, for gliding through the air, 3I, 47.

Gyropter. A flying machine with rotary wings, 108.

Hangar. The shed in which an aeroplane is housed, 3. 
Helicopter. A flying machine driven by propellers working in an horizontal plane, I08.

Lift. The vertical lifting force of a flying machine, 28.

Monoplane. An aeroplane with one main plane (or pair of outstretched wings), 4,6 .

Multiplane. An aeroplane with several planes placed one above the other, 4.

Ornithopter. A flying machine with flapping wings, I08.

Pitch of a Propeller. The distance it would travel in one complete turn if screwing in some unyielding medium, 66.

Plane. Any surface of a flying machine used for support or control, 3,23 .

Radiator. An arrangement of tubes in which the water used for cooling the cylinders of an engine is itself cooled, 65 .

Rudder. A movable; vertical plane, or planes, by which an aeroplane is steered to right or left, 34 .

Shock Absorber. An arrangement of elastic bands in the chassis of a Blériot machine for breaking the shock of descent, 74 .

Skid. A wooden sledge-runner placed beneath an aeroplane on which it may rest in landing ,6o.

Skin Friction. The resistance caused by the "stickiness" of the air, 67 .

Slip of a Propeller. The difference between the "pitch" (q.v.) and the distance actually travelled by a propeller screwing in an elastic medium, as air or water, 66.

Span, or Spread. The length of a plane from right to left, 25 .

Stream-lines. Minute threads of fluid, arranged side by side, of which currents of water or air are imagined to be composed, 24, 25 .

Stream-line form. In general terms, fish-shaped with the blunt end foremost, 25 .

Thrust of a Propeller. The force with which the propeller drives the air backwards, 66 . 


\section{GLOSSARY INDEX}

Tractor. A screw propeller placed at the front of a flying machine, 76.

Trailing Edge. The rear edge of a plane, 23.

Triplane. An aeroplane with three main planes placed one above the other, 4.

Virage. The action of turning, Io.

Vol plane. The gliding descent of an aeroplane with engine stopped, 8, 31, 78 .

Warping. "Feathering" or flexing the tips of the planes of an aeroplane to preserve the balance when turning, 34, 63 .

Wind Pockets. "Holes in the Wind"-or small regions of the atmosphere where, to the aviator, the resistance of the air appears suddenly to fail, 32 . 
PRINTED BY

Casseli \& Company, Limited, La Belle Sauvage LoNDon, E.C. 
male a
is nut 
1. . .

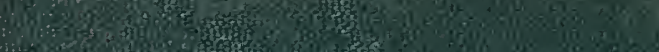

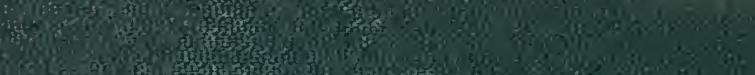

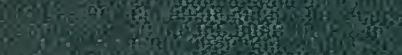

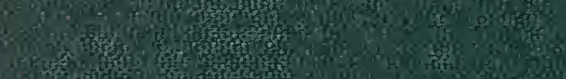

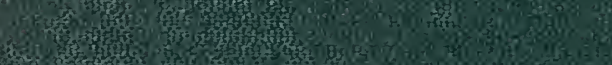

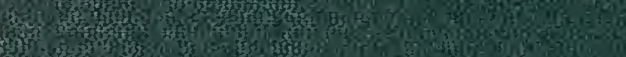

W.

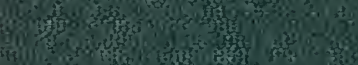

H

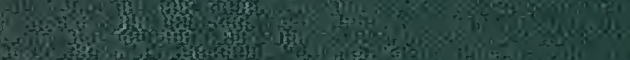

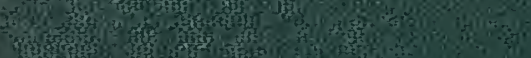

H.

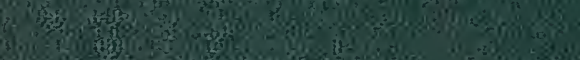

20

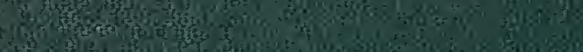

H.

(4)

W. ${ }^{2}$.

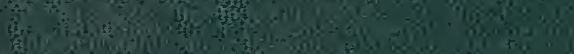

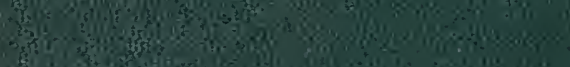

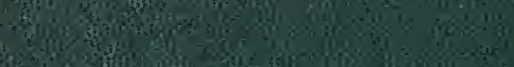

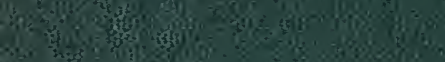

T.

7.

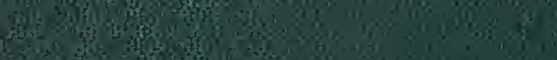

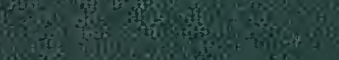

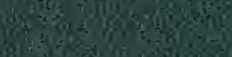

3.

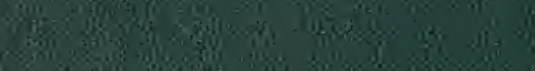

a

Whations

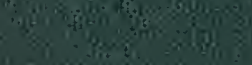

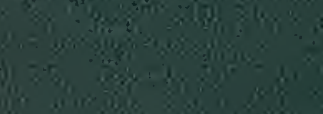

